ANL/FPP/TM-138
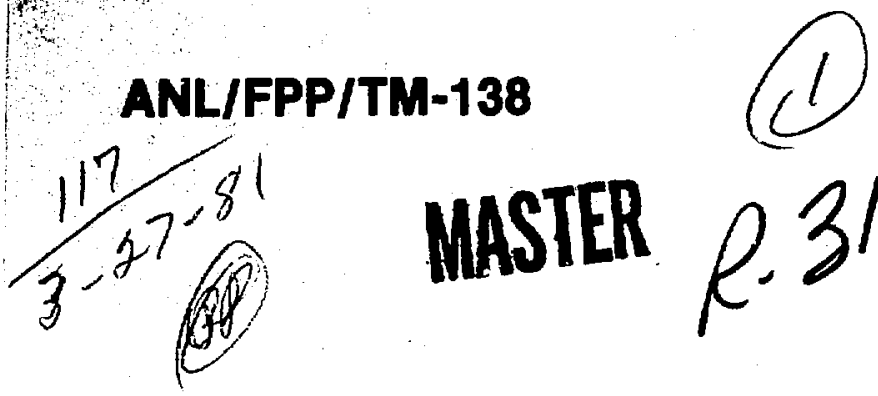

Dr.2460 ANL/FPP/TM-138

\title{
D-D TOKAMAK REACTOR STUDIES
}

by

K. E. Evans, Jr., C. C. Baker, J. N. Brooks,

D. A. Ehst, P. A. Finn, J. Jung,

R. F. Mattas, B. Misra, D. L. Smith,

and H. C. Stevens

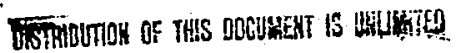

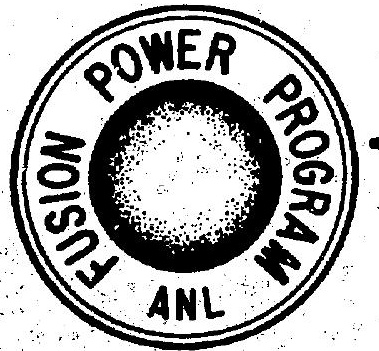

\section{FUSION POWER PROGRAM}

Argonne Mational Laberatery

9700 Seuth Cass Avenue

Arronme, Elanols 60439

Propared for the

U. 3. Departmeist of Eacryy

wader Contract W-31-10s-Em-38 


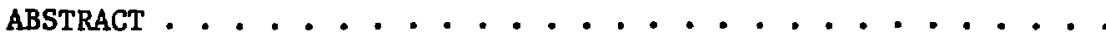

1.0 Introduction ................... 1-1

2.0 Plasma Engineering Studies ............. 2-1

2.1 Alternate Fuel Tokamak Reactor Model ....... 2-1

2.2 Reactor Parameter Studies . . . . . . . . . 2-6

2.2.1 MHD Parameters 2-7

2.2.2 Impurity Concentration . . . . . . . . 2-9

2.2.3 Plasma Temperature . . . . . . . . 2-9 2-9

2.2.4 Density and Temperature Profiles...... 2-11

2.2.5 Cyclotron Reflection Coefficient...... 2-12

2.2.6 Confinement Times .......... 2-12

2.2.7 Reactor Type ............ 2- 2-14

2.2.8 Beta, Toroidal Field, Size, and Aspect Ratio. 2-16

2.3 Reference Design .............. 2-. 218

2.4 Burn Cycle Studies .............. 2-18

2.4.1 Reference Burn Cycle . . . . . . . . 2-18

2.4.2 D-D Burn Cycle Model . . . . . . . . . 2-26

2.5 Impurity Control Concepts............ 2-29

2.6 Steady-State Current Drive Considerations . . . . . 2-32

3.0 First-Wall/Blanket/Shield Studies . . . . . . . . 3-1

3.1 Radiation Shielding and ilanket Energy Multiplication 3-1

3.1.1 Inboard Radiation Shielding ....... 3-4

3.1.2 Blanket Energy Multiplication ....... 3-10

3.2 Thermal Hydraulic Analysis . . . . . . . . 3-18

3.2.1 Coolant Panel Design Concept ........ 3-18

3.2.2 Cylindrical Module Design Concept . . . . . 3-19

3.2.3 Liquid Metal (sodium) Coolant ....... 3-22

3.2 .4 Conclusions .............. 3-22

3.3 Structural Materials .............. 3-22 
3.4 Moderator Materials . . . . . . . . . . .

3.5 First-Wall Surface Effects . . . . . . . .

3.5.1 Physical Sputtering . . . . . . . . . 3-29

3.5.2 Electron Cyclotron Radiation ........ 3-30

3.5.3 Plasma Disruptions . . . . . . . . . 3-32

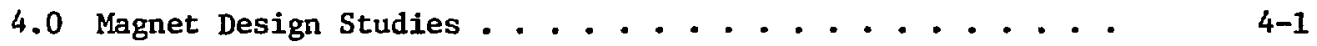

4.1 Ohmic Heating Coil System ............. 4-1

4.2 Equilibrium Field Coil System ........... 4-3

4.3 Toroidal Field Coll System ........... 4-4

4.3.1 Choice of Peak Toroidal Field . . . . . . 4-5

4.3 .2 Conductor ............. . . 4-6

4.3.3 Conductor Support ............ 4-8

4.3 .4 Cooling ............... 4-10

5.0 Tritium/Fue1/Vacuum Considerations for the D-D Design . . . 5-1

5.1 Fuel Cycle .. . . . . . . . . . . . 5-1

5.2 Fuel Reprocessing, Fuel Supply, and Tritium Safety . 5-4

5.3 Vacuum System Analysis ............. 5-7

5.4 Conclusions . . . . . . . . . . . . . 5-7

6.0 Summary and Conclusions . . . . . . . . . . . . . 6-1

6.1 General Features ................ 6-1

6.2 Plasma Engineering Considerations .......... 6-3

6.3 First. Wall/Blanket/Shield ConsideratIons ...... 6-5

6.4 Magnet Design Considerations ............ 6-7

6.5 Tritim/Fuel/Vacuum Considerations ......... 6-8 
2-1 Flux surfaces for typical high $\beta$, MHD equilibrium. The plasma pressure can be shown to be constant on the flux surfaces. It is assumed the density and temperature are constant on the flux surfaces as well. The global plasma model is obtained by spatially averaging quantities over these surfaces ...................

2-2 Superthermal particles produced as a consequence of the basic deuterium-based alternate fuel reactions or from a high energy deuterium beam. The numbers refer to the reactions listed in the text................

2-3 Confinement parameter as a function of Xe concentration. The quantity, $\alpha_{\text {EMP, }}$ is the ratio of the required confinement parameter to that predicted by empirical confinement. (7) For any Xe concentration below the maximum of $5.4 \times 10^{-5}$, there are two possible sets of reactor parameters. . . . . . . . . . . . . . . . . .

2-4 The maximum allowed impurity concentration as a function of nuclear charge for $D-D$ and $D-T$ reactors. The given iupurity was the only one present in all cases. . . . .

2-5 Cross-sectional view of the reference Cat-D design . . .

2-6 Top view of the reference design . . . . . . . . .

2-7 Ohmic heating $(\mathrm{OH})$ and equilibrium field (EF) waveforms for the startup phase of the D-D burn cycle . . . . . .

2-8 Plasma current, ion temperature and $B$ for the D-D burn cycle .........................

2-9 Ion densities for the $D-D$ burn cycle ..........

2-10 Fusion powers and rf heating for the D-D burn cycle....

2-11 Major radius (dashed) and $P_{\text {rf }}$ for two low frequency current drivers (Magnetosonic wave (MS) and Alfven wave) versus aspect ratio. Here $B_{t}=0.36 / A, P_{T}=2.2 \mathrm{GW}, T_{e}=$

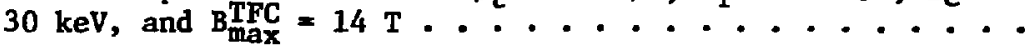

3-1 Effect of material selection upon Inboard radiation shielding for helium-cooled Cat-D designs . . . . . . .

3-2 Effect of material selection upon inbcard radiation shielding for water-cooled Cat-D designs . . . . . . .

3-3 Impact of coolant material selection upon Cat-D plant lifetime 
3-4 Stress relaxation in first wall tube section directly facing plasma in STARFIRE and D-D reactors . . . . . . 3-25

3-5 Temperature response of Be-Coating for plasma disruption time $=100 \mathrm{~ms} . . . . . . . . . . .43-33$

3-6 Temperature response of Be-coating for plasma disruption time $=200 \mathrm{~ms} \ldots \ldots$ 3-34

3-7 Temperatire response of structural material for plasma disruption time $=200 \mathrm{~ms} . \ldots$ 3-34

4-1 Cross section of $\mathrm{TF}$ coil ................ 4-5

4-2 High field grade (11-15 T) conductor and support . . . . 4-7

4-3 Low fielō grade $(0-5 \mathrm{~T})$ conductor and support ..... 4-8

5-1 Fuel processing cycle for catalyzed D-D . . . . . . $\quad$ 5-2

5-2 Tritium facility scenario for D-T reactor . . . . . . . 5-3 
2-1 A comparison of the profile-averaged, MHD flux surface mode1; 3 profile-averaged, low beta model; and a low beta point model. The case considered $\mathrm{h}_{\mathrm{as}} \mathrm{R}_{\mathrm{o}}=8.6 \mathrm{~m}$, $B_{T F C}=14 \mathrm{~T}, B_{t}=117, q(a)=3$, and $\bar{T}_{e}=40 \mathrm{keV}$ with no impurities and $100 \%$ reflection of the cyclotron radiation. The density and temperature profiles are the same in the profile-averaged cases. . . . . . . . . 2-4

2-2 Summary of Notation . . . . . . . . . . . 2-8

2-3 Variation of reactor parameters with the average electron temperature, $\mathbf{T}_{\epsilon}$. The case shown has $R_{G}=$ $9.0 \mathrm{~m}, A=3.25, B_{t}=11 \%$, and $B_{T F C}=14 \mathrm{~T}$ and fully catalyzed. The minimum temperature for

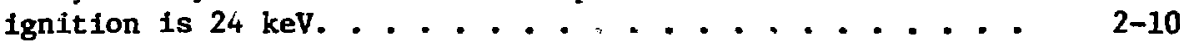

2-4 Variation of reactor parameters with the temperature and density profiles. The case shown has $R_{0}=9 \mathrm{~m}$, $A=3.0, B_{t}=12 \%$, and $B_{T F C}=14 \mathrm{~T} . \ldots . . . . . . . .2-11$

2-5 Variation of reactor parameters with the cyclotron reflection coefficient. The case shown has $R_{0}=9 \mathrm{~m}$, $A=3.0, B_{t}=12 \%, B_{\text {TFC }}=14 \mathrm{~T}$, and $\overline{\mathbf{r}}_{\mathrm{e}}=30 \mathrm{kev} . .$.

2-6 Variation of particle and energy confinement times. The case considered has $R_{o}=9 \mathrm{~m}, A=3.0, B_{t}=12 \%$, ${ }^{B_{T F C}}=14 \mathrm{~T}$, and $\mathrm{T}_{\mathrm{e}}=\mathrm{keV}^{\mathrm{O}} \ldots . . . . . . . . . . . . .$.

2-7 Performance as a function of reactor type. The basic reactor considered has $R_{0}=8.6 \mathrm{~m}, A=3.25, B_{t}=11 \%$, and $B_{\mathrm{TFC}}=14 \mathrm{~T}$. The table is meant to show a cosparison of plasmas operated in the various modes only and should not be considered a comparison of viable reactors. . . . . . . . . . . . . . . . . ...

2-8 Variation of allowable ${ }^{3}$ He recycling. $R_{\text {min }}$ is the minimum recycling coefficient for which ignition occurs. A maximum fraction, $f_{3}=\left(1-R_{\text {min }}\right)$, of the $3_{\text {He }}$ diffusion flux incident on the wall can be divertad for other uses. . . . . . . . . . . . . . . . .

2-9 A sequence of reactor possibilities which have the sane total wall loading, $P_{w}=1.60 \mathrm{w} / \mathrm{m}^{2}$, and the exwe ohmic heating field swing, $\triangle B_{O H}=16 \mathrm{~T}$. The plaswa heta is assumed to scale as $B_{t}=0.36 / A$. The average temperature is $\mathrm{T}_{\mathrm{e}}=30 \mathrm{keV} . \ldots . . . . . . . .$. 
3-1 Maximum Radiation Response Rates in Inner TF

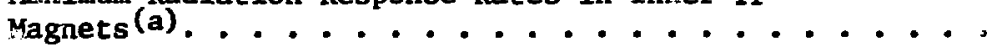

3-2 System Energy Hultiplication in a D-D-Tokenak Reactor

3-3 A Comparison of System Energy Multiplication ......

3-5 Potential of Energy Multiplication by Neutron Multipliez:

3-6 System Energy Multiplication with the Be Multiplier . . •

3-8 Summary of Analytical Results for Cylindrical Blanket Modules (750 psia helium inlet pressure) .........

3-12 considerations for Selection of Coating/Cladding

Material for the First-hall ................

3-13 Paremeters for Calculation of Physical-Sputter

Ylelds for Candidate Wall Katerials . . . . . . . . .

4-1 OH Coil Locations and Currents ..............

EF Coil Losations and Currents.

4-4 Comparison of TF Coil Parameters for Different Peak Field Values, as Predicted by the TF Coil Model

5-1 Fuel System Parametery for the Cat-D-D Reactor and the

STARFIRE D-T Reactor

5-2 Tritium Inventory ( 8 ) for the D-D Reactor and the

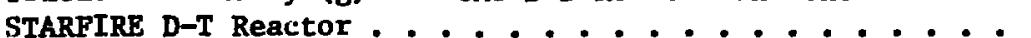

5-3 Vacuum System Parameters for the D-D Reactor and the

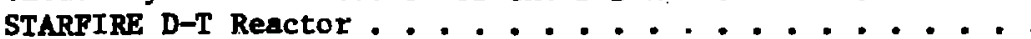




\section{$\underline{\text { ABSTRACT }}$}

A tokamak D-D reactor design, utilizing the advantages of a deuteriumfueled reactor but with parameters not unnecessarily extended from existing D-T designs, is presented. Studies leading to the choice of a design and initial studies of the design are described. The studies are in the areas of plasma engineering, first-wall/blanket/shield design, magnet design, and tritium/fuel/vacuum requirements. Conclusions concerning D-D tokamak reactors are stated. 
The densities of $\mathrm{P}, \mathrm{D}, \mathrm{T},{ }^{3} \mathrm{He},{ }^{4} \mathrm{He}$, and $\mathrm{e}^{-}$are determined along with the fon and electron temperatures. (All ions are assumed to have the same temperature.) The reactions included are the deuterium-based alternate fuel reactions:

$$
\begin{aligned}
& \text { 1. } \mathrm{D}+\mathrm{T}+\mathrm{n}(14.06 \mathrm{MeV})+{ }^{4} \mathrm{He}(3.52 \mathrm{MeV}) \\
& \text { 2. } \mathrm{D}+{ }^{3} \mathrm{He} \rightarrow \mathrm{p}(14.67 \mathrm{MeV})+{ }^{4} \mathrm{He}(3.67 \mathrm{MeV}) \\
& \text { 3. } \mathrm{D}+\mathrm{D} \rightarrow \mathrm{p}(3.03 \mathrm{MeV})+\mathrm{T}(1.01 \mathrm{MeV}) \\
& \text { 4. } \mathrm{D}+\mathrm{D} \rightarrow \mathrm{n}(2.45 \mathrm{MeV})+{ }^{3} \mathrm{He}(0.82 \mathrm{MeV}) .
\end{aligned}
$$

The superthermal fusion products are classically slowed down ${ }^{(1)}$ and in the case of $T$ and ${ }^{3} \mathrm{he}$ also undergo fision reactions as they slow down. This superthermal fusion increases the power output. The energy of the slowingdown particles also, however, contributes to the plasma pressure, which is limited by MHD requirements. A schematic view of the possible superthermal particles produced in the above reactions and for the injection of a deuterium beam is shown in Fig. 2-2.

The cyclotron radiation model follows Trubnikov ${ }^{(2)}$ and assumes uniform profiles and homogenous wall properties. It is considered to be the best simple model available. At the temperatures ( $\approx 30 \mathrm{keV}$ ) appropriate to D-D tokamaks, the cyclotron loss is substantially less than losses due to bremsstrahlung, line, and recombination radiation. The model used for these losses is the same as that used for the STARFIRE study ${ }^{(3)}$ and is described in detail in Ref. 4. along with the slowing-down model and the rethermalization model. The rf heating model assumes $90 \%$ of the rf power is given to the electrons and the remainder to the lons.

The reactor model includes a consistent MHD treatment. The plasma pressure distribution, safety factor, current, and magnetic flux configuration are the result of 2-D, numerical calculations, and the equilibria are realistic, high $\beta$ equilibria with elongated and D-shaped cross sections. Account is taken of the $R^{-1}$ variation of the vacuum toroidal field. The full MHD treatment is used because the results of actual MHD calculations for reactorrelevant plasmas are known to be substantially different from the analytic approximations sometimes used. The MHD calculations are of the fixed boundary type. The calculational model is described in detail in Ref. 5. 

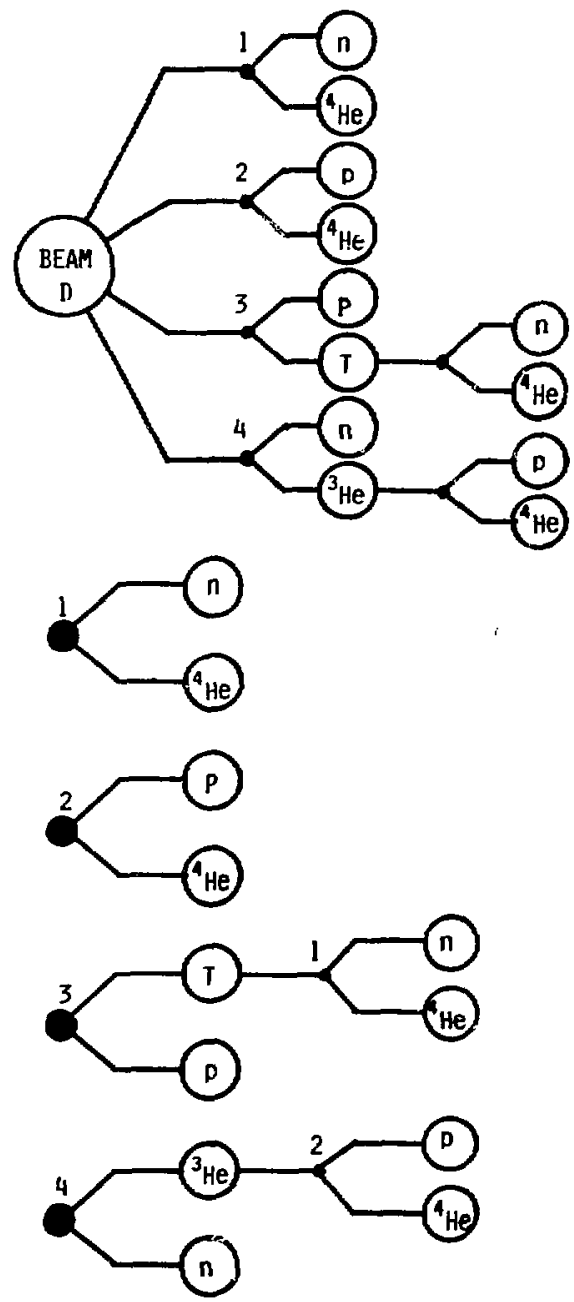

Figure 2-2. Superthermal particles produced as a consequence of the basic deuterium-based alternate fuel reactions or from a high energy deuterium beam. The numbers refer to the reactions listed in the text. 
The differences between a point global model and the profile-averaged. global model, as well as the effects of the MHD calculation compared to the low beta approximations, are shown for a typical case in Table 2-1. For this case the more accurate treatment provides the same reactor with $20 \%$ more power with half the required confinement. The analytic approximation for the plasma current substantially underestimates its true value.

The reason the profile effects indicate increased performance is that most of the fusion occurs in the high temperature center of the plasma. For the same peak. temperature the average temperature of a realistic profile is lower, depending on the sharpness of the profile. Transport losses from the system are more likely reĩated to the average temperatures. For a high beta plasma with its outwardly shifted flux surfaces, the high temperature region occupies a larger volume toroidally than it would with concentric, circular flux surfaces.

The reason for not using a $i-D$ model with realistic flux surfaces, apart from the increased computational difficulty, is that diffusion coefficients necessary for the 1-D transport are not known with a sufficient degree of

Table 2-1. A compaxison of the profile-averaged, MHD flux surface model; a profile-averaged, low beta model; and a low beta point model. The case considered has $R_{0}=8.6 \mathrm{~m}, B_{T F C}=14 \mathrm{~T}, \beta_{t}=11 \%$, $q(a)=3$, and $\bar{T}_{e}=40 \mathrm{keV}$ with no impurities and $100 \%$ reflection of the cyclotron radiation. The density and temperature profiles are the same in the profile-averaged cases.

\begin{tabular}{|c|c|c|c|}
\hline & $\begin{array}{l}\text { Full MHD/ } \\
\text { Profiles }\end{array}$ & $\begin{array}{l}\text { Low Beta/ } \\
\text { Profiles }\end{array}$ & $\begin{array}{l}\text { Low Beta/ } \\
\text { Point }\end{array}$ \\
\hline Thermal power, $P_{T}(G W)$ & 2.4 & 2.3 & 2.0 \\
\hline $\begin{array}{l}\text { Confinement, } \\
\quad\left(10^{20} \mathrm{~s} / \mathrm{m}^{3}\right)\end{array}$ & 6.5 & 8.3 & 12.7 \\
\hline Ion temperature, $T_{I}$ (keV) & 45 & 43 & 42 \\
\hline $\begin{array}{l}\text { Deuterium density, } \\
\bar{n}_{D} \\
\left(10^{20} m^{-3}\right)\end{array}$ & 1.3 & 1.5 & 1.7 \\
\hline Plasma current, $I_{p}(M A)$ & 29 & 19 & 19 \\
\hline
\end{tabular}


accuracy. In the profiie-averaged global model the transport is a global quantity, obtained by integrating a term of the form $\nabla \cdot \Gamma$ by parts, leaving only the surface contribution. This reduces the transport unknowns to one parameter, n .

In practice the model determines the required confinement parameter, $\bar{n}_{D} \tau_{E}$, the product of the deuterium density, $\vec{n}_{D}$, and the electron energy confinement time, $\tau_{E}$. The particle and ion energy confinement times, $\tau_{P}$ and $\tau_{I}$, are each assumed equal for all species and are given by:

$$
\begin{aligned}
& \tau_{P}=\lambda_{P} \tau_{E} \\
& \tau_{I}=\lambda_{I} \tau_{E},
\end{aligned}
$$

where the factors, $\lambda_{P}$ and $\lambda_{I}$, are specified, making a three parameter model. The quantity, $\lambda_{I}$, for instance, could be picked to make the ion energy confinement time correspond to the prediction of neoclassical theory.

In a 1-D model the profiles would be calculatec assuming the transport coefficlents were known. For the global model the temperature and density profiles are specified ins:ead. The profile dependences of quantities such as the reaction rate, for example, are calculated. It is assumed tr $c$ the temperature and density are constant on flux surfaces and that their profiles multiply to give the pressure profile; that 1s, the density and temperature have broader profiles than the pressure. The pressure must be constant on flux surfaces as a result of MHD theory. The teta of the MHD equilibrium is related to the pressure profile, broader profiles typically having higher credible beta. (6) All of the equilibria studied in this report have the same, relatively broad pressure profile.

A feature of this type of calculation for alternate fuel reactors is the frequent appearance of two solutions with similar parameters. For D-T reactors, there is typically only one relevant solution. The proton and alpha densities are approximately proportional to $\mathrm{n} \tau$. To the extent that terms containing these densities are unimportant compared to the predominant appearance of $n \tau$ In the transport terms, there is only one solution for the required value of nt. For the alternate fuel reactors the required confinement parameter is typically an order of magnitude larger, and the density terms become Important, resulting in an approximately cubic equation for $n \tau$. One of the roots is always negative and hence unphysical, but the other two are often both relevant. 
One mode has a higher confinement parameter, $n \tau$, higher proton and alpha concentrations, more bremsstrahlung radiation losses, and higher rethermalization rates (although lower $T_{I}$ ), with a power balance tending toward fusion energy production balanced only by radiation losses. This mode is generally less attractive than the lower nt mode, for which the power balance is fusion energy production versus comparable amounts of radiation and diffusion losses. There is, in general, a branch point in the solutions as a function of a given parameter. At this point the solutions are equal, and beyond it they become complex and hence are not real physical solutions. A typical example is shown in Fig. 2-3, where the parameter varied is impurity concentration. Unless stated otherwise, the results shown in this report are for the lower ni mode.

\subsection{Reactor Parameter Studies}

In order to understand the effects of various reactor parameters on a D-D tokamak design, a number of parameter variation studies have been performed. In this way the relevant ranges of the parameters can be determined,

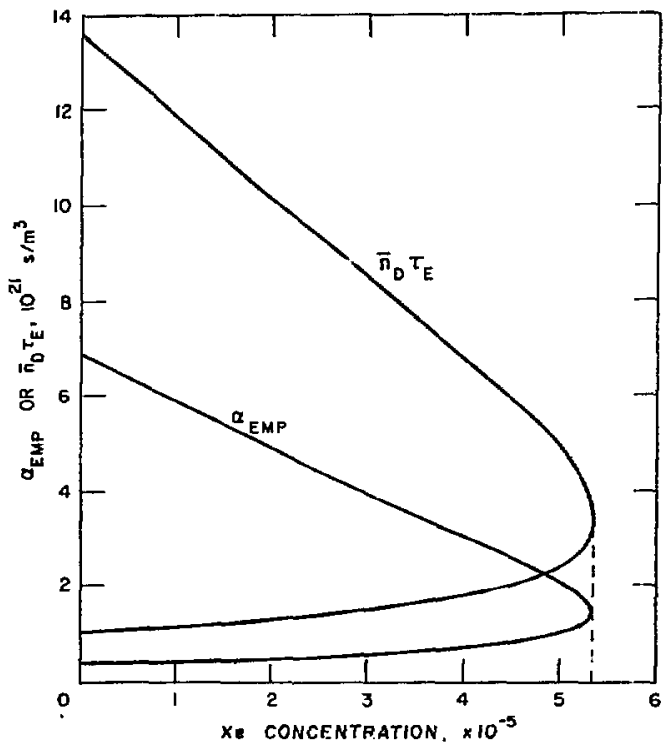

Figure 2-3. Confinement parameter as a function of Xe concentration. The quantity, $\alpha_{E M P}$, is the ratio of the required confinement parameter to that predicted by empirical confinement. (7) For any Xe concentration below the maximum of $5.4 \times 10^{-5}$, there are two possikle sets of reactor parameters. 
and the relative importance of the parameters to the design can be understood. The result of these studies is to determine a "performance envelope" of the relevant operating regimes. Some of the parameters can be optimized or set at values representing physical or practical limits relatively indepently of the other parameters. The remaining parameters are determined by trade-off considerations. Thz notation used is sunmarized in Table 2-2.

It should be noted that in the parameter studies to follow, the results may not be consistent from study to study since not all studies were done with the same set of parameters and/or assumptions. It is only intended to demonstrate the main features of the parameter variations.

\subsubsection{MHD Parameters}

The MHD considerations for D-D tokamaks are not essentially different from those for D-T tokamaks. Consequently, many of the MHD parameters, which have been studied previously in many places, have been chosen to be the values used for STARFIRE ${ }^{(3)}$ in order to facilitate comparison. These include the pressure profile shape exponent, $\alpha_{p}=1.4$, and the elongation, $\kappa=1.6$.

The plasma edge is parameterized by the following equations:

$$
\begin{aligned}
& \mathrm{R}=\mathrm{R}_{\mathrm{o}}+\mathrm{a} \cos (\theta+d \sin \theta) \\
& \mathrm{Z}=k \mathrm{a} \sin \theta .
\end{aligned}
$$

The quantity $\theta$ is a parameter and not the poloidal angle. The plasma becomes more $\mathrm{D}$-shaped (outwardly pointing) as $\mathrm{d}$ increases. The demands on the equilibrium field (EF) coils also increase with d. $(8,9)$ In particular, for $d \geq 0.25$, coils in the center hole of the reactor are probably required. For a pulsed device with a current induction solenoid, however, center-hole crils are not practical. For this reason and to ease the demands on the EF system, the quantity d has been taken to be 0.2 throughout this study. The penalty for such a cholce is that the MHD stability increases somewhat with d. (6) (STARFIRE has $d=0.5$, near the EF coll design IImit for EF colls outside of the toroidal field (TF) coils.)

The MHD equilibria considered in this stuojy are of a more conventional and more atudied type than used in STARFIRE. They all have $q(0)=1$ and $q(a)=3$ and have more centrally peaked current profiles with moderate $\beta_{p}$. They are of the type considered in Ref. 6. The MHD equilibrium for STARFIRE 


\begin{tabular}{|c|c|c|c|}
\hline$R_{0}$ & major radius & $\bar{n}_{D}$ & $\begin{array}{l}\text { avezage deuterium } \\
\text { density }\end{array}$ \\
\hline $\mathbf{a}$ & plasma half-width & & \\
\hline A & aspect ratio & & average tritium density \\
\hline $\mathbf{k}$ & plasma elongation & $n_{3}$ & average ${ }^{3} \mathrm{He}$ density \\
\hline d & plasma D-shapedness & $\mathbf{n}_{4}$ & average ${ }^{4} \mathrm{He}$ density \\
\hline & scrape-off thickness & $\mathbf{P}_{\mathbf{T}}$ & thermal power \\
\hline$\Delta_{\mathrm{BS}}^{i}$ & $\begin{array}{l}\text { inside blanket/shield } \\
\text { thickness }\end{array}$ & $P_{w f}$ & $\begin{array}{l}\text { If input power } \\
\text { total wall load }\end{array}$ \\
\hline$q(a)$ & $\begin{array}{l}\text { safety factor at } \\
\text { limiter }\end{array}$ & $P_{w}(14.06)$ & $\begin{array}{l}14.06 \mathrm{MeV} \text { neutron wall } \\
\text { load }\end{array}$ \\
\hline$q(0)$ & safety factor on axis & $P_{w}(2.45)$ & $\begin{array}{l}2.45 \mathrm{MeV} \text { neutron wall } \\
\text { load }\end{array}$ \\
\hline$\beta_{t}$ & $\begin{array}{l}\text { toroldal beta } \\
\text { poloidal beta }\end{array}$ & $P_{w, \text { neut }}$ & neutron wall load \\
\hline$I_{p}$ & plasma current & $P_{w, \text { diff }}$ & diffusion wall load \\
\hline$\Delta \mathrm{B}_{\mathrm{OH}}$ & ohmic heating field & & \\
\hline$\overline{\mathrm{T}}_{\mathrm{e}}$ & $\begin{array}{l}\text { average electron } \\
\text { temperature }\end{array}$ & EMP & $\begin{array}{l}\text { ratio of required con- } \\
\text { finement to that pre- } \\
\text { dicted by empirical } \\
\text { scaling }(7)\end{array}$ \\
\hline $\mathbf{T}_{\text {eo }}$ & $\begin{array}{l}\text { peak electron } \\
\text { temperature }\end{array}$ & $\bar{n}_{\mathrm{D}} \tau_{\mathrm{E}}$ & $\begin{array}{l}\text { electron energy con- } \\
\text { finement parameter }\end{array}$ \\
\hline$\overline{\mathrm{T}}_{\mathbf{I}}$ & $\begin{array}{l}\text { average Ion tempera- } \\
\text { ture }\end{array}$ & $\Gamma_{c}$ & $\begin{array}{l}\text { cyclotron reflection } \\
\text { coefficlent }\end{array}$ \\
\hline $\bar{n}_{e}$ & $\begin{array}{l}\text { average electron } \\
\text { density }\end{array}$ & $\lambda_{P}$ & $\begin{array}{l}\text { ratio of particle con- } \\
\text { finement time to electron } \\
\text { energy confinement time }\end{array}$ \\
\hline $\mathbf{n}_{\mathrm{P}}$ & $\begin{array}{l}\text { average proton } \\
\text { density }\end{array}$ & $\lambda_{I}$ & $\begin{array}{l}\text { ratio of ion energy con- } \\
\text { finement time to electron } \\
\text { energy confinement time }\end{array}$ \\
\hline
\end{tabular}


was optimized for the lower hybrid rf current drive and has high $\beta_{p}$, a skin current distribution, and lower plasma current for a given $B_{t}{ }^{*}$ The stability of this type of equilibria has not been as extensively studied. The theoretically highest stable $\beta_{t}$ values are found for a third type of MHD equilibria with $10 \mathrm{w} B_{p}$ and broad current distributions. (10) This type of equilibxia results from systematically optimizing the MHD parameters to maximize the scable beta values.

The maximum stable $\beta_{t}$ for the type of equilibria considered scales as $A^{-1}$. (6) (The optimized, low $\beta_{p}$ equilibria scale more like $A^{-2}{ }^{(10)}$ ) Iri all cases where different aspect ratios have been considered, the $A^{-1}$ scaling has been used, although the constant of proportionality has been varied.

\subsubsection{Impurity Concentration}

There is a maximum impurity concentration in the plasma that will allov Ignition as shown, for example, in Fig. 2-3. This maximum Impurity concentration as a function of the nuclear charge (the actual charge state depends on the temperature) is shown in Fig. 2-4. The allowable concentration decreases approximately exponentially with charge. It can be seen that the alternate fuel D-D reactor must be an order of magnitude cleaner ihan a corresponding $\mathrm{D}-\mathrm{T}$ reactor. The standard impurity concentration used in the rest of the studies is $3 \% \mathrm{Be}$ (compared to a maximum possible of $\approx 5 \% \mathrm{Be}$ ).

\subsubsection{Plasma Temperature}

The variation of several reactor parameters with electron temperature is shown in Table 2-3 for a typical case. The reactor performance improves with decreasing temperature until just above the lowest temperature that allows ignition. This lowest temperature is near $25 \mathrm{keV}$, depending mainly on the shape of the density and temperature profiles. Most of the studies at fixed temperature have used $\bar{T}_{e}=30 \mathrm{keV}$, near the optimum, but allowing. some mariin for variations. These results are typical of Cat-D, semi-Cat $-D$, and $\mathrm{D}-{ }^{3} \mathrm{He}$ reactors (see Sec. 2.2.7). A D-T reactor would be optimum in the same sense at $\overline{\mathrm{T}}_{e}=7-8 \mathrm{keV}$. 


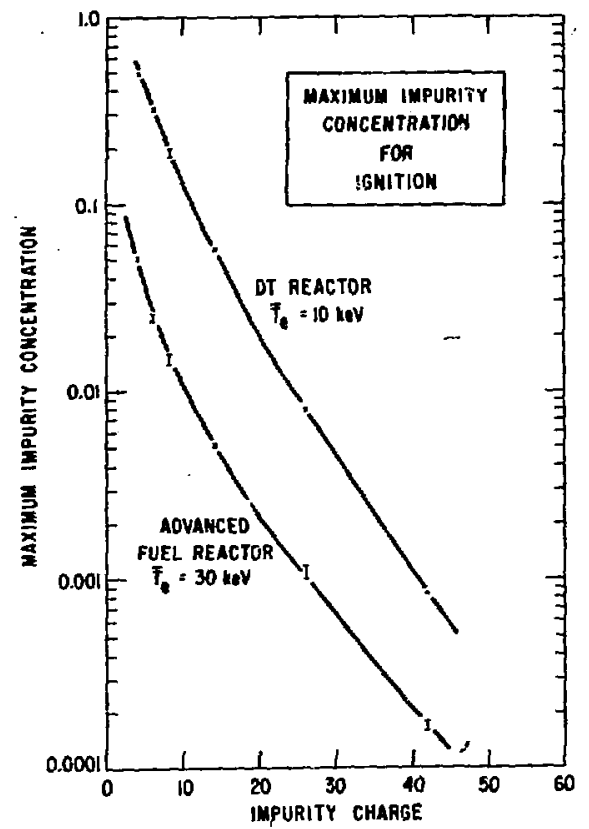

Figure 2-4. The maximum allowed impurity concentration as a function of nuclear charge for $\mathrm{D}-\mathrm{D}$ and $\mathrm{D}-\mathrm{T}$ reactors. The given impurity was the only one present in all cases.

Table 2-3. Variation of reactor parameters with the average electron temperature, $T_{e}$. The case shown has $R_{0}=9.0 \mathrm{~m}, A=3.25, \beta_{t}=11 \%$, and $\mathrm{B}_{\mathrm{TFC}}=\mathrm{I}_{4} \mathrm{~T}$ and is fully catalyzed. The minimum temperature for ignition is $24 \mathrm{keV}$.

\begin{tabular}{lcccccccc}
\hline $\begin{array}{c}\overline{\mathrm{T}}_{\mathrm{e}} \\
(\mathrm{keV})\end{array}$ & $\begin{array}{c}\overline{\mathrm{T}}_{\mathrm{I}} \\
(\mathrm{keV})\end{array}$ & $\begin{array}{c}\overline{\mathrm{n}}_{\mathrm{D}} \\
\left(10^{20} \mathrm{~m}^{-3}\right)\end{array}$ & $\begin{array}{c}\overline{\mathrm{n}}_{\mathrm{D}} \tau_{\mathrm{E}} \\
\left(10^{20} \mathrm{~s} / \mathrm{m}^{3}\right)\end{array}$ & $\begin{array}{c}\mathrm{P}_{\mathrm{T}} \\
(\mathrm{GW})\end{array}$ & $\begin{array}{c}\mathrm{P}_{\mathrm{w}}(14.06) \\
\left(\mathrm{MN} / \mathrm{m}^{2}\right)\end{array}$ & $\begin{array}{c}\mathrm{P}_{\mathrm{w}}(2.45) \\
\left(\mathrm{MN} / \mathrm{m}^{2}\right)\end{array}$ & $\alpha_{\mathrm{EMP}}$ \\
\hline 24 & 25 & 2.1 & 28 & 3.3 & 0.56 & 0.11 & 0.6 \\
26 & 27 & 2.0 & 20 & 3.3 & 0.56 & 0.11 & 0.5 \\
30 & 32 & 1.7 & 14 & 3.1 & 0.53 & 0.11 & 0.5 \\
34 & 37 & 1.5 & 13 & 2.9 & 0.49 & 0.10 & 0.6 \\
38 & 42 & 1.3 & 12 & 2.6 & 0.44 & 0.09 & 0.7 \\
\hline
\end{tabular}




\subsubsection{Density and Temperature Profiles}

The general form of the profile-spectfled quant 1 ties is:

$$
x=\bar{x}^{\alpha} / \overline{\hat{\psi}^{\alpha}},
$$

where $\vec{x}$ is the average of $x$ and $\hat{\psi}$ is related to the MDD flux function, $\psi$, by:

$$
\hat{\psi}=\frac{\psi_{\ell}-\psi}{\psi_{2}-\psi_{m}}=\left\{\begin{array}{ll}
1 & \text { magnetic axis } \\
0 & \text { limiter }
\end{array},\right.
$$

where $\psi_{l}$ and $\psi_{\mathrm{m}}$ are the values of $\psi$ at the limiter and magnetic axis respectively. The flux function is defined so that the poloidal fleld lines are the lines $\psi=$ constant. The pressure can be shown to be constant on flux 11nes. It is assumed the density and temperature are, also. Since the pressure profile exponent, $a_{p}$, has been fixed at 1.4 , the density and temperature profile exponents, $a_{n}$ and $a_{T}$, must satisfy $a_{n}+a_{T}=a_{p}=i .4$. The varlation of several reactor parameters with these profile exponents is shown In Table 2-4 for a typical case. The performance can be seen to be best for sharp density and broad temperature profiles. Present experimen's tend to show broad density and sharp temperature profiles, however. In add ion, refueling and/or recycling at the plasma edge should tend to favor broad density profiles in reactor plasmas. A compromise of $\alpha_{n}=\alpha_{T}=0.7$ is taken for the remalnder of these studies.

Table 2-4. Varlation of reactor parameters with the temperature and density profiles. The case shown has $R_{0}=9 \mathrm{~m}, A=3.0, B_{t}=12 \%$, and $B_{\text {TFC }}=14 \mathrm{~T}$.

\begin{tabular}{lllccc}
\hline$a_{n}$ & $a_{T}$ & $\begin{array}{l}T_{\text {eo }} \\
(\mathrm{keV})\end{array}$ & $\begin{array}{c}\mathrm{P}_{\mathrm{T}} \\
(\mathrm{GW})\end{array}$ & $\begin{array}{c}\overline{\mathrm{n}}_{\mathrm{D}} \tau_{\mathrm{E}} \\
\left(10^{20} \mathrm{~s}_{\mathrm{m}} \mathrm{m}^{3}\right)\end{array}$ & $a_{\mathrm{BMP}}$ \\
\hline 0.1 & 1.3 & 70 & 2.0 & 21 & 0.6 \\
0.4 & 1.0 & 61 & 2.2 & 16 & 0.5 \\
0.7 & 0.7 & 52 & 2.4 & 14 & 0.5 \\
1.0 & 0.1 & 42 & 2.5 & 17 & 0.6 \\
1.3 & & & No solution & &
\end{tabular}




\section{2 .5 Cyclorron Reflection Coefficient}

For alternate fuel reactors with their higher temperatures, the cyclotron radiation loss becomes important. This loss depends on the cyclotron reflection coefficient, $\Gamma_{c}$. In the Trubntkov madel ${ }^{(3)}$ used in these studies, the loss is proportional to $\left(1-\Gamma_{c}\right)^{\frac{1}{2}}$. Reflection coefficients near unity tend to minimize this 1oss. It is useful to see how deleterious a low value of $\Gamma_{c}$ may be. The variation of several reactor parameters with $\Gamma_{c}$ for a typical case is shown in Table 2-5. The effect on the performance is not major for $\Gamma_{c} \geq 0.4$, below which ignition is difficult to obtain. Above this value the main effect of a low coefficient is to increase the required confinemert parameter. The results would be worse, of course, at higher temperatures. Unless stated otherwise, the standard cyclotron reflection coefficient for the rest of the studies is $\Gamma_{c}=0.9$.

\section{2 .6 Confinement Times}

As described in Sec. 2.1, the ratio, $\lambda_{P}$, of the particle and electron energy confinement times and the ratio, $\lambda_{I}$, of the ion energy and electron energy confinement times can be varied. The results of such a variation are shown in Table 2-6. The performance decreases slightly as $\lambda_{P}$ increases

Table 2-5. Variation of reactor parameters with the cyclotron reflection coefficient. The case shown has $R_{0}=9 \mathrm{~m}, A=3.0, B_{t}=12 \%$, $\mathrm{B}_{\mathrm{TFC}}=14 \mathrm{~T}$, and $\overline{\mathrm{T}}_{\mathrm{e}}=30 \mathrm{keV}$

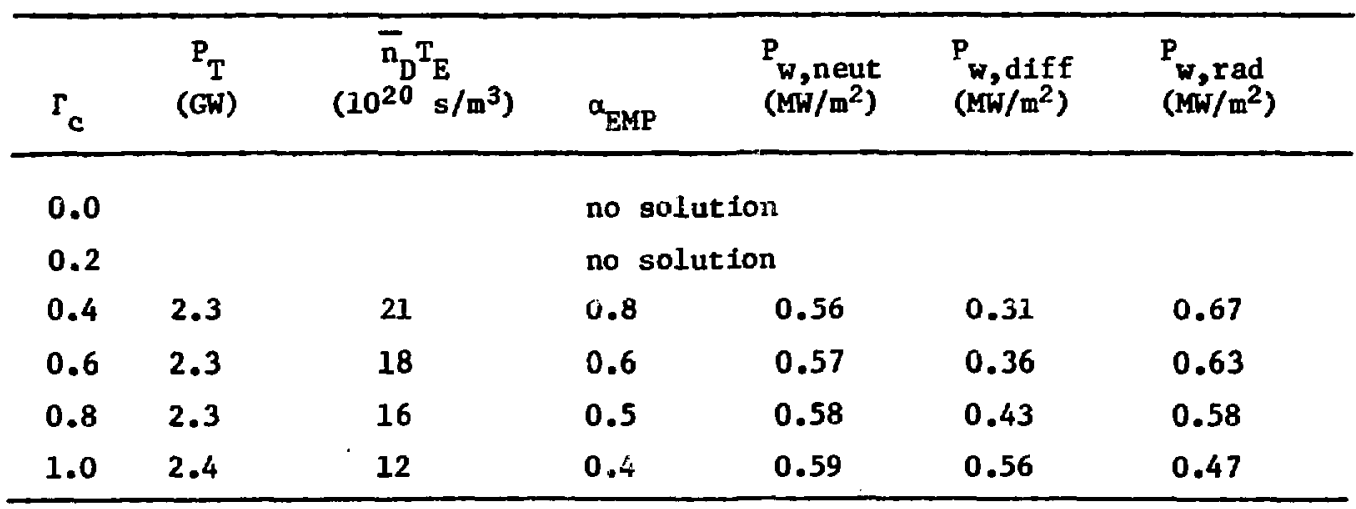


Table 2-6. Variation of particle and energy confinenent times. The case considered has $R_{0}=9 \mathrm{~m}, \mathrm{~A}=3.0, \mathrm{~B}_{\mathrm{t}}=127, \mathrm{~B}_{\mathrm{TFC}}=14 \mathrm{~T}$, and $T_{e}=k e v$.

\begin{tabular}{|c|c|c|c|c|}
\hline$\lambda_{\mathrm{p}}$ & $\lambda_{I}$ & $\begin{array}{c}P_{T} \\
\text { (GW) }\end{array}$ & $\begin{array}{c}\bar{n}_{D^{\top} T_{E}} \\
\left\langle 10^{20} \mathrm{~s} / \mathrm{m}^{3}\right\rangle\end{array}$ & $\alpha_{\text {EMP }}$ \\
\hline 0.5 & 4.0 & 2.2 & 20 & 0.5 \\
\hline 1.0 & & 2.2 & 21 & 0.6 \\
\hline 1.5 & & 2.1 & 23 & 0.7 \\
\hline 2.0 & Y & 2.0 & 27 & 0.7 \\
\hline 1.0 & 2.0 & 2.1 & 27 & 0.7 \\
\hline 1 & 4.0 & 2.2 & 21 & 0.6 \\
\hline & 6.0 & 2.2 & 20 & 0.5 \\
\hline & 8.0 & 2.2 & 19 & 0.5 \\
\hline 7 & 10.0 & 2.2 & 18 & 0.5 \\
\hline
\end{tabular}

(as the particles are confined better compared to the electron energy). The main effect is that the required electron energy confinement increases. There is an upper limit ( $\lambda_{\mathrm{P}} \approx 2$ for this case) beyond which ignition is not possible. The performance increases slight!y as $\lambda_{I}$ increases, again reflected in decreased required confinement. There is a lower limit $\left(\lambda_{I} \approx 2\right.$ for this case) beyond which Ignition is not possible.

The standard values chosen for these ratios are $\lambda_{P}=0.25$ and $\lambda_{I}=4.0$. The low particle confinement is balanced by high particle recyling at the wall. (90\% of the protons and $75 \%$ of the ${ }^{3} \mathrm{He}$ are assumed recycled. For a fully catalyzed reactor $100 \%$ of the tritfum and ${ }^{3} \mathrm{He}$ are recycled or reinjected.) The high ion energy confinement is a reflection of the fact that if ions continue to be neoclassical and electrons continue to be empirical as indicated in present experinents, the Ion energy will be confined wuch better than the electron energy. On the other hand, there is no confirmation at this time that this will happen at temperatures as high as $30 \mathrm{keV}$ in reactor-like plasmas. For this reason the confinement times in this study are kept reasonably close to each other. No significant advantage is obtained for $\lambda_{I}$ much larger than 10 in any event. 


\section{2 .7 Reactor Type}

It is interesting to see how the plasma performance varies with the reactor type or mode of opeation. For a D-T reactor more tritium is injected into the plasma than is produced by nuclear reactions in the plasma. Similarly, for a $\mathrm{D}-{ }^{3} \mathrm{He}$ reactor more ${ }^{3} \mathrm{He}$ is injected than is produced. For a Cat-D reactor all of the tritium and ${ }^{3} \mathrm{He}$ that are produced in the plasma are reinjected, but no extra is provided. In a semi-Cat-D. reactor some fraction of the tritium and/or ${ }^{3} \mathrm{He}$ is retained and not put back into the plasma. These cases differ by the recycling coefficients, $R_{i}\left(i=P, D, T,{ }^{3} \mathrm{He},{ }^{4} \mathrm{He}\right.$ ). The recycling coefficients, $k_{i}$, are the fraction of the diffusion transport incident on the first wall which is either reflected or reinjected back into the plasma.

Table 2-7 indicates how the plasma performance varies for a single basic device if it were operated in each of these modes. It should be understood that the basic device, which is optimized for fuli Cat-D operation, might not be the most satisfactory for the other modes. The blanket/shield thickness, $\Delta_{\mathrm{BS}}^{i}=0.82 \mathrm{~m}$, is too thin for a D-T reactor and could be made thinner for a $D-{ }^{3} \mathrm{He}$ reactor. The neutron energy multiplication $\left(\varepsilon_{14.06}=1.4\right.$ and $\left.\varepsilon_{2.45}=4.2\right)$ is too high for a tritium-breeding D-T reactor, and the power and wall-loading are unreasonably high in the D-T case. The table is meant only to show the relative characteristics of a plasma operated in the different modes and should not be interpreted as a comparison of viable reactors of the specified types.

For the deuterium-fueled case, the Cat-D mode typically has the better performance. It can be noted that the recycling coefficients, which determine the reactor type, are nearly the same for Cat-D and D- ${ }^{3} \mathrm{He}$. The difference is, however, significant: the small amount of additional ${ }^{3} \mathrm{He}$ fueling for the $\mathrm{D}-{ }^{3} \mathrm{He}$ case is sufficient to assure a high ${ }^{3} \mathrm{He}$ concentration, which results in lower neutron production and slightly lower power.

Since most of the tritium is burned up in a D-D reactor, it is not critically important if all of the tritium is replaced, allowing the entire range of semi-catalyzed operation with respect to tritium. The performance is substantially better, however, the more tritium is put back into the plasma.

It Is critical that most of the. ${ }^{3} \mathrm{He}$ diffusion loss be replaced. Ignition cannot be obtained unless more than about $94 \%$ of the ${ }^{3} \mathrm{He}$ is recycled or reinjected for the impurity concentration and cyclotron reflection coefficients 
Table 2-7. Performance as a function of reactor type. The basic reactor considered has $R=8.6 \mathrm{~m}$, $A=3.25, B_{t}=11 \%$ and $B_{T F C}=14 \mathrm{~T}$. The table is meant to show a comparison of plasmas operated in the various modes only and should not be considered a comparison of viable reactors.

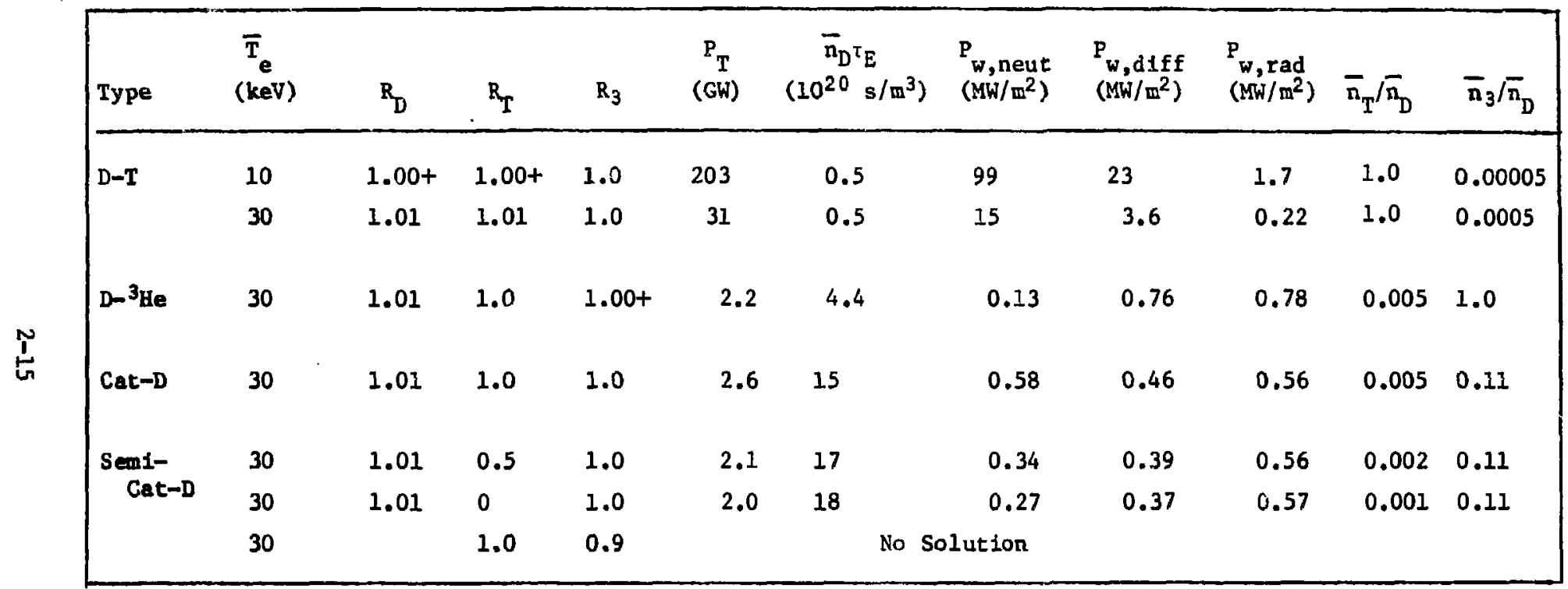

+ Some small net fueling $(\leq 1 \%)$ is required. 
used in this study. This conclusion depends on some of the assumptions made concerning the reactor parameters. Table 2-8 shows how much ${ }^{3} \mathrm{He}$ could be diverted under relaxed assumptions.

\subsubsection{Beta, Toroldal Field, Size, and Aspect Ratio}

Probably the most important three parameters are the size, characterized by the major radius, $R_{0}$; the toroidal field, $B_{T F C}$, at the toroldal field coils; and the plasma beta, $B_{t}$. The power is proportional to $B_{t}^{2} B_{T F C}^{4} R_{0}^{3}$. Most of the effects of varying these parameters can be seen from these scalings. In addition, the plasma current ircreases with $B_{T F C}$ and $R_{0}$ but not appreciably with $\beta_{t}$ (if the other MHD parameters are kept constant). While the general results of varying these parameters singly is well understood, it is often more useful to vary them together so as to keep quantities such as the wall load, for example, constant.

In particular, when designing a conventional, pulsed tokamak reactor, it is desirable to work at the first wall loading, $P_{w}$, linit and at the limit for the oimic heating magnetic field swing, $\Delta \mathrm{B}_{\mathrm{OH}}$. In comparing different reactors, it is convenient to hold these quantities fixed. If one fixes

Table 2-8. Variation of allowable ${ }^{3}$ He recycling. $R_{\text {min }}$ is the minimum recycling coefficient for which ignition occurs. A maximum fraction, $f_{3}=\left(1-R_{\text {min }}\right)$, of the 3 He diffusion flux incident on the wall can be diverted for other uses.

\begin{tabular}{|c|c|c|c|c|}
\hline $\begin{array}{c}\mathrm{T}_{\mathrm{e}} \\
\text { (kev) }\end{array}$ & Impurity & $\Gamma_{c}$ & $R_{\text {min }}$ & $\mathbf{f}_{3}$ \\
\hline \multirow[t]{3}{*}{30} & none & 1.0 & 0.00 & 1.00 \\
\hline & none & 0.9 & $0.60-0.65$ & $0.35-0.40$ \\
\hline & $3 \% \mathrm{Be}$ & 1.0 & $0.85-0.90$ & $0.10-0.15$ \\
\hline 1 & $37 \mathrm{Be}$ & 0.9 & $0.90-0.95$ & $0.05-0.10$ \\
\hline \multirow[t]{4}{*}{40} & none & 1.0 & 0.00 & 1.00 \\
\hline & none & 0.9 & $0.75-0.80$ & $0.20-0.25$ \\
\hline & $32 \mathrm{Be}$ & 1.0 & $0.45-0.50$ & $0.50-0.45$ \\
\hline & $37 \mathrm{Be}$ & 0.9 & $0.90-0.95$ & $0.05-0.10$ \\
\hline
\end{tabular}


$P_{w}$ and $\Delta B_{O H}$ and assumes a scailng of $B_{t}$ with $A$, the result is a series of reactors with varying $R_{0}, B_{T F C}, B_{t}$, and $A_{\text {. }}$

Such a series is shown in Table 2-9. The scaling for $B_{t}$ is assumed to be $\beta_{t}=0.36 / A$, a faicly optimistic estimate of $\beta_{t}$ but with the scaling established in Ref. 6. All of the designs In this series should be equally credible from an $\mathrm{MD}$ standpoint. The total wall $10 \mathrm{ad}, \mathrm{F}_{\mathrm{w}}=1.60 \mathrm{NW} / \mathrm{m}^{2}$, is typically composed as follows:

$$
\begin{aligned}
& 14.06 \mathrm{MeV} \text { neutron wall load, } P_{w}(14.06)=0.5 \mathrm{MW} / \mathrm{m}^{2} ; \\
& 2.45 \mathrm{MeV} \text { neutron wall load, } P_{w}(2.45)=0.1 \mathrm{MW} / \mathrm{m}^{2} ; \\
& \text { Charged particle wall load, } P_{w, d i f f}=0.5 \mathrm{MW} / \mathrm{m}^{2} ; \text { and } \\
& \text { Radtation wall load, } P_{w, \mathrm{rad}}=0.5 \mathrm{MW} / \mathrm{m}^{2} .
\end{aligned}
$$

The first wall total surface heat $f l u x$ was set at $1.0 \mathrm{MW} / \mathrm{m}^{2}$ for steadystate operation and $0.8 \mathrm{MW} / \mathrm{m}^{2}$ for pulsed operation. The flux, $\Delta \phi_{\mathrm{OH}}$, gupplfed to the plasma 15 also shown in Table 2-9. This number is approximately the Inductive volt-seconds required; however, the EF system typicaily provides about $40 \%$ of the Inductive volt-seconds so that $40 \%$ of the $\mathrm{OH}$ contribution is available for resistive volt-seconds (see Secs. 4.1 and 4.2).

Having fixed several of the important parameters in such a sequence of designs, it is possible to select the best candidate, depending on the design criteria. It can be seen that the lower aspect ratio devices have higher power,

Table 2-9. A sequence of reactor possibilities which have the same total wall loading, $P_{w}=1.60 \mathrm{MW} / \mathrm{m}^{2}$ arit the same ohmic heating fleld swing, $\Delta \mathrm{B}_{\mathrm{OH}}=16 \mathrm{~T}$. The plasma beta $1 \mathrm{~s}$ assumed to scale as $B_{t}=0.369 \mathrm{~s}$. The average temperature is $T_{e}=30 \mathrm{keV}$.

$\begin{array}{cccccccc} & R_{0} & B_{T F C} & & P_{T} & I_{P} & & \Delta \phi_{O H} \\ A & (m) & (T) & B_{t} & (G W) & (M A) & \alpha_{\text {EMP }} & (V-8)\end{array}$

$\begin{array}{lrrrrrrr}2.4 & 13.7 & 11.4 & 0.15 & 6.6 & 65 & 0.26 & 1410 \\ 3.0 & 9.8 & 13.4 & 0.12 & 2.8 & 36 & 0.46 & 670 \\ 3.25 & 9.2 & 14.1 & 0.11 & 2.3 & 31 & 0.51 & 560\end{array}$


lower toroidal fields, and more room in the center of the device, but are larger and have higher plasma currents.

\subsection{Reference Degign}

A tentative design point has been selected for this stage of the study based on the surveys indicated in the preceding section. While there are certain advantages of alternate fuel reactors, they produce less than $5 \%$ of the power of a D-T reactor for a given geometry, size, toroidal field and plasma beta. This difference has to be made up primarily by increases in $\mathrm{R}_{0}$, $\mathrm{B}_{\text {TFC" }}$ and/or $B_{t}$, although some gains are possible due to a thinner blanket/shield between the toroidal coils and the plasma and by increased neutron multiplication in a non-breeding blanket.

An attempt has been made to develop a reference design so that major parameters are not extended appreciably beyond values typically used for $D-T$ reactors; e.g., STARFIRE. (3) The major parameters for the reference design are: given in Table 2-10. The Xe impurity shown represents an impurity added for thermal stability control (see Sec. 2.4.1) and could be another element such as iodine. Both a conventional, pulsed version and an rf driven, steady-state version have been considered for the same basic geomecry. A preliminary cross-section view of the reactor is shown in FIg. 2-5, and a top view in Fig. 2-6.

\subsection{Burn Cycle Studies}

\subsubsection{Reference Burn Cycle}

The burn cycle of the reference $D-D$ tokamak reactor has been studied using the time dependent model described in Sec. 2.4.2. In developing the D-D burn cycle, use has been made of the many studies of the D-T tokamak cycle. (See, for example, Refs. 4 and 11 for the general features and consideratIons involved in a pulsed D-T cokamak burn cycle.) For the D-D cycle there appear to be two key issues, First, because of the typically larger size of a D-D reactor, the energy stored in the $O H$ and EF coils is large (about 20 GJ for each aystem for the reference reactor). The power supply requirements for these colls 18 , therefore, a major " ncern. Secondly, because the D-D fuston cross sections are low, particular at the temperatures when starting the plasma, there is concern about how much external heating power 
Major radius, $R_{0}$

$8.58 \mathrm{~m}$

Aspect ratio, A

3.25

Peak toroidal ffeld, B TFC

14

Plasma beta, $B_{t}$

0.11

Scrape-off region, $\Delta_{v}$

$0.20 \mathrm{~m}$

Inside blanket/shield thickness, $\Delta_{B S}$

$0.82 \mathrm{~m}$

OH solenoid mean radius, $\mathrm{R}_{\mathrm{OH}}$

$3.23 \mathrm{~m}$

Elongation, $k$

1.6

D-shapedness, d

0.2

Safety factor at edge, $q(a)$

3

at axis, $q(0)$

1

Plasma current, $I_{p}$

OH field swing, $\triangle \mathrm{B}_{\mathrm{OH}}$

29.2 MA

Average electron temperature, $\overline{\mathrm{T}}_{\mathrm{e}}$

$15.2 \mathrm{~T}$

Peak electron temperature, $T_{\text {eo }}$

$30 \mathrm{keV}$

$52 \mathrm{keV}$

Average Ion temperature, $\overline{\mathrm{T}}_{\mathrm{I}}$

$32 \mathrm{keV}$

Average densities:

$$
\begin{aligned}
& \text { proton, } \bar{n}_{P} \\
& \text { deuterium, } \\
& \text { tritium, } \bar{n}_{\mathrm{n}} \\
& \text { helium } 3, \overline{\mathrm{n}}_{3} \\
& \text { helium } 4, \overline{\mathrm{n}}_{4} \\
& \text { electron, } \bar{n}_{e}
\end{aligned}
$$

$1.1 \times 10^{19} \mathrm{~m}^{-3}$

$1.7 \times 10^{20} \mathrm{~m}^{-3}$

$7.8 \times 10^{17} \mathrm{~m}^{-3}$

$1.8 \times 10^{19} \mathrm{~m}^{-3}$

$4.3 \times 10^{18} \mathrm{~m}^{-3}$

$2.4 \times 10^{20} \mathrm{~m}^{-3}$

Impurities:

$$
\text { bery111um, }{\overline{n_{B}}}_{\text {xenon, }} / \bar{n}_{X e} \sqrt{n_{D}}
$$

Energy confinement parameter, $\overline{\boldsymbol{n}}_{D} \boldsymbol{\tau}_{E}$

14.06 $\mathrm{MeV}$ neutron multiplication,

$$
\varepsilon_{14.06}
$$

$2.45 \mathrm{MeV}$ neutron multiplication, $\varepsilon_{2.45}$

Wall loading: total, $P_{w}$

$$
14.06 \mathrm{MeV} \text { neutron, } P_{W}(14.06)
$$

2.45 neutron, $P_{W}(2.45)$

charged particle, $P$ w, diff radiation, $P$
net heat, $P$, rad

RF heating, $P_{\text {rf }}$

Thermal power, $P_{T}$
0.03

$2-5 \times 10^{-5}$

$2.4 \times 10^{21} \mathrm{~s} / \mathrm{m}^{3}$

1.4

4.2

$1.5-1.7 \mathrm{MN} / \mathrm{m}^{2}$

$0.5 \mathrm{~mW} / \mathrm{m}^{2}$

$0.1 \mathrm{MW} / \mathrm{m}^{2}$

$0.3 \mathrm{~kW} / \mathrm{m}^{2}$

$0.7-0.9 \mathrm{MH} / \mathrm{m}^{2}$

$0.8-1.0 \mathrm{~mW} / \mathrm{m}^{2}$

0 - 220 MW

$2.5-2.7 \mathrm{GH}$ 


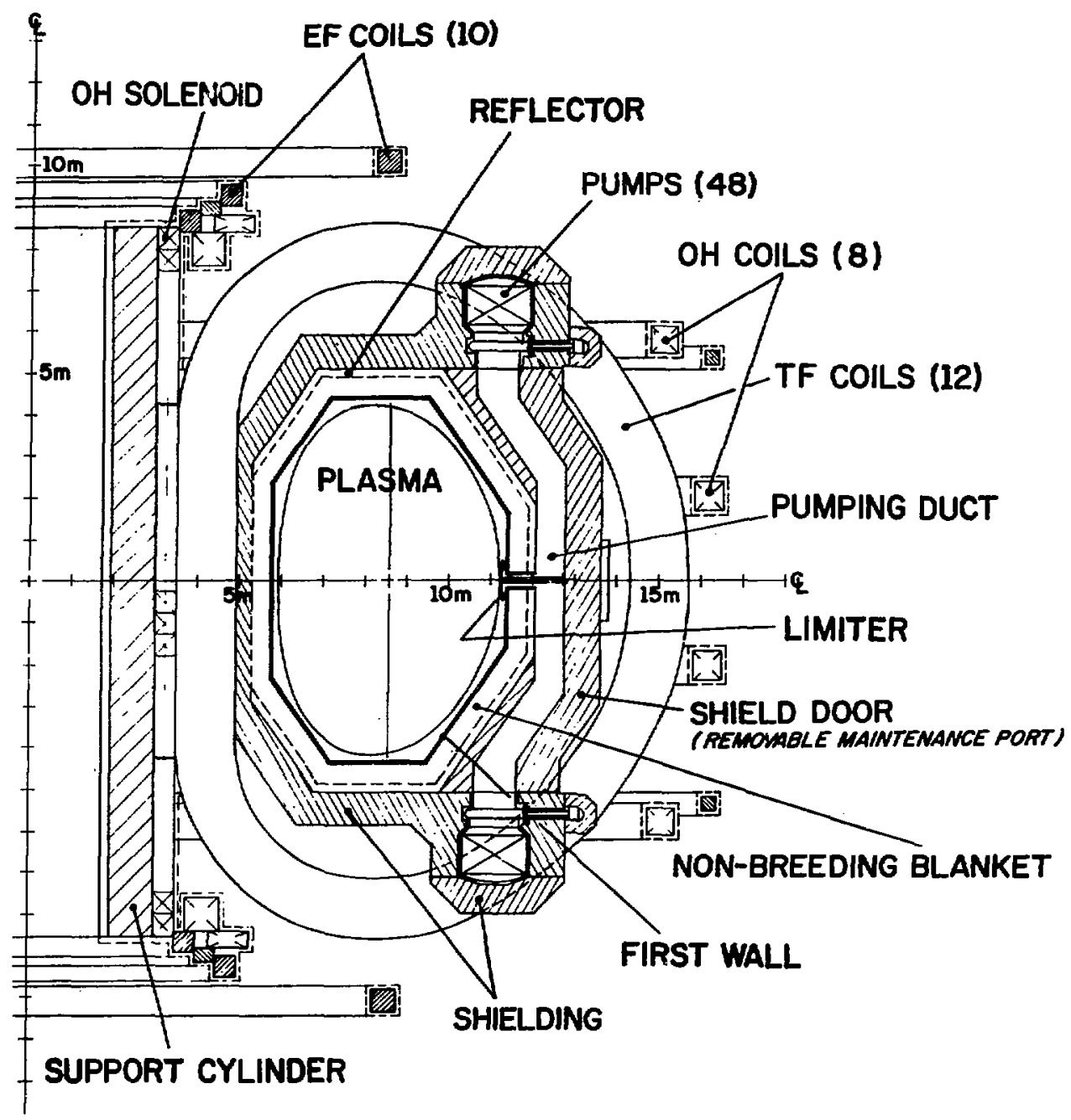

Figure 2-5. Cross-sectional view of the reference Cat-D design.

Is needed to reach ignition. Unless the burn cycle parameters are carefully chosen, both the power supply and heating requirements could be excessive. The burn cycle developed here for the reference $D-D$ reactor solves these heating requirement problems through the use of extra tritium and ${ }^{3}$ He during the startup. While the power supply requirements are still fairly large, they have been minimized through the use of a lons startup time and by carefully controlling the plasma densities and heat rate. 


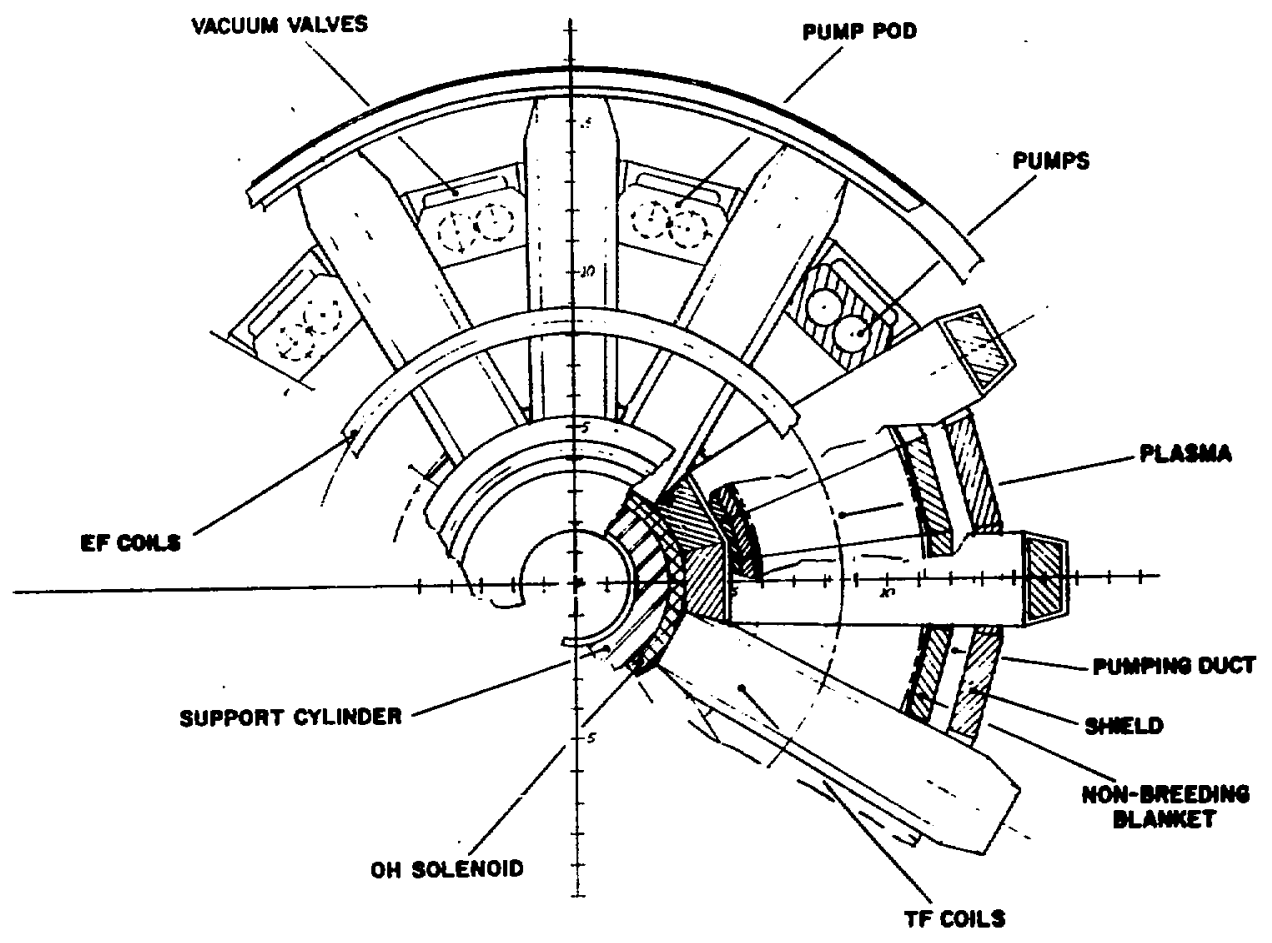

Figure 2-6. Top view of the reference design.

The main parameters of the burn cycle are summarized in Table 2-11. F1gures 2-7 through 2-10 show the important coll and plasma parameters during the startup period. In accordance with the conclusions of Ref. 11, which treated the general subfect of power supply requirenents for tokamak reactors, the startup period has been broken up into two phases: an "ohnic heating" perfod and a "main heating" period. During the ohmic heating perlod the OH current is ramped up to Induce the bulk of the plasma current. During the main heating period the plasma is brought up to full density, temperature, and current. A fairly long (18 8 ) of ramp time is used to minimize the OH power supply requirements. After the OH period an add1tional 27 seconds are used for the main heating period for a total startup 
Table 2-11. D-D Burn Cycle Parameters

\begin{tabular}{lll}
\hline Parameter & Unit & Value \\
\hline Ohmic heating period & $s$ & 18 \\
Main heating period & $s$ & 27 \\
Total startup time & $s$ & 45 \\
Burn time & hrs & 2.5 \\
Shutdown time & s & 30 \\
Dwell time & s & 30 \\
Duty factor & z & 99 \\
Required rf power & MW & 100 \\
Required OH power & MN & 2160 \\
Required EF power & MVA & 1000 \\
\hline
\end{tabular}

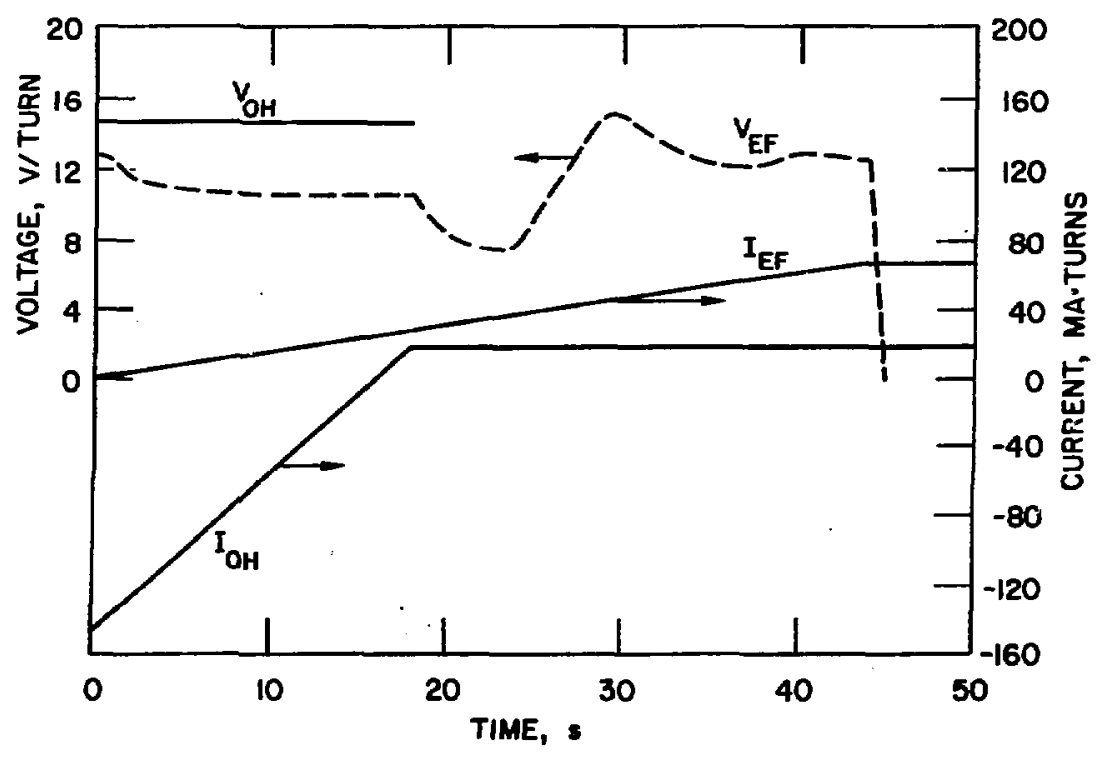

Figure 2-7. Ohnic heating (OH) and equilibrium fleld (EF) waveforns for the startup phase of the D-D burn cycle. 


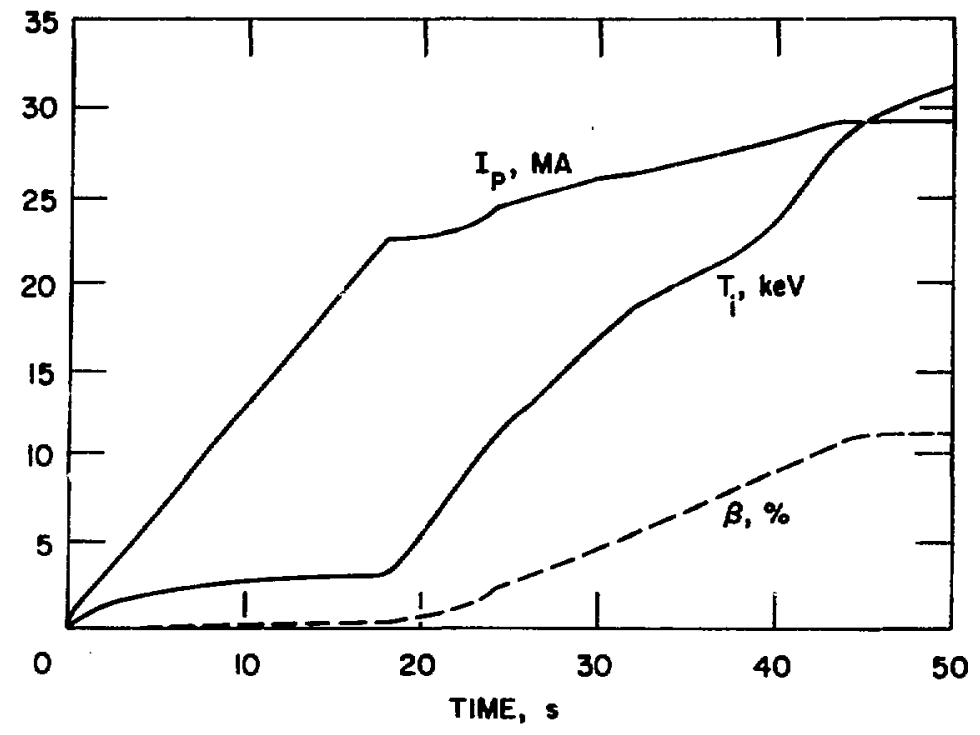

Figure 2-8. Plasma current, Ion temperature and $\beta$ for the D-D burn cycle.

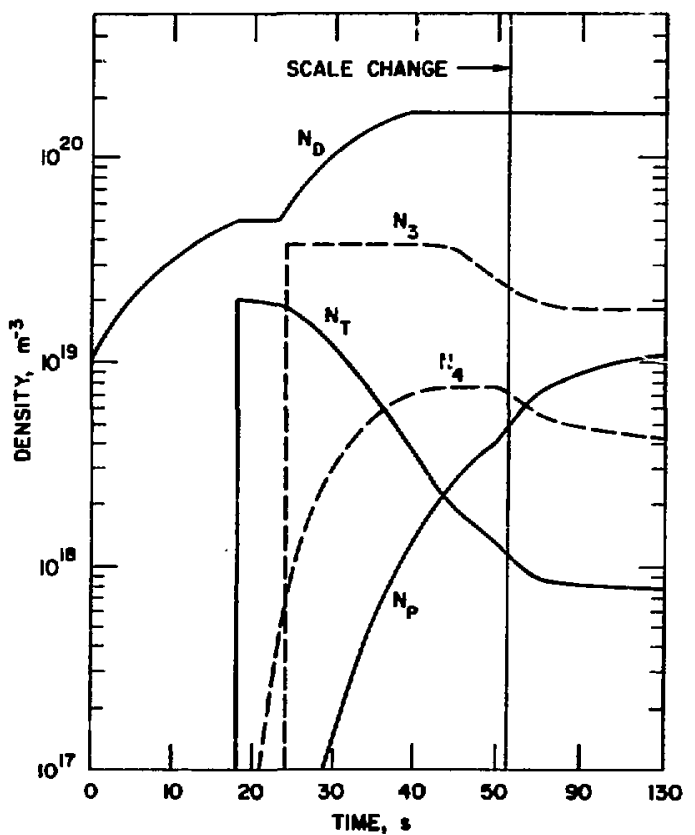

Figure 2-9. Ion denatiles for the D-D burn cycle. 


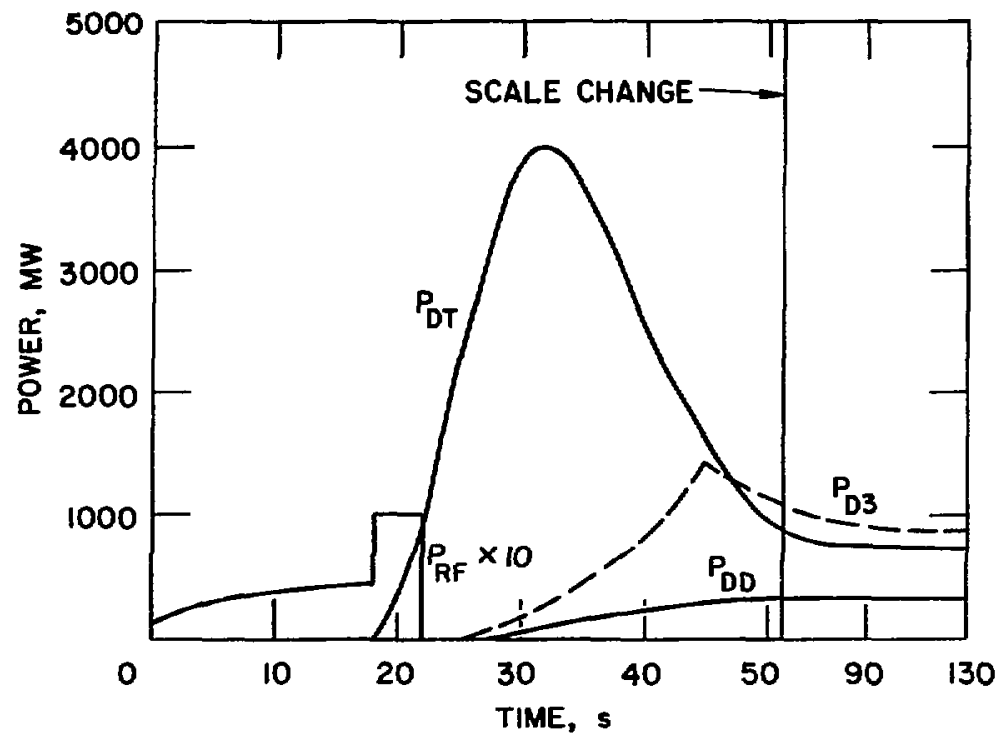

Figure 2-10, Fuston powers and rf heating for the D-D burn cycle.

time of $45 \mathrm{~s}$. This is a long time, relative to typical D-T pulsed reactors. Together with the estimated 60 seconds needed for shutdown and dwell time, the long startup time would require the use of thermal energy storage to maintain a constant electrical power ouput. Such storage is warranted because of the overriding need for reasonable size power supplies. There could be some tradeoffs between the down-time, power supply costs, and the thermal storage costs. Similarly, further studies may Indicate a more optimum tradeoff between the oH and main heating periods. The indicated startup time of $45 \mathrm{~s}$ and the division thereof should be reasonabiy accurate cholces, however.

The $\mathrm{OH}$ and $\mathrm{EF}$ voltage and current waveforms for the startup period are shown in Fig. 2-7. Prior to startup the of coil is charged to its full $-7.6 \mathrm{~T}$ value. A constant voltage is then applied to the $\mathrm{OH}$ coil to ramp down the OA current. After 18 seconds the of coil has induced its share of the plasma current, and the $O$ t ramp is terminated. Subsequently, only a small voltage is applied (not visible on the scale of Fig. 2-7) to to make up for resistive losses in the plasma. In order to minimize the 
resistive lossas during startup, a law plesma density is used and some external heating power, assumed to be $r f$ power, is applied to the plasma during the of period (see Fig. 2-10). This gradually heats the plasma, reducing its resistance. The startup resistive volt-seconds are held to a very low value of $\approx 5 \mathrm{~V}-\mathrm{s}$ by this method. After $18 \mathrm{~s}$ the $\mathrm{OH}$ period ends, and the main heating period begins. The goals for this perfod are as followg: (1) to minimize the rf power required to heat the plasma, (2) to minimize the required rate of increase in EF current and hence minimize the EF voltage, and (3) to minimize the time $n$ zeded for this period. These goals are mutually exclusive, and some tradeoff is needed. Accordingly, various combinations of fuel densities, refueling rates, and $\mathrm{rf}$ power levels have been studied. The scenario shown gives reasonably good results and is probably typical of the strategies to be employed in a D-D tokamak. In this scenario a pulse of tritium gas is infected (at $t=18 \mathrm{~s}$ ) by the refueling system to create In the plasma a tritium density equal to 25 times the steady-state tritium density during most of the burn cycle. This tritium is obtained by withholding a very small amount of the tritium produced by the D-D reaction during the 2-1/2 hour burn phase. The full rf power is also turned on at this iime. The minimum value of $\mathrm{rf}$ power needed is about $100 \mathrm{MW}$. This is an order of $r$ gnitude less than if no extra tritium were used. The rf power is kept on for 5 seconds, heating the plasma enough so that substantial D-T fusion starts to occur. At the end of this $5 \mathrm{~s}$ interval a ramp of the deuterium density is begun, and a charge of ${ }^{3} \mathrm{He}$ is added. This results in a ${ }^{3} \mathrm{He}$ density of about twice the final value. The resulting $D-T$ and $D-{ }^{3} \mathrm{He}$ fusion reaction products then heat the plasma to ignition. Towards the end of the startup period lodine (not shown) is added to the plasma to prevent the plasma from heating up too rapidly and placing excessive demands on the EF system. During the heating phase the ${ }^{3} \mathrm{He}$ density is held constant by the refueling system, but iritium is allowed to burn up without full replacement. At 45 seconds the plasma has for the most part reached its steady-state parameters. This constitutes the end of the startup period. Subsequently the ${ }^{3} \mathrm{He}$ level is allowed to fall to its steady-state value by stopping the excess ${ }^{3} \mathrm{He}$ fueling; that is, the fueling system then recycles only the ${ }^{3}$ He pumped out by the limiter/vacuim system. The plasma then gradually evolves to the full steadystate values of the various densities and fusion powers. 
This type of startup uses excess tritium and ${ }^{3} \mathrm{He}$ for the startup and must, therefore, compensate by using less tritium and ${ }^{3} \mathrm{He}$ for the burn phase. However, the reduction is negligible when spread out over the 2.5 hr burn phase. One concern about the enhanced tritium startup is the high first wall loading from $D-T$ fuston during the startup.

The 2.5 hr burn time 18 set by the volt-seconds avallable from the oH coll after startup. Considering the total downtime, the duty factor is $\approx 99 \%$. During the burn phase the proton and ${ }^{4} \mathrm{He}$ impuritles are controlled by the 1imiter/vacuum system which removes these reaction products at the rate they are produced. The beryllium density (not shown) from sputtering of the first wall and Iimiter surface 18 held to about $3 \%$ of the deuterlum density. An lodine density of about 0.0037 is also maintained to keep the plasma in thermal equilibrium while radiating away as much power as possible to the wall.

As with a $D-T$ reactor, the power supply requirements for the $D-D$ reference reactor are set during startup. These requirements are as follows: for the OH supply, a power requirement of $2160 \mathrm{MW}$, and for the EF supply, a reactive power requirement of $\approx 1000 \mathrm{MVA}$. These values are about twice as much as for a D-T reactor of about the same electrical power oitput, for example, the STARFIRE reactor if it were operated in a pulsed mode. In this respect a smaller D-D reactor would help, if it were possfble, since the $\mathrm{OH}$ and $\mathrm{E}_{2}$ ' colls could be made smaller. Steady-state operation would be a major advantage, virtually eliminating most of the power supply costs.

\subsubsection{D-D Burn Cycle Model}

This model and its assoclated computer code solves particle and energy balances as a function of tine for a D-D tokamak fusion reactor. All relevant terms in the balance equations are averaged over spatial profiles, these being specified a priort and fixed over time as discussed in Sec. 2.1. The coupled poloidal coil and MHD model described in Ref. 11 is also included. The code treats elght lòn species: protons $(P)$, deuterons (D), tritons ( $T$ ), 3He (3), "He ( $\alpha$ ), beryllium (2) from sputtering, oxygen (0) from various sources, and lodine (I), which 18 used to control the plasma therwal atability. The particle balance equations for the first five apecies are as follows: 


$$
\begin{aligned}
& \frac{d \bar{N}_{P}}{d t}=\overline{N_{D} N_{3}\langle\sigma v\rangle_{D 3}+\frac{1}{2} N_{D}^{2}\langle\sigma v\rangle_{D D_{1}}}-\frac{\bar{N}_{P}}{\tau_{P}}\left(1-\tilde{R}_{P}\right) \\
& \frac{d \bar{N}_{D}}{d t}=I_{D}-\overline{N_{D} N_{T}\langle\sigma v\rangle_{D T}}-\overline{N_{D} N_{3}\langle\sigma v\rangle_{D 3}}
\end{aligned}
$$

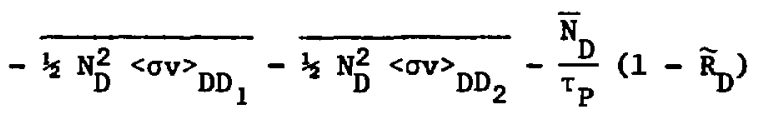

$$
\begin{aligned}
& \frac{d \bar{N}_{T}}{d t}=I_{T}+\overline{\frac{1}{2} N_{D}^{2}\langle\sigma v\rangle_{D D_{1}}}-\overline{N_{D} N_{T}\left\langle\sigma v{ }_{D T}\right.}-\frac{\bar{N}_{T}}{T_{P}}\left(1-\widetilde{R}_{T}\right) \\
& \frac{d \bar{N}_{3}}{d t}=I_{3} \overline{\frac{1}{2} N_{D}^{2}\left\langle\sigma v{ }_{D D}\right.}-\overline{N_{D} N_{3}<\sigma v D_{D 3}}-\frac{\bar{N}_{3}}{\tau_{P}}\left(1-\widetilde{R}_{3}\right) \\
& \frac{d \bar{N}_{\alpha}}{d t}=\overline{N_{D} N_{T}\langle\sigma V\rangle_{D T}}+\overline{N_{D} N_{3}\langle\sigma V\rangle_{D 3}}-\frac{\bar{N}_{\alpha}}{\tau_{P}}\left(1-\widetilde{R}_{\alpha}\right)
\end{aligned}
$$

In these equations $\overline{\mathrm{N}}_{j}$ is the average value of the density of species $f, I_{j}$ is an external source of species $j$ to the plasma, $\tau_{P}$ is the particle containment time, assumed equal for all spectes, and $\widetilde{\mathrm{R}}_{\mathfrak{j}}$ is the $j$ th reflection coefficient of the Iimiter/vacuum impurity control system. The reflection coefficients used are $\widetilde{R}_{P}=\widetilde{R}_{D}=\widetilde{R}_{T}=0.9$ and $\widetilde{R}_{3}=\widetilde{R}_{\alpha}=0.75$. These reflection coefficients do not include reinjection as do those discussed in Sec. 2.2.7. The term $\langle\sigma v\rangle_{j k}$ denotes the fusion reaction rate between the $j$ th species and the kth species, with two branches for the D-D reaction. A bar in Eqs. (1)-(5) Indicates averaging over the spatial profile. Superthermal fusions are not included in the particle balance equations. The Be density in the plasma is given by the following equation:

$$
\begin{aligned}
\frac{d \bar{N}_{Z}}{d t}=\frac{\bar{N}_{P}}{\tau_{P}} s_{P} & +\frac{\bar{N}_{D}}{\tau_{P}} s_{D}+\frac{\bar{N}_{T}}{\tau_{P}} s_{T}+\frac{\bar{N}_{3}}{\tau_{P}} s_{3}+\frac{\bar{N}_{\alpha}}{\tau_{P}} s_{\alpha}+\frac{\bar{N}_{Z}}{\tau_{P}}\left(s_{z}-\widetilde{R}_{Z}\right) \\
& +\frac{N_{D}}{\tau_{P}} \gamma s_{c x}
\end{aligned}
$$


In this equation $\bar{N}_{j} / \tau_{p}$ represents the flow of particles of species $j$ to the Iimiter, $s_{j}$ is the sputtering coefficient for species $f$ in units of Be atoms sputtered per incident ion of species $j$, and $\tilde{R}_{Z}$ is the reflection coefficient of Be from the limiter. The last term in $\mathrm{Eq}$. (6) represents charge exchange sputtering at the first wall by neutral deuterium, where $\gamma$ is the ratio of charge exchange neutrals hitting the first wall to deuterlum ions hitting the limiter, and $S_{c x}$ is the sputtering coefficient of the charge exchange neutrals. Although there could be some charge exchange sputtering due to tritium and protium, these are not included at the present time.

The oxygen concentration in the plasma is given by the model described in Ref. 11. The iodine concentration is given by:

$$
\frac{d N_{I}}{d t}=I_{I}-\frac{N_{I}}{\tau_{P}}\left(1-\widetilde{R}_{I}\right)
$$

where $I_{I}$ is an external source of iodine, and $\tilde{R}_{I}=0.25$ is the reflection coefficient from the limiter. Finally, the electron density is given by requiring charge neutrality:

$$
\bar{N}_{e}=\sum_{j} \overline{N_{j} Z_{j}},
$$

where $z_{j}$ is the charge state of species $j$. For hydrogen the charge state is always taken as 1 and for helium as 2 . For the other fons the charge state is computed from the coronal equilibrium model of Ref. 12.

The energy balance equations for lons and electrons are, respectively:

$$
\begin{aligned}
& \frac{d}{d t} \overline{\left(\frac{3}{2} N_{1} T_{1}\right)}=\overline{N_{D} N_{T}\langle\sigma v\rangle_{D T} u_{1, \alpha}^{I}} \\
& +\overline{\left.N_{D} N_{3}<\sigma v\right\rangle_{D 3}\left(U_{2, P}^{I}+U_{2, \alpha}^{I}\right)} \\
& +\overline{\frac{1}{2} \mathrm{~N}_{\mathrm{D}}^{2}\langle\sigma \mathrm{V}\rangle_{\mathrm{DD}_{1}}\left(\mathrm{U}_{3, \mathrm{P}}^{\mathrm{I}}+\mathrm{U}_{3, \mathrm{~T}}^{\mathrm{I}}\right)}
\end{aligned}
$$

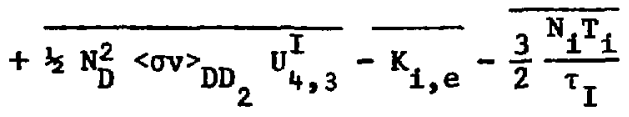




$$
\begin{aligned}
& \frac{d}{d t} \overline{\left(\frac{3}{2} N_{e} T_{e}\right)}=\overline{N_{D} N_{T}\left\langle\sigma v{ }_{D T} U_{1, \alpha}^{E}\right.} \\
& +\overline{N_{D} N_{3}\langle\sigma\rangle_{D 3}\left(U_{2, P}^{E}+U_{2, \alpha}^{E}\right)} \\
& +\overline{\frac{1}{2} N_{D}^{2}\langle\sigma v\rangle_{D v_{1}}\left(U_{3, P}^{E}+U_{3, T}^{E}\right)} \\
& +\overline{\frac{1}{2} \mathrm{~N}_{\mathrm{D}}^{2}\left\langle\sigma \mathrm{VV} \mathrm{DD}_{2} \mathrm{U}_{4,3}^{\mathrm{E}}\right.}+\overline{\mathrm{K}_{1, e}}+\overline{\mathrm{K}_{\Omega}} \\
& -\overline{\mathrm{K}_{\mathrm{rad}}}+\overline{\mathrm{K}_{\mathrm{rf}}}-\overline{\frac{3}{2} \frac{\mathrm{N}_{\mathrm{e} e} \mathrm{~T}}{\tau_{E}}} \text {. }
\end{aligned}
$$

In these equations $\vec{N}_{1}=\sum \bar{N}_{j}$ is the total ion density, and $\bar{T}_{i}$ and $\bar{T}_{e}$ are the average ion and electron temperatures. The $U_{N, j}^{I}$ and $U_{N, j}^{E}$ terms are the energy given to the ions and electrons, respectively, from particle $j$ created in reaction $N$. These terms include the superthermal fusion from the reaction products as discussed in Sec. 2.1 (also see Fig. 2-2). The $K_{i, e}$ term is the ion-electron thermalization term as defined in Ref. 4. $\mathrm{K}_{\Omega}$ is the ohmic heating term, $\mathrm{K}_{\Omega}=\eta \mathrm{J}^{2}$, where $\eta$ is the Spitzer resistivity of the plasma (with neoclassical corrections), and $J$ is the current density. The term, $\mathrm{K}_{\mathrm{rad}}$, is the radiation loss, including bremmstrahliung, line, and recombination radiation from a coronal equilibrium model (12) and cyclotron radiation described in Ref. 4. The quantities, $\tau_{I}$ and $\tau_{E}$, are the Ion and electron energy confinement times, respectively. The electron energy confinement is taken to have Alcator scaling, $\tau_{E}=5 \times 10^{-21} \overline{\mathrm{N}}_{\mathrm{e}} \mathrm{ka}^{2}$, and ion energy confinement is taken to be neoclassical (see Ref. 4). The common particle containment time is taken to be $\tau_{P}=\frac{1}{4} \tau_{E}$.

\subsection{Impurity Control Concepts}

The requirements of an impurity control system have been assessed for the $D-D$ reference reactor. As with a D-T reactor, a Iimiter/vacuum system is believed to be the simplest and most desirable system and has been chosen for the D-D design. A comparison between the impurity control system parameters for the reference $D-D$ reactor and the recent STARFIRE ${ }^{(3)}$ reactor design is shown in Table 2-12. 
Table 2-12. Impuricy Control System Comparison

\begin{tabular}{|c|c|c|c|}
\hline Item & Unit & $\begin{array}{l}\text { D-D Reactor } \\
\text { Value }\end{array}$ & $\begin{array}{l}\text { D-T (STARFIRE) } \\
\text { Reactor Value }\end{array}$ \\
\hline $\begin{array}{l}\text { Impurity control } \\
\text { system }\end{array}$ & - & $\begin{array}{l}\text { Limiter/vacuum } \\
\text { system }\end{array}$ & $\begin{array}{l}\text { Limiter/vacuum } \\
\text { system }\end{array}$ \\
\hline Thermal power & MW & 2470 & 3590 \\
\hline $\begin{array}{l}{ }^{4} \text { He production } \\
\text { rate }\end{array}$ & $s^{-1}$ & $5.5 \times 10^{20}$ & $1.3 \times 10^{21}$ \\
\hline$P$ production rate & $s^{-1}$ & $5.5 \times 10^{20}$ & -- \\
\hline Limiter radius & $m$ & 11.2 & 9.0 \\
\hline Limiter height & $\mathrm{m}$ & 1.0 & 1.0 \\
\hline $\begin{array}{l}\text { Displacement of } \\
\text { leading edge }\end{array}$ & $\mathrm{cm}$ & 7.0 & 7.0 \\
\hline $\begin{array}{l}\text { Transport power to } \\
\text { limitei }\end{array}$ & $\mathbf{M W}$ & 166 & 90 \\
\hline $\begin{array}{l}\text { Heat load on leading } \\
\text { edge }\end{array}$ & $\mathrm{MW} / \mathrm{m}$ & 6.0 & 4.0 \\
\hline Edge temperature & keV & 1.2 & 1.2 \\
\hline $\begin{array}{l}\text { Particle fall-off rate } \\
\text { in scrape-off region }\end{array}$ & $\mathrm{cm}$ & 10.0 & 10.0 \\
\hline $\begin{array}{l}\text { Energy fall-off rate in } \\
\text { scrape-off region }\end{array}$ & $\mathrm{cm}$ & 5.0 & 5.0 \\
\hline $\begin{array}{l}\text { Fraction of particles } \\
\text { entering slot region }\end{array}$ & - & 0.28 & 0.28 \\
\hline $\begin{array}{l}\text { Hydrogen reflection } \\
\text { coefficient }\end{array}$ & - & 0.90 & 0.90 \\
\hline $\begin{array}{l}\text { Helium reflection } \\
\text { coefficient }\end{array}$ & - & 0.75 & 0.75 \\
\hline $\begin{array}{l}\text { Fractional concentra- } \\
\text { tion of protons }\end{array}$ & - & 0.065 & - \\
\hline $\begin{array}{l}\text { Fractional concentra- } \\
\quad \text { tion of }{ }^{4} \mathrm{He}\end{array}$ & - & 0.026 & 0.14 \\
\hline $\begin{array}{l}\text { Fractional concentra- } \\
\text { tion of } \mathrm{Be}\end{array}$ & - & 0.03 & 0.04 \\
\hline
\end{tabular}


In general, the impurity control requirements on a 1imiter/vacuum system for D-D are fairly similar to those for D-T. The ash products to be removed for the $D-D$ reaction are protons and alpha particles, compared to only alphas for D-T. The amount of $P$ and ${ }^{4} \mathrm{He}$ to be removed for $D-D$ is similar to the amount of ${ }^{4} \mathrm{He}$ for $\mathrm{D}-\mathrm{T}$ if the reactors are of about the same power class. Because of the fact that protons charge exchange, however, they are more difficult to remove than ${ }^{3} \mathrm{He}$. On the other hand, protons are somewhat less troublesome than helium because they have half the number of electrons. Sputtering of the boundary coating is a somewhat lesser problem for a $D-D$ reactor because the average mass of a $D-D$ plasma is lower than the average mass of a D-T mixture, i.e., 2.0 AMU compared to 2.5 AMU. This results in a $20 \%$ reduction in sputtering, all other things being equal.

The question of a limiter/vacuum system is described in detail in Ref. 13. The same basic limiter dimensions for STARFIRE are used for the D-D design except that the limiter major radius is different. The computed edge temperature and scrape-off zne parameters are also virtually identical to STARFIRE. Transport power to the limiter is, however, almost twice as much for the reference D-D reactor even when as much plasma heating power as possible is radiated to the first wall. This is basically due to the fact that proportionally more of the power is in the form of charged particles for D-D than for D-T. is a result of the higher transport power, the maximum heat load for the reference design is higher than for STARFIRE, but is probably stiil tolerable.

In both types of reactors the helium pumping efficiency is higher than the hydrogen pumping efficiency. This helps a D-T machine in minimizing the ${ }^{4}$ He concentration while permitting a high tritium burnup. For D-D this phenomera is a mixed blessing: it reduces the deuterium gas load on the vacuum pumps, but it results in a higher proton concentration in the plasma. The impurity concentrations in the D-D machine are acceptably low, however. Further details of the vacuum system are given in Sec. 5 . 


\subsection{Steady-State Current Drive Considerations}

It appears possible that the toroldal plasma current in a tokamak might be maintained in a steady-state mode with the injection of wave momentum. $(14,15)$ The STARFIRE reactor uses lower hybrid waves ${ }^{(16)}$ for steady-state operation with D-T fuel, but the typically very large toroidal current in a D-D reactor makes the rf power prohibitive for this type of current dxive. Consequently, alternative waves have been examined: both coinpressional Alfven waves (17) with frequencies less than the ion cyclotron frequency ( $\omega<\Omega_{i}$ ) and fast magnetosonic waves ${ }^{(18)}$ with $\omega \gg \Omega_{i}$ appear to be more efficient drivers. The reason is that these low frequency waves can be broadcast with parallel phase speeds less than the electron thermal speed, in contrast to lower hybrid waves. (14) A variety of high beta MHD equilibria of different aspect ratios have been studied. Figure 2-11 displays the major radius and $r$ current drive power required for three $D-D$ reactors $(A=2.0,2.5$ and 3.0) with plasma beta scaling as $\beta_{t}=0.36 / \mathrm{A}$. In all cases the cotal power, $\mathrm{P}_{\mathrm{T}}=2.2 \mathrm{GW}$, temperature, $\vec{T}_{e}=30 \mathrm{keV}$, and toroidal field, $B_{\max }^{\mathrm{TFC}}=14 \mathrm{~T}$, are held constant.

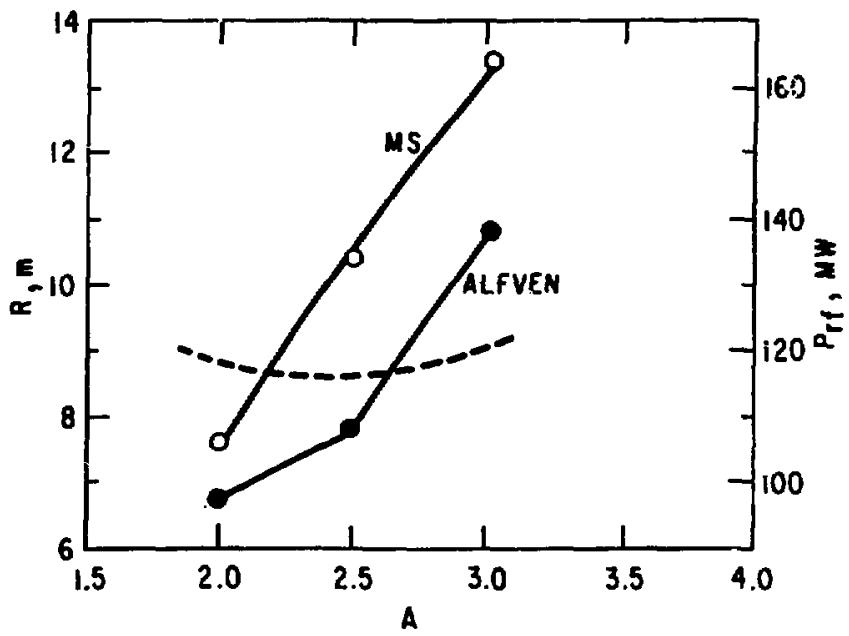

Figure 2-11. Major radius (dashed) and $P_{r f}$ for two low frequency current drivers (Magnetosonic wave (MS) and Alfven wave) versus aspect ratio. Here $B_{t}=0.36 / \mathrm{A}, \mathrm{P}_{\mathrm{T}}=2.2 \mathrm{GW}, \overline{\mathrm{T}}_{\mathrm{e}}=30 \mathrm{keV}$, and $\mathrm{B}_{\max }^{\mathrm{TFC}}=14 \mathrm{~T}$. 
The lower aspect ratios have larger currents, but the electron density, which also determines rf power requirements, is much lower at small A. The consequence is that less $\mathrm{rf}$ power is needed at low $\mathrm{A}$. In searching for waves which minimize $P_{\text {rf }}$, one is constrained by the dispersion relations to select eigenmodes of the torus. The Alfven wave is attractive since it requires less absorbed power and because the parallel wavelengths are manageable (on the order of one meter). The magnetosonic wave requires $\lambda \approx 10 \mathrm{~cm}$, which may complicate antenna design. However, the magnetosonic wave is a higher frequency (100-140 MHz) wave and may permit the use of waveguide launchers. One final caution should be noted; i.e., Fig. 2-11 displays only one parameter - the rf power absorbed by electrons to create current density. Additional information regarding wave generation, transmission, and coupling to the plasma is needed before the candidate drivers can be properly compared.

\section{References}

1. D. J. Rose and M. Clark, Jr., Plasmas and Controlled Fusjon (MIT Press, Cambridge, Massachusetts, 1961).

2. B. A. Trubnikov, in Plasma Physics and the Problems of Controlled Thermonuclear Reactions (Pergamon Press, London, 1959), Vol. III, p. 122.

3. C. C. Baker, et al., "STARFIRE - A Commercjal Tokamak Fusion Power Plant Study," Argonne National Laboratory, ANL/FPP -80-1 (September, 1980).

4. W. M. Stacey, Jr., et al., "Tokamak Experimental Power Reactor Conceptual Design," Argonne National Laboratory, ANL/CTR-76-3 (1976).

5. K. Evans, Jr., "High $B_{t}$ Equilibria in Tokamaks," Argonne National Laboratory, ANL/FPP/TM-98 (1977).

6. A. M. M. Todd, et al., Nuclear Fusion 19, 743 (1979).

7. D. R. Cohn, R. R. Parker and D. L. Jassby, Nuclear Fusion 16, 31 (1976); and D. L. Jassby, D. R. Cohn and R. R. Parker, Nuclear Fusion 16, 1045 (1976).

8. J. Brooks, K. Evans, Jr., H. Stevens, and L. Turner, "The Equilibrium Field Coil Design for the Argonne EPR Design," Proc. 7th Symp. Engineering Problems of Fusion Research, Knoxville, Tennessee (1977).

9. K. Evans, Jr., D. A. Ehst and P. Messerschmidt, "Equilibrium Fleld Coil Considerations for Tokamak Reactors," Proc. 3rd Topical Mtg. on the Technology of Controlled Nuclear Fusion, ANS Publication No. CONT-780508, Vol. 2, p. 1084 (1978). 
10. L. C. Bernard and R. W. Moore, "Systematic Optimization of Tokamaks to Al1 Ideal MHD Modes," General Atomic Company, GA-A15694 (1980).

11. J. N. Brooks and R. L. Kustom, Nuclear Technol. 46, 61 (November, 1979).

12. D. E. Post, et al., "Steady-State Radiative Cooling Rates for LowDensity High-Temperature Plasmas," Princeton Plasma Physics Laboratory, PPPL-1352 (1977).

13. M. A. Abdou, et al., "A Limiter/Vacuum System for Plasma Impurity Control and Exhaust in Tokamaks," 4th ANS Topical Mtg. on the Teahnology of Controlzed Nuclear Fusion, King of Prussia, Pennsylvania (October 14-17, 1980).

14. N. J. Fisch, Phys. Review Letters 41, 873 (1978).

15. D. A. Ehst, Nucleap Fusion 19, 1369 (1979).

16. D. A. Ehst, et al., "Lower-Hybrid Heating and Current Drive System for the STARFIRE Tokamak," 4th ANS Topical Mtg. on the Technology of Controlzed Nuclear Fusion, King of Prussia, Pennsylvania (October 14-17, 1980).

17. N. J. Fisch and C. F. F. Karney, "Current Generation with Low-Frequency Waves," Princeton Plasma Physics Laboratory, PPPL-1624 (1979).

18. D. K. Bhadra, et a1., "RF Current Drive for a Steady-State Tokamak," General Atomic Company, GA-A15656 (1979). 
A preliminary study of the technological aspects of the first-wall/ blanket/shield system for a D-D tokamak reactor has been conducted. Since tritium breeding is not required, those materials and design constraints in the blanket that are associated with breeding and recovery of tritium are eliminated. The present study has focused on the neutronic, thermal hydraulic, materials and plasma-wall interaction considerations that are unique to the D-D tokamak reactor. The neutronic studies include an analysis of the radiation shielding requirements and the implications of energy multiplication in the blanket region. The thermal-hydraulic studies relate primarily to the impacts of coolant selection. The materials assessment includes an evaluation of both structural materials and potential moderator materials that enhance the energy multiplication in the blanket. The surface effects considered for the first-wall include physical sputtering, reflectivity of cyclotron radiation and erosion or ablation of the first wall caused by plasma disruptions. Key areas where further development and analysis are required have been identified.

\subsection{Radiation Shielding and Blanket Energy Multiplication}

The fusion power density of a D-D fuel system with a $30 \mathrm{keV}$ ignition temperature is only about $1-3 \%$ of the power density of a typical D-T tokamak for the same values of $\beta$ and $B_{\text {TFC }}$. Because of such an inherently lower power performarce, the neutron power multiplication is a very important design consideration in alternate-fuel systems. On the other hand, tritium breeding, which is one of the primary blanket functions in D-T systems, can be eliminated in alternate fuel system designs. This fact provides a degree of flexibility in the latter system designs in which the blanket can be optimized largely on the basis of energy multiplication. In D-T-Li fuel cycles a substantial fraction of the fusion power is consumed for tritium production through the endothermic $7_{L i}\left(n, n^{\prime} \alpha\right) t$ reaction. The energy consumption is particularly large in D-T-liquid lithium systems due to the hard neutron spectrum inherent in slich systems. In the case of solid tritiumbreeder systems, where ternary compounds such as $\mathrm{LiAlO}_{2}$ and $\mathrm{Li}_{2} \mathrm{SiO}$ are used, a neutron multiplier is required to achieve adequate tritium production. The neutron multiplication relies on the $(n, 2 n)$ reaction with the multiplier 
materials. In many cases such a neutron multiplication process by the $(n, 2 n)$ reaction contributes to an energy loss because the associated reaction $Q-v a l u e$ is generally higher than the $Q-v a l u e$ for the $(n, \gamma)$ reaction, which is the major energy multiplication mechanism for fusion neutrons. An exception where the $(n, 2 n)$ reaction is favored from the energy balance standpoint is for beryllium or its compounds since the $\operatorname{Be}(n, 2 n)$ reaction has an extremely low Q-value of $\approx 1.67 \mathrm{MeV}$.

The basic approach for neutronic power optimization in alternatefuel systems is, therefore, to focus on blanket materials that have a high $(n, \gamma)$ reaction potential as well as a high energy release associated with the reaction. In most cases the $(n, \gamma)$ reaction cross section is characterized by its " $1 / v$ " energy dependence;"(1) i.e., the potential for the reaction increases as the neutron energy decreases. Consequently, a high rate of energy moderation is an important characteristic of systems with favorable energy multiplication. The effective neutron moderation is essential not only for a higher $(n, \gamma)$ reaction, but also for minimizing various endothermic reactions that occur at $\mathrm{keV}$ neutron energies.

In addition to energy multiplication, the blanket/shield system must also be designed to provide adequate radiation shielding. The functions of the shielding system are: (1) to protect reactor components from excessive radiation damage and nuclear heating; (2) to protect reactor personnel as well as the general public from radiation exposure at all times during reactor operation and after reactor shutdown; and (3) to reduce induced activation in reactor components.

In the present study the shielding analysis is focused on the inboard blanket/shield design since it has a large impact on the overall reactor performance, which affects the rest of the system design. The primary concern of the inboard blanket/shield design is related to possible radiation-induced damage of the components of the superconducting toroidal field (TF) coils. These components include: (1) superconductors $\left(\mathrm{Nb}_{3} \mathrm{Sn}\right.$ and $\left.\mathrm{NbTi}\right)$; (2) the normal conductor or stabilizer (Cu); (3) electrical and thermal insulator (epoxy-base G10); and (4) structural material (stainless steel: SS). Among several radiation-induced damage effects, the property degradation of the organic insulator is considered to be the most limiting design constraint by the fact that the damage is irreversible. Other radiation damage effects 
such as changes in the critical properties of the superconductor and changes in the resistivity of the stabilizer are partially recoverable by magnet annealing $(2,3)$ at room temperature or slightly higher temperatures.

There exists, however, some speculation $(2,4,5)$ about the effect and the practicability of magnet anneaiing at high temperatures for recovering the critical properties of $\mathrm{Nb}_{3} \mathrm{Sn}$ and NbTi. Therefore, the radiation damage to the superconductors should also be regarded as permanent and cumulative with neutron fluence. A recent study ${ }^{(6)}$ has shown that organic insulators such as G10CR and Kapton $\mathrm{H}$ can withstand an absorbed gamma dose of up to $\approx 10^{8} \mathrm{~Gy}$ at a cryogenic temperature. The study has also found that the fast neutron $(>0.1 \mathrm{MeV})$ fluence up to $8.7 \times 10^{22} \mathrm{~m}^{-2}$ has very little effect upon the electrical and mechanical property changes in the insulators. Considering the fact that most of the dose in the epoxy-base insulator in the TF-coils is attributable to the energy deposition caused by the neutron interaction, it appears adequate to use a total dose of $10^{8} \mathrm{~Gy}$ as the irsulator damage criterion.

The analysis in this section is oriented toward identifying: (1) the impact of material selection on the inboard radiation shielding, and (2) the blanket energy multiplication mechanism, both based on a catalyzed D-D system. The neutron wall loads and power breakdown are assumed to be:

\begin{tabular}{rcc}
\hline Source Neutron & Wall Load $\left(\mathrm{MW} / \mathrm{m}^{2}\right)$ & Neutron Power (MW) \\
\hline $14.06 \mathrm{MeV}$ & 0.4830 & 710 \\
$2.45 \mathrm{MeV}$ & 0.0967 & 142. \\
\hline
\end{tabular}

The neutronic model used in the analysis is an infinite cylinder with a wall radius of $4.14 \mathrm{~m}$, which is equivalent to a wall area of $26 \mathrm{~m}^{2} / \mathrm{unit}$ length in the toroidal direction (or a total wall area of $1470 \mathrm{~m}^{2}$ for a torus with a $9 \mathrm{~m}$ major radius). The plasma scrape-off region is assumed to be $0.2 \mathrm{~m}$.

The particle transport calculations were carried out using ANISN ${ }^{(7)}$ with the $\mathrm{S}_{8}-\mathrm{P}_{3}$ approximation. The transport cross section library and the response function library, VITAMIN-C ${ }^{(8)}$ and MACKLIB-IV, ${ }^{(9)}$ both based on $E: D F-B / I V,(10)$ were utilized in the 46-neutron/21-gamma group structure. 


\subsubsection{Inboard Radiation Shielding}

The most critical design constraint on the inboard shield is the large sensitivity of the reactor performance and economics to the radial thickness, $\Delta_{\mathrm{BS}}^{i}$, from the first wall to the location of the maximum magnetic field. According to a sensitivity study carried out for a reference system where the reactor power, $P_{0}$, the major radius, $R_{0}$, the maximum toroidal field, $B_{\max }$, the scrape-off, $\Delta_{v}$, and the aspect ratio, $A$, are defined as $2.35 \mathrm{GW}, 9 \mathrm{~m}, 14 \mathrm{~T}$, $0.2, \mathrm{~m}$ and 3 , respectively, a $1 \%$ decrease in a one meter $\Delta_{B S}^{i}$ results in:

$$
\begin{array}{ll}
{ }_{0}^{\Delta P_{0}} \simeq+0.9 \% & \text { for fixed } R_{o}, B_{\max } \\
\Delta R_{0} \simeq-0.3 \% & \text { for fixed } P_{0}, B_{\max } \\
\Delta B_{\max } \simeq-0.2 \% & \text { for fixed } P_{o}, R_{0} .
\end{array}
$$

These results clearly indicate the substantial dependence of the overall reactor performance upon the shielding design and that the selection of $\Delta_{B S}^{i}$ and shielding materials to be used must evolve from a careful optimization.

One of the important design decisions is the coolant selection. Since the D-D system does not need to breed tritium, use of lithium coolant is not considered. Two candidate coolants, pressurized light water and helium gas, are considered in the present analysis, along with four candidate shielding materials, viz., stainless steel (PCA), tungsten, $\mathrm{TiH}_{2}$, and water. A detailed analysis of the PCA (similar to Type 316 SS neutronically) structure design has been already shown in Ref. (11) in comparison with other candidate alloys such as V15Cr5Ti and Ti4381. In the present analysis an attempt is made to compare the shielding performance of different non-structural materials. In all the cases studied the primary structural material is assumed to be PCA. Tungsten ls considered because of its excellent shielding performance. Although there are some concerns about the use of tungsten, such as the resource limitation and the high material cost, the possible reduction in $\Delta_{B S}^{i}$ with tungsten may compensate for the associated penalty. In addition it should be emphasized that the inboard shield volume is small (typically $\approx 10 \%$ of the total) and that tungsten is an intrinsically low-activation material, and hence, a large part of the tungsten shield is expected to be recyclable on a reasonably short time scale after its 
decommissioning. (12) $\mathrm{TiH}_{2}$ and water are included in the shield material consideration because of their low-activation characteristics and their relatively low costs. Further, it is of interest to examine how these hydrogeneous shielding materials, which are efficient moderators, would affect the radiation damage characteristics of the superconducting magnets.

Figures 3-1 and 3-2 show comparisons of the nuclear performance of the four shielding materials for water-cooled and hellum-cooled systems, respectively. Plotted in the figures are the total absorbed nuclear doses in an epoxy-base magnet insulator. The computation is based on a simple model as follows:

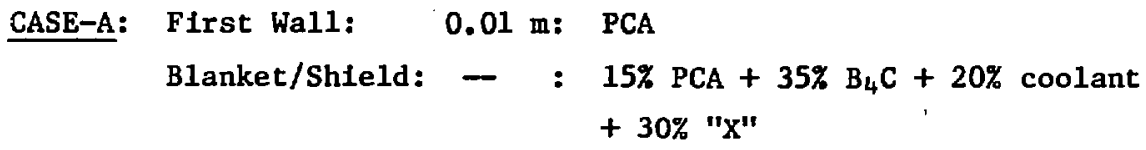

where the " $X$ " stands for either one of the four candidate materials.

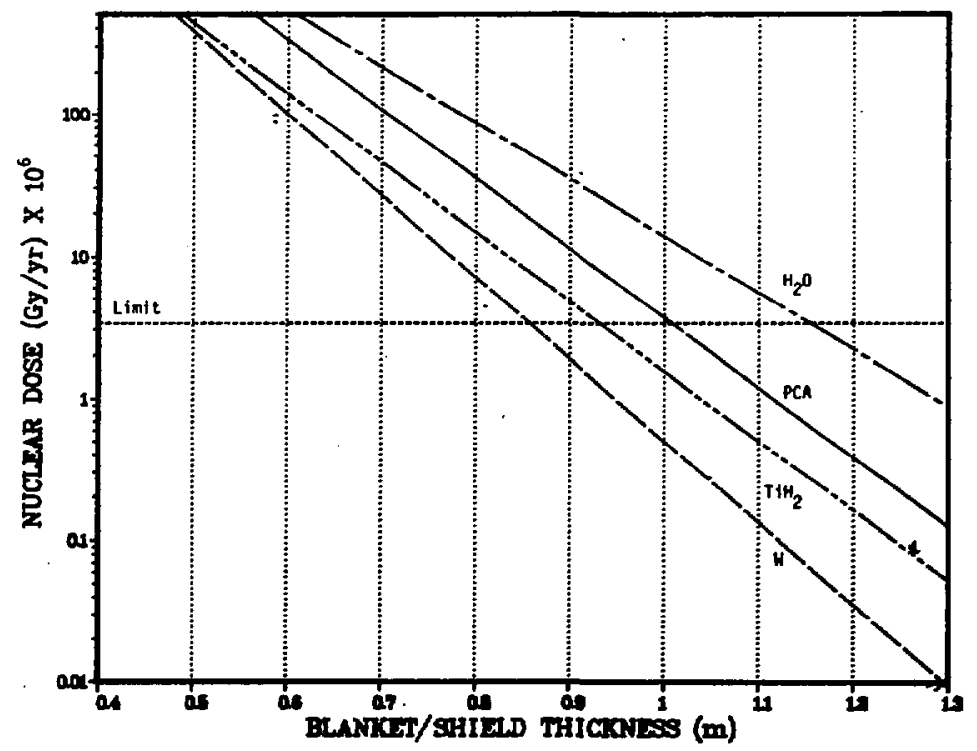

Figure 3-1. Effect of materlal selection upon inboard radiation shielding for helium-cooled Cat-D designs. 


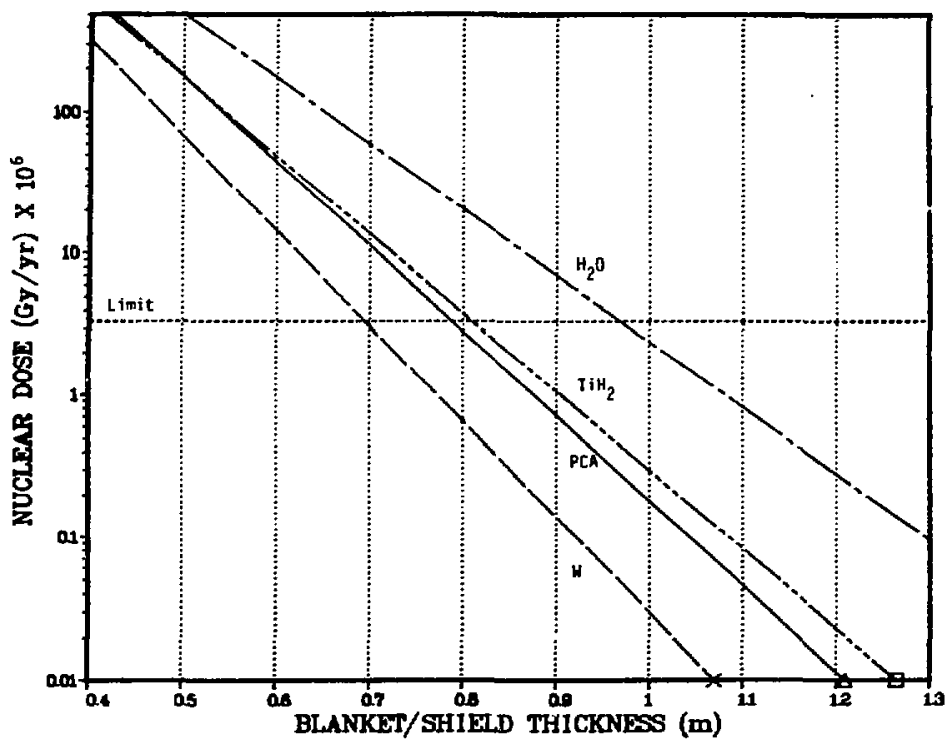

Figure 3-2. Effect of materlai selestion upon inboard radiation shielding for water-cosled Cat-D desigüis.

It is found that for a dose range of interest, the shielding performance in the helium-cooled systems is graded as $\mathrm{W}>\mathrm{TiH}_{2}>\mathrm{PCA}>\mathrm{H}_{2} \mathrm{O}$ compared to the order, $\mathrm{W}>\mathrm{PCA}>\mathrm{TiH}_{2}>\mathrm{H}_{2} \mathrm{O}$ in the water-cooled systems. The better shielding performance with $\mathrm{TiH}_{2}$ compared to PCA in the helium coolant designs reflects the fact that the relatively hard neutron spectrum is significantly softened by hydrogen in $\mathrm{TiH}_{2}$ which improves the absorption in $\mathrm{B}_{4} \mathrm{C}$. The variance in the shielding performance yields an increase in the required shield thickness relative to the tungsten design as follows:

\section{Helium-Coolant Case}

$$
0.07 \mathrm{~m}\left(\mathrm{TiH}_{2}\right)<0.14 \mathrm{~m}(\mathrm{PCA})<0.29 \mathrm{~m}\left(\mathrm{H}_{2} \mathrm{O}\right)
$$

\section{Water-Coolant Case}

$$
0.09 \mathrm{~m}(\mathrm{PCA})<0.12 \mathrm{~m}\left(\mathrm{TIH}_{2}\right)<0.27 \mathrm{~m}\left(\mathrm{H}_{2} \mathrm{O}\right)
$$

The calculation here is based on the dose limit of $10^{8}$ Gy over a 40-yr plant Ilfetime with $75 \%$ availability (annual dose 1 imit of $\approx 3.3 \times 10^{6}, \mathrm{~Gy} / \mathrm{yr}$ ). It is noted that the use of water in a large quantity substantially degrades the shielding performance. As expected, the use of tungsten, in particular, 
along with the water coolant, significantly reduces the shield thickness required for magnet protection.

Figure 3-3 shows the impact of coolant selection on the shielding design as a function of plant lifetime. In the cases of both the PCA and $W$ shields, the increase in $\Delta_{B S}^{i}$ caused by the use of helium is $\approx 0.2 \mathrm{~m}$ for a broad range of the plant lifetime. Also shown in the figure for comparison is the case of the D-T-fueled STARFIRE ${ }^{(13)}$ design in which the $\mathrm{LAAlO}_{2}$ solid breeder is placed in the inboard blanket. The STARFIRE design is similar to the $\mathrm{H}_{2} \mathrm{O} / \mathrm{W}$ case in terms of the shielding material composition. It is seen that the elimination of tritium breeding requirement in the Cat-D design can bring about $\approx 0.4 \mathrm{~m}$ reduction in the inboard shield thickness. Note that the first walls of both STARFIRE and the present D-D systern are designed for approximately the same non-neutron surface heat load of $\approx 1 \mathrm{MW} / \mathrm{m}^{2}$.

This study led to the following inboard blanket/shield design for more detailed analysis.

$$
\begin{aligned}
& \text { CASE-B: First Wall: } 0.01 \mathrm{~m}: 50 \% \mathrm{PCA}+50 \% \mathrm{H}_{2} \mathrm{O} \\
& \text { Blanket: } \quad 0.30 \mathrm{~m}: 85 \% \mathrm{PCA}+15 \% \mathrm{H}_{2} \mathrm{O} \\
& \text { Shield: } \quad 0.41 \mathrm{~m}: 15 \% \mathrm{Fel} 422+15 \% \mathrm{H}_{2} \mathrm{O}+35 \% \mathrm{~B}_{4} \mathrm{C}+35 \% \mathrm{~W}
\end{aligned}
$$

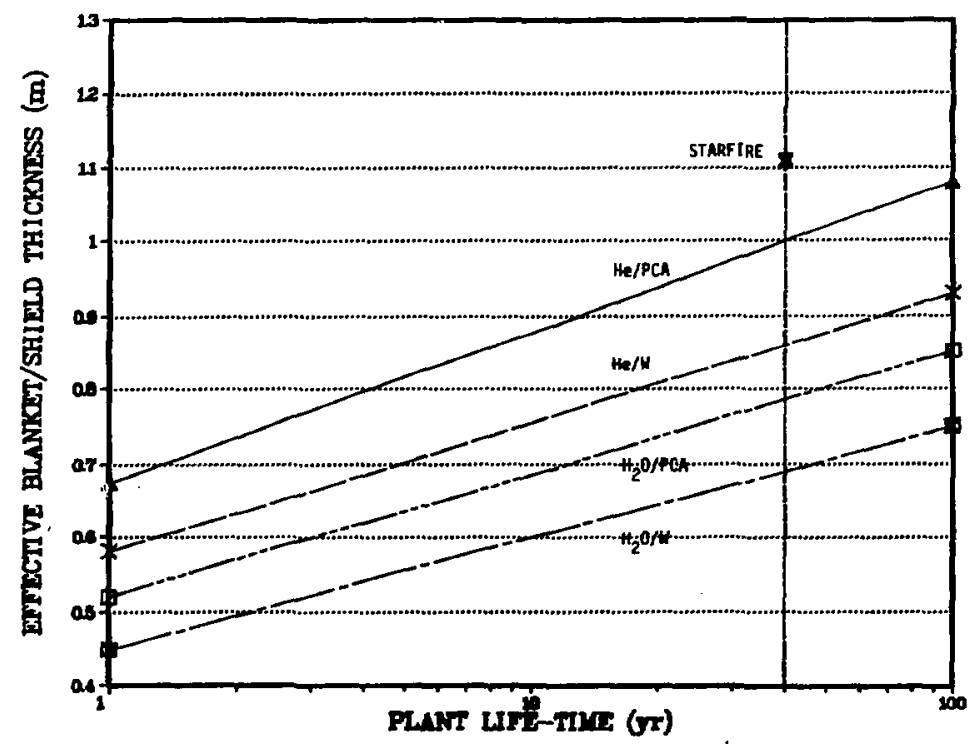

Figure 3-3. Impact of coolant materlal selection upon Cat-D plant lifetime. 
The total $\Delta_{B S}^{i}$ thickness of $0.72 \mathrm{~m}$ does not include a space allowance which is required for isolating the high temperature blanket from the low temperature shield, isolating the magnet thermal dewar from the liquid helium vessel, or other allowances. Based on the STARFIRE design, a total radial distance of $0.1 \mathrm{~m}$ is set aside for the space allowances, leading to the actual inboard $\Delta_{\text {BS }}^{i}$ thickness of $0.82 \mathrm{~m}$. The Fel422 ${ }^{(14)}$ in the shield is a non-magnetic iron-base alloy that contains $14 \mathrm{wt} \% \mathrm{Mn}, 2$ wt \% $\mathrm{Ni}$, and 2 wt \% $\mathrm{Cr}$ as the major constituents. The application of Fel422 to the shield is very attractive comparej to more conventional iron-base alloys such as Type 316 SS and Type 304 SS. The potential advantages are: (1) the reduced use of resource limited chromium and (2) reduced long-term activation caused by nickel. The possible increase in activation due to the increased $\mathrm{Mn}$ content results primarily from a larger production of $56 \mathrm{Mn}$. Since $56_{\mathrm{Mn}}$ has a decay half-life of $2.6 \mathrm{hr},(15)$ it will become trivial in several hours after reactor shutdown.

Table 3-1 summarizes the maximum damage response rates in the inner TF-magnets based on the effective shield thickness of $0.72 \mathrm{~m}$. As mentioned earlier, the total dose in the insulator is $10^{B}$ Gy over a 40 yr plant lifetime with $75 \%$ availability. About $90 \%$ of the dose is contributed by the neutron interaction. The anticipated maximum nuclear heating rate of $\approx 10^{-4} \mathrm{MW} / \mathrm{m}^{3}$ is substantially lower than the heat removal capacity in the system provided for Joule-loss heat removal. (13) The resistivity increase of $2.4 \times 10^{-10} \Omega-m$ in the $\mathrm{Cu}$ stabilizer is lower than the magnetoresistivity increase in the high field region, which is estimated to be $\approx 6 \times 10^{-8} \Omega-\mathrm{m}(16,17)$ at $14 \mathrm{~T}$. The estimate is based on a commercial grade copper having a residual resistivity ratio (RRR) of $\approx 100$. The non-radiation-induced resistivity increase will be further enhanced during operation due to the cyclic strain effects ${ }^{(17)}$ at the cryogenic temperature if the system is operated in a pulsed mode. In any event, the resistivity increase of $2.4 \times 10^{-10} \Omega-m$ does not seem to require magnet annealing over the whole plant lifetime. The neutron fluence shown in Table 3-1 includes the total neutron contribution. The fast neutron ( $>1 \mathrm{MeV}$ ) fluence is $\approx 1.4 \times 10^{22} \mathrm{~m}^{-2}$ at the end of plant life. According to Ref. 20, no appreciable property deterioration of $\mathrm{Nb}_{3} \mathrm{Sn}$ is observed at a magnetic field of $4 \mathrm{~T}$ under the neutron fluence in question. Although Refs. 20 and 21 show a very rapid decrease in the $\mathrm{Nb}_{3} \mathrm{Sn}$ critical current density with magnetic field strength applied, the fast neutron fluences used for the measurements 
Table 3-1. Maximum Radiation Response Rates In Inner TF Magnets (a)

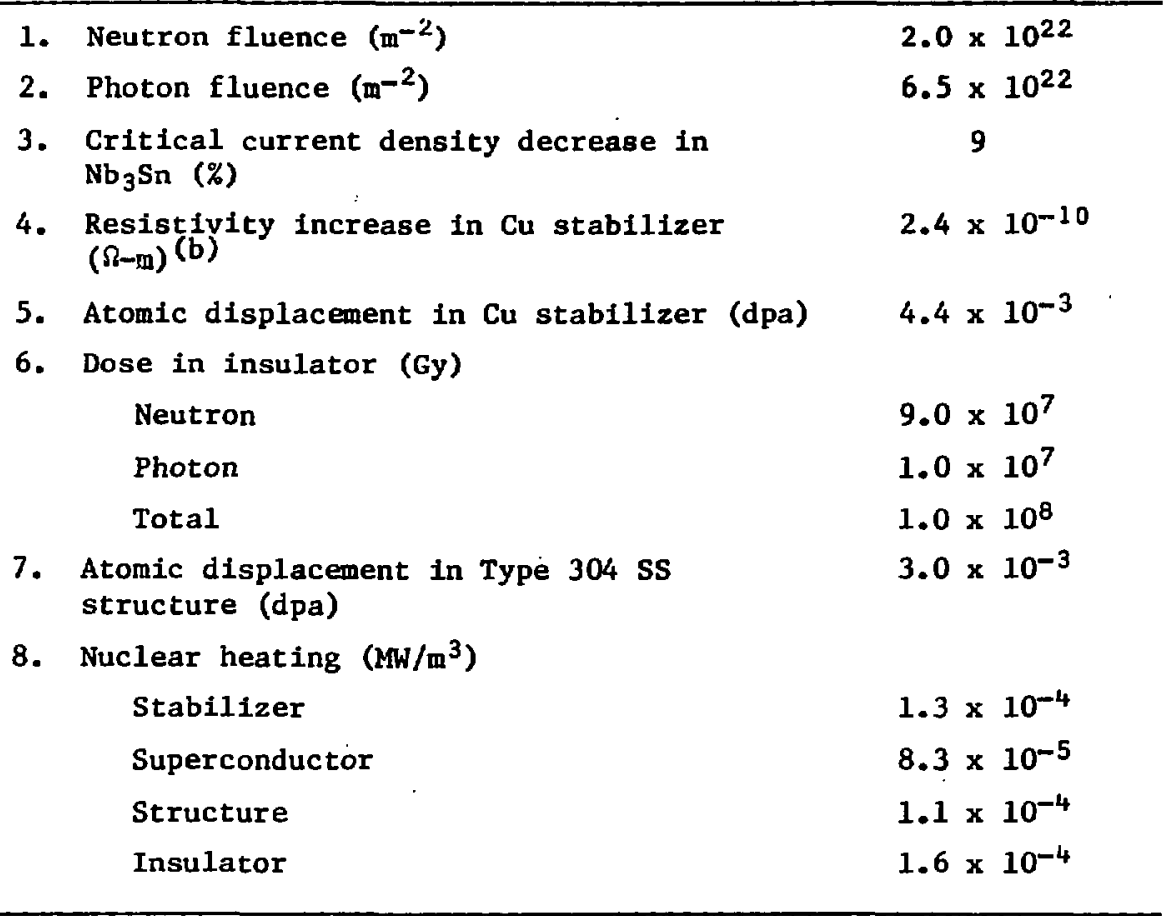

(a) Based on:

$\begin{array}{lll}\text { Neutron Wall Load }\left(\mathrm{MW} / \mathrm{m}^{2}\right): & 14.06 \mathrm{MeV} \text { source: } & 0.483 \\ & 2.45 \mathrm{MeV} \text { source: } & 0.0967 \\ & \text { Total: } & 0.5797 \\ \text { Plant Llfetime (yr): } & 40 & \\ \text { Plant Avallability }(\bar{m}): & 75 & \end{array}$

(b) See References $(18,19)$. 
are significantly higher whan the present case. In addition, there is some evidence $(19,21)$ that the critical current density in $\mathrm{Nb}_{3} \mathrm{Sn}$ increases as a function of irradiation fluence in a certain range. If the experimental data of Rế. 23, based on neutron fluences of $10^{23}-10^{2.4} \mathrm{~m}^{-2}$, are extrapolated to the present case, the critical current density change is expected to be a decrease of $\approx 9 \%^{(22)}$ of the unirradiated value at $14 \mathrm{~T}$. It is conceivable, therefore, that near the end of plant life, the extent of the radiation damage in the $\mathrm{Nb}_{3} \mathrm{Sn}$ superconductors would reach a non-trivial level. It should be noted, however, that the decrease in the critical current density can be accommodated by adding more $\mathrm{Nb}_{3} \mathrm{Sn}$ to offset the decrease and produce the same required ampere-turns. (19) Therefore, the radiation damage in $\mathrm{Nb}_{3} \mathrm{Sn}$ is amenable to an economic tradeoff between the increased magnet cost and the increased inboard shield thickness required to reduce the damage level. By virtue of the graded magnet design, the NbTi superconductors do not appear to pose any serious radiation damage problems.

\subsubsection{Blanket Energy Multiplication}

Distinction between the inboard and outboard blanket/shield designs is necessary as the design objectives and constraints are quite different in the two regions. As already discussed, the volume of the inboard section is typically $\approx 10 \%$ of the total blanket/shield volume. The implication is that most of the important blanket functions, such as fusion energy conversion, heat removal, and tritium breeding (if any), must occur in the outboard section. This fact leads us to take a quite different design approach for the outboard blanket/shield than for the inboard blanket/shield, which was designed to minimize $\Delta_{\mathrm{BS}}^{i}$. In addition the fact that the space of the outboard section is not so restrictive as that of the inboard section provides another consideration with respect to the material. selection for the outboard blanket design. For example, use of a tungsten shield that may be justified for the inboard region may not be the best for the outboard region because of the high material cost involved. Less effective, but less expensive, shielding materials may be sufficient to perform the required radiation shielding for the outboard shield.

In this section the analysis is focused on the neutronic power optimization in the outboard blanket. Nuclear design and Its optimization for reactor components beyond the outboard blanket require additional study 
and analysis. Within the framework of the one-dimensional analysis, the same infinite cylinder model as that used in the previous section is assumed for the present analysis. We define a reference outboard blanket/shteld system of $1.0 \mathrm{~m}$ as follows:

$$
\begin{array}{lll}
\text { CASE C: First Wall: } & 0.01 \mathrm{~m}: 50 \% \mathrm{PCA}+50 \% \mathrm{H}_{2} \mathrm{O} \\
& \text { Blanket: } & 0.30 \mathrm{~m}: 85 \% \mathrm{PCA}+15 \% \mathrm{H}_{2} \mathrm{O} \\
& \text { Shield: } & 0.69 \mathrm{~m}: 50 \% \mathrm{Fel} 422+15 \% \mathrm{H}_{2} \mathrm{O}+35 \% \mathrm{~B}_{4} \mathrm{C}
\end{array}
$$

Table 3-2 shows the nuclear energy deposition in the reference system. More than $97 \%$ of the nuclear energy is deposited in the $\approx 0.3-\mathrm{m}$-thick first wall/blanket. The energy leakage into the shield region, which is considered to be non-recoverable because of its low-grade heat, is quite sma11. The energy multiplication factor of 1.47 (1.43 in the first wall/blanket only) by the $14.06 \mathrm{MeV}$ source is substantially higher than a typical energy amplification in D-T-fueled tokamaks. For example, the D-T STARFIRE ${ }^{(14)}$ yields a gross nuclear (neutron + gama) power of $3200 \mathrm{MWth}$ out of the 2810 MWth fusion neutron power Input to the first-wall/blanket, resulting in a blanket power amplification factor of 1.14. The high blanket energy gain in the $D-D$ system examined above results from the significant neutron energy moderation by the water-coolant and the $(n, \gamma)$ reaction in the PCA-structure. Despite the facts that the $(n, \gamma)$ reaction $Q$-value of PCA is modest $(\approx 7.9 \mathrm{MeV}$ ) and the $(n, 2 n)$ reaction ( $Q$-value of $\approx 9.9 \mathrm{MeV}$ ) probability is fairly high, the PCA structure can provide substantial energy multiplication because of the relatively high $(n, \gamma)$ reaction probability. For example, an energy loss from the $(n, 2 n)$ reaction takes place at a rate of $\approx 0.21$ per $14.06 \mathrm{MeV}$ source neutron in the PCA blanket. This figure is compared to the total $(n, \gamma)$ reaction rate in the blanket of $\approx 0.99$ per $14.06 \mathrm{MeV}$ neutron, Indicating that approximately $80 \%$ of the neutrons derived from the $14.06 \mathrm{MeV}$ gource eventually undergo the $(n, \gamma)$ reaction.

One of the most outstanding features of the D-D system is associated with its extremely high energy multiplication potential by the $2.45 \mathrm{MeV}$ source neutrons. Due to the fact that the source energy is below most of the threshold energies for endothermic neutron reactions, the $2.45 \mathrm{MeV}$ source neutrons and their descendent neutrons possess a higher probability for inducing the $(n, \gamma)$ reaction. In fact, the energy multiplication factor 
Table 3-2. System Energy Miltiplication in a D-D-Tokamak Reactor (a)

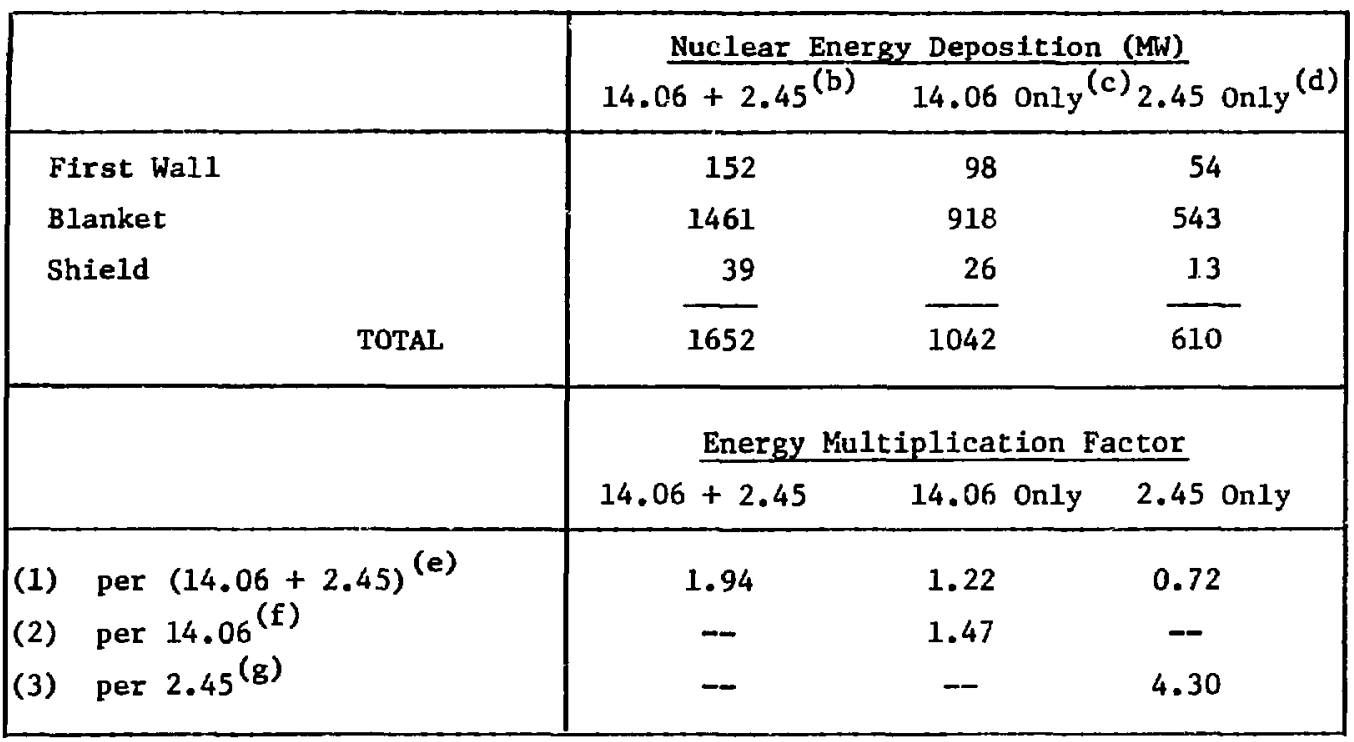

(a) First Wall: $0.01 \mathrm{~m}: 50 \% \mathrm{PCA}+50 \% \mathrm{H}_{2} \mathrm{O}$

Blanket: $\quad 0.30 \mathrm{~m}: \quad 85 \% \mathrm{PCA}+15 \% \mathrm{H}_{2} \mathrm{O}$

Shield: $\quad 0.69 \mathrm{~m}: 50 \% \mathrm{Fel} 422+15 \% \mathrm{H}_{2} \mathrm{O}+35 \% \mathrm{~B}_{4} \mathrm{C}$

(b) Both $14.06 \mathrm{MeV}$ and $2.45 \mathrm{MeV}$ source neutrons.

(c) $14.06 \mathrm{MeV}$ source neutron only.

(d) $2.45 \mathrm{MeV}$ source neutron only.

(e) Energy multiplication per $852 \mathrm{MW}(=710+142)$ fusion neutron power.

(f) Energy multiplication per $710 \mathrm{MW}$ fusion neutron power.

(g) Energy multiplication per $142 \mathrm{MW}$ fusion neutron power. 
of $\approx 4.3$ for the $2.45 \mathrm{MeV}$ source shown in Table 3-2 is very close to the maximum energy amplification that one can theoretically expect. It is remarkable that the initial fusion neutron power of 852 MW $(=710+142)$ is eventually amplified to $1652 \mathrm{MW}$, resulting in a totai system energy of $3150 \mathrm{MW}$ (system energy multiplication factor of $\approx 1.34$ ) based on the total fusion power of 2350 MW including a non-neutron fusion power of 1498 MW.

The long-term radioactivity is an important design consideration for future fusion commercialization as it may result in long-term storage requirements and depletion of some resource-limited materials. For example, construction of a very large number of reactors in which the PCA steel is used in a large quantity, would eventually pose a serious chromium resource availability problem ${ }^{(23)}$ because of the lack of recycling potential of PCA due to its associated high-level long-term activation. (12) Note that the PCA activation is not due to chromium on a long time-scale, but primarily is due to $\mathrm{Ni}$ and Mo. (12) It is, therefore, critical to select itrinsically lowactivation materials or reasonably abundant materials for a mature fusion power economy.

Table 3-2 compares the system energy multiplication for several blanket systems. Three refractory materials ( $\mathrm{CrN}, \mathrm{Si}_{3} \mathrm{~N}_{4}$ and $\mathrm{SiC}$ ) are considered because of their relatively low-induced activation (or natural abundance) aild high potentials for high energy release by the $(n, \gamma)$ reaction. For example, the reaction Q-values of $\mathrm{Cr}, \mathrm{N}$, and $\mathrm{Si}$ are $\approx 9.2 \mathrm{MeV}, \approx 10.8 \mathrm{MeV}$ and $\approx 8.8 \mathrm{MeV}$, respectively, which can be compared to $\approx 7.9 \mathrm{MeV}$ for the PCAsteel. Unfortunately, however, light elements, such as N, Si and C, typically have smali $(n, \gamma)$ reaction probabilities. In addition, there exist several endothermic reactions, which have relatively low threshold energies with the light elements. For Instance, the reaction $Z$-value for the $N(n, \alpha)$ reaction is only $\approx 160 \mathrm{keV}$ indicating that even the $2.45 \mathrm{MeV}$ source neutron dissipates its energy through the $(n, a)$ reaction.

According to the results of Table 3-3, the energy multiplication in the $\mathrm{Si}_{3} \mathrm{~N}_{4}$ system is appreciably lower than inlthe other systems. The power generation in the PCA, CrN and SIC systems is comparable, and the maximum difference is only $\approx 150 \mathrm{MW}$. As shown in Table 3-4, the primary energy deposition in the blanket relies on PCA and/or chromium In CrN. The contribution from the light elements themselves is small. They serve primarily as moderators for 
Table 3-3. A Comparison of System Energy Multiplication (a)

\begin{tabular}{|c|c|c|c|c|c|}
\hline \multirow[b]{2}{*}{ System $^{(b)}$} & \multicolumn{5}{|c|}{ Neutron Energy Deposition (MW) } \\
\hline & 14.06 Only & 2.45 Only & \multicolumn{2}{|c|}{$14.06+2.45$} & System Power \\
\hline PCA & 1042 & 610 & \multicolumn{2}{|c|}{1652} & 3150 \\
\hline $\mathrm{CrN}$ & 981 & 515 & \multicolumn{2}{|c|}{1497} & 2995 \\
\hline $\mathrm{Si}_{3} \mathrm{~N}_{4}$ & 775 & 367 & \multicolumn{2}{|c|}{1142} & 2640 \\
\hline Sic & 927 & 590 & \multicolumn{2}{|c|}{1518} & 3016 \\
\hline \multirow[b]{2}{*}{ System } & & \multicolumn{4}{|c|}{ Energy Multiplication Factor } \\
\hline & & \multicolumn{2}{|c|}{ Per $(14.06+2.45)$} & Per 14.06 & Per 2.45 \\
\hline PCA & & 1.5 & & 1.47 & 4.30 \\
\hline $\mathrm{CrN}$ & & 1.7 & & 1.38 & 3.63 \\
\hline $\mathrm{Si}_{3} \mathrm{~N}_{4}$ & & 1.3 & & 1.09 & 2.59 \\
\hline SiC & & 1.7 & & 1.31 & 4.12 \\
\hline
\end{tabular}

(a) First Wall: $0.01 \mathrm{~m}: 50 \% \mathrm{PCA}+50 \% \mathrm{H}_{2} \mathrm{O}$

Blanket: $\quad 0.30 \mathrm{~m}: \quad 15 \% \mathrm{PCA}+15 \% \mathrm{H}_{2} \mathrm{O}+70 \%$ "X"

Shield: $\quad 0.69 \mathrm{~m}: \quad 50 \%$ Fel $1422+15 \% \mathrm{H}_{2} \mathrm{O}+35 \% \mathrm{~B}_{4} \mathrm{C}$

(b) The materials shown are used as " $\mathrm{X}$ " in the blanket composition defined above.

neutrons that are absorbed in PCA or $\mathrm{Cr}$ of $\mathrm{CrN}$. In this regard emphasis should be placed on the importance of the water-coolant on the blanket energy multiplication. In fact, when the water-coolant in the PCA system in Table 3-3 is replaced by a helium coolant of the same volume, the energy multiplication decreases to $\approx 1.4$, and the resultant neutron power is only $\approx 1200 \mathrm{MW}$. This occurs because of the hard neutron spectrum caused by lack of water coolant/moderator, leading inevitably to higher endothermic reaction probabilities for the high energy neutrons.

As discussed earlier, beryllium and its compounds have a great potential for energy multiplication. Although there are some well-known problems, 
Table 3-4. A Comparison of $(n, \gamma)$ Reaction Rates ${ }^{(a)}$

\begin{tabular}{|c|c|c|c|c|c|c|c|c|}
\hline \multirow{4}{*}{$\begin{array}{l}\text { Component } \\
\text { Material }\end{array}$} & \multicolumn{8}{|c|}{ Reaction Rate/Source Neutron } \\
\hline & \multicolumn{4}{|c|}{$14.06 \mathrm{MeV}$ Source } & \multicolumn{4}{|c|}{$2.45 \mathrm{MeV}$ Source } \\
\hline & \multirow{2}{*}{ PCA } & \multirow[b]{2}{*}{$\operatorname{CrN}$} & \multirow[b]{2}{*}{$\mathrm{Si}_{3} \mathrm{~N}_{4}$} & \multicolumn{2}{|c|}{ Blanket Systen: } & \multirow[b]{2}{*}{$\operatorname{CrN}$} & \multirow[b]{2}{*}{$\mathrm{SI}_{3} \mathrm{~N}_{4}$} & \multirow[b]{2}{*}{ Sic } \\
\hline & & & & Sic & PCA & & & \\
\hline $\mathrm{H}_{2} \mathrm{O}$ & 0.013 & 0.012 & 0.017 & 0.048 & 0.013 & 0.013 & 0.025 & 0.064 \\
\hline PCA & 0.976 & 0.153 & 0.213 & 0.570 & 0.932 & 0.169 & 0.307 & 0.761 \\
\hline $\operatorname{CrN}$ & - & 0.463 & - & - & - & $0.5 \mathrm{i} 1$ & - & - \\
\hline $\mathrm{Si}_{3} \mathrm{~N}_{4}$ & - & - & 0.044 & -- & - & - & 0.063 & - \\
\hline SiC & -- & - & - & 0.082 & -- & -- & - & 0.108 \\
\hline $\begin{array}{l}\text { Blanket } \\
\text { Total }\end{array}$ & 0.989 & 0.628 & 0.274 & 0.707 & 0.945 & 0.693 & 0.395 & 0.933 \\
\hline
\end{tabular}

(a) Blanket: $0.30 \mathrm{~m}$ : $15 \% \mathrm{PCA}+15 \% \mathrm{H}_{2} \mathrm{O}+70 \%$ " $\mathrm{X} "$

(b) Materials shown stand for component " $\mathrm{X}$ ".

such as resource limitation, ${ }^{(24)}$ chemical toxicity, and radiation-induced swelling, regarding the use of Be in fusion reactors; it is of interest to assess its potential for energy multiplication. Consider a case where one $14.06 \mathrm{MeV}$ source neutron undergoes a neutron multiplication process by the $(n, 2 n)$ reaction with a given multiplier, $M$, while the secondary neutrons induce the $(n, \gamma)$ reactions with given absorber materials $A 1$ and $A 2$. The energy balance involved in the sequence of events described above can be well predicted by a simple formula for the multiplication factor, $f$ :

$$
f=\frac{E_{g}-Q^{M}(n, 2 n)+Q^{A 1}(n, \gamma)+Q^{A 2}(n, \gamma)}{E_{s}},
$$


where

$E_{S}$ is the source neutron energy, $14.06 \mathrm{MeV}$.

$Q^{M}(n, 2 n)$ is the $(n, 2 n)$ reaction $Q$-value of the multiplier, $M$, in MeV. $Q^{A}(n, \gamma)$ is the $(n, \gamma)$ reaction $Q-v a l u e$ of the absorber, $A$, in MeV.

It is expected that the equation given here can predict the energy amplification by the $14.06 \mathrm{MeV}$ source neutron in an actual situation, provided that: (1) the $(n, 2 n)$ reaction by the multiplier has a high probability, (2) the secondary neutrons do not undergo any further endothermic reactions, and (3) the contributions from other reaction processes are trivial.

Table 3-5 presents a matrix of the potential energy amplification factor $f$ for $\mathrm{Be}$ and $\mathrm{Pb}$ multipliers with several absorber elements. It is assumed that both of the secondary neutrons are absorbed by a single kind of absorber (i.e., A1 = A2). It is noted from Table 3-5 that: (1) in general, the energy multiplication is significantly enhanced by the multipliers, (2) the Be-multiplier system can yield a higher energy multiplication than the $\mathrm{Pb}$-multiplier system, and (3) the absorption event by the multiplier material itself lowers the otherwise possible energy multiplication. The lower energy

Table 3-5. Potential of Energy Multiplication by Neutron Multipliers

\begin{tabular}{|l|cc|}
\hline \multirow{2}{*}{ Abscrber } & \multicolumn{2}{|c|}{ Energy Multiplication Factor } \\
\cline { 2 - 3 } & Be-Multiplier & Pb-Multiplier \\
\hline Be & 1.85 & - \\
Pb & - & 1.29 \\
Cr & 2.20 & 1.84 \\
N & 2.42 & 2.06 \\
Si & 2.13 & 1.77 \\
PCA & 2.00 & 1.64 \\
\hline
\end{tabular}

* Based on:

$$
\frac{14.06-Q^{M}(n, 2 n)+2 Q^{A}(n, \gamma)}{14.06} \text {, }
$$

$Q^{M}(n, 2 n)$ : the $(n, 2 n)$ reaction $Q$-value of multiplier (in Mev) $Q^{A}(n, \gamma)$ : the $(n, \gamma)$ reaction Q-value of absorber (in MeV). 
multiplication with $\mathrm{Pb}$ stems from the higher $\mathrm{Pb}(n, 2 \mathrm{n}) \mathrm{Q}-\mathrm{value}(-6.73 \mathrm{MeV})$ than the $\operatorname{Be}(n, 2 n)$ Q-value $(-1.66 \mathrm{MeV})$. Obviously, the extent to which the system energy is actually multiplied strongly depends upon the macroscopic reaction cross section of each element and the geometrical layout of these elements. However, it is very probable that in a system making use of a Be-multiplier, the energy amplification of the $14.06 \mathrm{MeV}$ source would $\mathrm{be} \approx 2.0$ or higher in many actual combinations of the candidate blanket materials ( $\mathrm{PCA}, \mathrm{S} \pm \mathrm{C}, \mathrm{CrN}, \mathrm{S}_{3_{3} \mathrm{~N}_{4}}$ ).

Table 3-6 shows the effect of the energy enhancement by a Be-multiplier of $0.1 \mathrm{~m}$ placed between the first wall and the blanket. The energy multiplication factor of the $14.06 \mathrm{MeV}$ source (multiplication per 14.06 in the table) shows good agreement with our prediction. The energy enhancement by

Table 3-6. System Energy Multiplication with the Be Multiplier

\begin{tabular}{|c|c|c|c|c|}
\hline \multirow[b]{2}{*}{ System ${ }^{*}$} & \multicolumn{4}{|c|}{ Neution Energy Deposition (MW) } \\
\hline & 14.06 only & \multicolumn{2}{|r|}{$14.06+2.45$} & Total System Power. \\
\hline PCA & 1335 & 601 & 1936 & 3434 \\
\hline $\mathrm{CrN}$ & 1337 & 595 & 1932 & 3430 \\
\hline $\mathrm{Si}_{3} \mathrm{~N}_{4}$ & 1284 & 568 & 1854 & 3352 \\
\hline SiC & 1216 & 533 & 1749 & 3247 \\
\hline PCA (no Be) & 1042 & 610 & 1652 & 3150 \\
\hline \multirow[b]{2}{*}{ Systen $^{*}$} & \multicolumn{4}{|c|}{ Energy Multiplication Factor } \\
\hline & Per & $(14.06+2.45)$ & Per 14.06 & Per 2.45 \\
\hline PCA & & 2.27 & 1.88 & 4.23 \\
\hline $\mathrm{CrN}$ & & 2.27 & 1.88 & 4.19 \\
\hline $\mathrm{Si}_{3} \mathrm{~N}_{4}$ & & 2.18 & 1.81 & 4.00 \\
\hline $\mathrm{SiC}$ & & 2.05 & 1.71 & 3.76 \\
\hline PCA (no Be) & & 1.94 & 1.47 & 4.30 \\
\hline
\end{tabular}

First Wall: $0.01 \mathrm{~m}: \quad 50 \% \mathrm{PCA}+50 \% \mathrm{~B}_{2} \mathrm{O}$

Multiplier: $0.1 \mathrm{~m}$ : Be (70\% density factor)

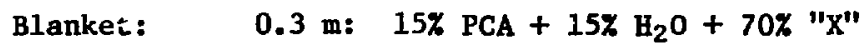

Shield: $\quad 0.59 \mathrm{~m}: 50 \%$ Fel $422+15 \% \mathrm{H}_{2} \mathrm{O}+35 \% \mathrm{~B}_{4} \mathrm{C}$ 
the multiplier varies from $\approx 0.25$ to $\approx 0.85$ in the multiplication factor per $(14.06+2.45)$ and from $\approx 250 \mathrm{MW}$ to $\approx 700 \mathrm{MW}$ in the system power output. It is important to note that the difference in the system power output produced by different blanket materials in the absence of a multiplier is greatly smeared out in the case where beryllium is used. This finding provides another degree of design flexibility upon the material selection for the $D-D$ outboard blanket design.

\subsection{Thermal Hydraulic Analysis}

An examination of some of the preliminary design data for an alternate fuel (D-D) fusion reactor shows that from a thermal hydraulics viewpoint the first wall/blanket system presents some unique design and cooling concepts. For example, due to no tritium breeding requirements, a variety of blanket and cooling concepts may be perceived based on an array of heat transport fluids and structural and blanket material combinations. The lower wall loadings for the current $D-D$ reactor design $\left(e . g ., 1.6 \mathrm{MW} / \mathrm{m}^{2}\right.$ for the D-D reactor vs. $3.5 \mathrm{MW} / \mathrm{m}^{2}$ for STARFIRE ${ }^{(13)}$ ) results in less severe demands on the heat transport system, although the surface heat fluxes on the first wall are about the same $\left(e_{*} g_{*}, 1.02 \mathrm{MW} / \mathrm{m}^{2}\right.$ for the $\mathrm{D}-\mathrm{D}$ reactor vs. $0.9 \mathrm{MW} / \mathrm{m}^{2}$ for STARFIRE). A series of thermal hydraulic analyses was carried out for two first wa1l/blanket design concepts (e.g., a coolant pane1-type first wall attached to monolithic blanket blocks and cylindrical modules with hemispherical front end) with water, helium and sodium as the heat transport fluids. The analytical studies presented herein are limited to three blanket materials: silicon nitride, silicon carbide, and chromium nitride. The results of the parametric investigations in terms of coolant inlet and outlet conditions, coolant velocities, maximum temperature of the structural material and the blanket material, coolant channel dimensions, and the pumping power losses are summarized below.

\subsubsection{Coolant Panel Design Concept}

In this design concept the coolant panels form the first wall are attached to blanket blocks. The coolant enters the first wall, flows in*a direction parallel to the toroidal field, and then returns through the blanket blocks which contain a set of $2.54-\mathrm{mm}(0.1-\mathrm{in})$ diameter coolant channels 
located at 25.4-mm (1.0-in) centers. The analytical results with water and helium as the coolants are sumarized in Table 3-7. The results show that fairly narrow coolant channels with stainless steel as the structural material and water as the coolant provide an acceptable first wall design. However, for a helium-cooled first wall it would not only be necessary to use shorter and larger coolant channels to minimize pumping power losses, but also it would be necessary to use refractory metals to withstand the higher operating temperature.

\subsubsection{Cylindrical Module Design Concept}

In this design the coolant (helium at 750 psia) enters the modules through an outer annulus (space between the container and blanket material) and, after reaching the hemispherical front end (first-wall), returns through a set of coolant channels (2.54-mm diameter located at $25.4-\mathrm{mm}$ centers). During these scoping studies, the thermal hydraulic calculations were confined to the return leg of the coolant through the blanket. (Note: cooling of the casing and hemispherical head is similar to the analyses presented in the previous section). Table 3-8 summarizes the results for three blanket materials -- silicon nitride (SiN), silicon carbide (SiC), and chromium nitride ( $\mathrm{CrN}$ ), based on $30-\mathrm{cm}$ thick blanket modules. As the maximum operating temperature for the nitride blanket is 1 imited to $\approx 1000^{\circ} \mathrm{C}, \mathrm{CrN}$ does not appear to be a viable blanket materlal. The pumping power losses for this design are quite small, being less than $1 \%$. However, because of the small module size (10 to $20 \mathrm{~cm}$ in diameter), blanket design and manifolding a large number of such units may present a formidable task.

The gap between the cylindrical modules must be filled with a filler material to prevent neutron streaming. An analysis was carried out for two sizes of cylindrical modules $(10-\mathrm{cm}$ diameter and $20-\mathrm{cm}$ diameter) to assess whether the uncooled filler elements will present any hot spot problems for the container wall. The maximum gap for closely-packed modules of the above two cylinder sizes was found to be $1.57 \mathrm{~mm}$ and $3.14 \mathrm{~mm}$, respectively. The maximum temperature of the filler elements was calculated based on the assumption that only $20 \%$ of the surfaces are in contact, and the interfacial gap conductance between the filler elements and the cylindrical modules is 
Table 3-7. Summary of Analytical Results - Coolant Panel Concept

\begin{tabular}{|c|c|c|c|c|c|c|}
\hline Coolant & $\begin{array}{l}\text { Coolant } \\
\text { Velocity } \\
\mathrm{m} / \mathrm{s}\end{array}$ & $\begin{array}{l}\text { Coolant Inlet } \\
\text { Temp. and } \\
\text { Pressure }\end{array}$ & $\begin{array}{l}\text { Coolant } \\
\text { Outlet Temp. } \\
{ }^{\circ} \mathrm{C}\end{array}$ & $\begin{array}{l}\text { Coolant } \\
\text { Channel } \\
\text { Size }\end{array}$ & $\begin{array}{l}\text { Max. Structural } \\
\text { Material } \\
\text { Temp. }{ }^{\circ} \mathrm{C}\end{array}$ & $\begin{array}{l}\text { Pumping Power } \\
\text { Loss ( } \% \text { of Thermal } \\
\text { Power }\end{array}$ \\
\hline Water & 7 & $\begin{array}{l}280^{\circ} \mathrm{C} \\
2200^{\mathrm{psia}}\end{array}$ & $320^{\circ} \mathrm{C}$ & $\begin{array}{l}4 \min \times 12 \mathrm{~mm} \\
\times 3.5 \mathrm{~m} \text { long }\end{array}$ & 423 & $<1$ \\
\hline \multirow[t]{6}{*}{ Helium } & 277 & $\begin{array}{l}225^{\circ} \mathrm{C} \\
750 \text { psia }\end{array}$ & $425^{\circ} \mathrm{C}$ & $\begin{array}{l}4 \min \times 12 \mathrm{~mm} \\
\times 3.5 \mathrm{~m} \mathrm{long}\end{array}$ & 563 & 65 \\
\hline & 198 & & & $\begin{array}{l}4 \mathrm{~mm} \times 12 \mathrm{~mm} \\
\times 2.5 \mathrm{~m} \mathrm{long}\end{array}$ & 581 & 31 \\
\hline & 139 & & & $\begin{array}{l}4 \mathrm{~mm} \times 12 \mathrm{~mm} \\
\times 1.75 \mathrm{~m} \text { long }\end{array}$ & 607 & 7 \\
\hline & 92 & & & $\begin{array}{l}6 \mathrm{~mm} \times 12 \mathrm{~m} \\
\mathrm{x} 1.75 \mathrm{~m} \mathrm{long}\end{array}$ & 646 & 4.2 \\
\hline & 69 & & & $\begin{array}{l}8 \mathrm{~mm} \times 12 \mathrm{~mm} \\
\times 1.75 \mathrm{~m} \mathrm{long}\end{array}$ & 683 & 2.2 \\
\hline & 55 & $\begin{array}{l}225{ }^{\circ} \mathrm{C} \\
1250 \mathrm{psia}\end{array}$ & & $\begin{array}{l}6 \mathrm{~mm} \times 12 \mathrm{~mm} \\
\times 1.75 \mathrm{~m} \mathrm{long}\end{array}$ & 646 & 2.5 \\
\hline
\end{tabular}


Table 3-3. Sumary of Analytical Results for Cylindrical Blanket Modules (750 psia helium inlet pressure)

\begin{tabular}{|c|c|c|c|c|c|c|}
\hline $\begin{array}{l}\text { Helium Inlet } \\
\text { Temperature } \\
{ }^{\circ} \mathrm{C}\end{array}$ & $\begin{array}{l}\text { Helium } \\
\text { Outlet Temp. } \\
{ }^{\circ} \mathrm{C}\end{array}$ & $\begin{array}{l}\text { Helium } \\
\text { Velocity } \\
\text { mis }\end{array}$ & \multicolumn{3}{|c|}{$\begin{array}{l}\text { Maximum } \\
\text { Breeder Temp. } \\
{ }^{\circ} \mathrm{C}\end{array}$} & $\begin{array}{c}\text { Pumping Power Loss } \\
\text { (\% of Thermal } \\
\text { Power }\end{array}$ \\
\hline & & & $\operatorname{SiN}$ & CrN & Sic & \\
\hline 225 & 400 & 22 & 544 & 995 & 511 & $<1$ \\
\hline 250 & 425 & & 570 & 1028 & 537 & \\
\hline 275 & 450 & & 596 & 1056 & 563 & \\
\hline 300 & 475 & & 622 & 1083 & 590 & \\
\hline 325 & 500 & & 649 & 1110 & 617 & \\
\hline 350 & 525 & & 675 & 1136 & 643 & \\
\hline
\end{tabular}

$0.452 \mathrm{~W} / \mathrm{cm}^{2}{ }^{\circ} \mathrm{C}\left(800 \mathrm{Btu} / \mathrm{hr} \cdot \mathrm{ft}^{2} \mathrm{R}\right)$. The results, based on the maximum nuclear heat generation rate (i.e., nuclear heat generation rate near the first wall), are summarized below.

\begin{tabular}{|l|r|r|r|}
\cline { 2 - 4 } \multicolumn{1}{c|}{} & \multicolumn{3}{c|}{ Filler Excess } \\
Temperature, ${ }^{\circ} \mathrm{C}$
\end{tabular}

Since the coolant enters the modules through the annular gap at $225^{\circ} \mathrm{C}$, and the temperature rise between the coolant inlet point and the hemispherical section will not exceed $50^{\circ} \mathrm{C}$, hot-spots at the filler elements may not pose serious material problems depending, of course, on the cholce of the structural materlal. 


\subsubsection{Liquid Metal (sodium) Coolant}

One of the serious limitations on the choice of a conducting fluid as coolant is the MHD interactions in high magnetic fields giving rise to large pressure 1osses. Because of the superior heat transfer characteristics of sodium, cooling of the first wall or heat removal from the blanket regions is not a problem. Hence, only an estimate of the pressure losses for a set of coolant channel and coolant manifold layouts was carried out. The result's show that the pumping power losses for the blanket and the inlet/outlet manifold are of the order of $2.5 \%$. Since a detailed inlet and outlet manifold layout and the details of the sodilum-cooled blanket moduies have not been worked out, the above results should be considered as preliminary.

\subsubsection{Conclusions}

Because of the relative low energy levels for the current $D-D$ reactor design, no serious thermal hydraulics problems are envisioned. Water, helium, and liquid metals appear as viable coolants. The choice of the coolant depends on the selection of the blanket and structural materials, compatibility of coolants with the structural material, and the maximum operating temperature limits. The choice of blanket module design is dictated by economic considerations.

\subsection{Structural Materials}

The structural material requirements, which are similar to the requirements for a D-T reactor, are that the material should be resistant to radiation damage, capable of elevated temperature operation, and environmentally compatible with its surroundings. In addition, it is desirable that the material exhibit low activation and that its properties should not be affected by the formation of transmutation products. The number of potential structural materials is large, and surveys have been conducted previously to evaluate their viability for D-T reactors. $(13,25)$ This evaluation focuses upon the comparison of two of the more attractive material candidates for the particular conditions expected in a D-D fueled reactor. The first candidate is an advanced austenitic stainless steel known as PCA (Prime Candidate Alloy), and the second candidate is the vanadium alloy, V-20Ti. 
A summary of the properties of the two materials is given in Table 3-9. The primary concern for PCA is its poor thermophysical properties, which could result in large thermal and stress gradients in the first wall. Under steady state conditions the thermal stresses are expected to relax due to creep and therefore should not pose a significant problem. However, if the reactor operates in a cyclic mode, the same stresses do result in fatigue that can lead to premature crack fallures. (13)

The mechanical properties of both materials are adequate for the temperature $\left(<500^{\circ} \mathrm{C}\right.$ ) and stress conditions expected in a pressurized water system. The effect of radiation on the swelling and mechanical properties of both materials is expected to be within acceptable limits. In fact, vanadium-titanium alloys have been found to be among the most radiation resistant materials tested. (26) A major concern in the use of $\mathrm{V}-20 \mathrm{TI}$ is a potentially higher corrosion rate caused by the water coolant. The corrosion rate of pure vanadium is unacceptably high in pressurized water to be considered for this system. However, alloying with strong oxide formers, such as titanium, should reduce the rate of corrosion. Additional experimental

Table 3-9. Structural Materials Comparison

\begin{tabular}{|c|c|c|}
\hline Property & PCA & V-20Ti \\
\hline Thermophysical & $\begin{array}{l}\text { Poor. Susceptible to } \\
\text { high temperature and } \\
\text { stress gradients. Can } \\
\text { not withstand high } \\
\text { cyclic heat fluxes. }\end{array}$ & $\begin{array}{l}\text { Good. Capable of with- } \\
\text { withstanding high heat } \\
\text { fluxes. }\end{array}$ \\
\hline Mechanical & $\begin{array}{l}\text { Strength adequate to } \\
\approx 500^{\circ} \mathrm{C} \text {. Retains ade- } \\
\text { quate ductility with } \\
\text { irradiation. }\end{array}$ & $\begin{array}{l}\text { Strength adequate to } \\
\approx 650^{\circ} \mathrm{C} \text {. Retains ade- } \\
\text { quate ductility with } \\
\text { irradiation. }\end{array}$ \\
\hline Swelling & $\begin{array}{l}\text { Low. Estimated to be } \\
\approx 1 / 10 \text { the swelling of } \\
20 \% \text { CW } 316 \text { sS. }\end{array}$ & $\begin{array}{l}\text { Low. No measurable } \\
\text { swelling has been ob- } \\
\text { served. }\end{array}$ \\
\hline Corrosion & $\begin{array}{l}\text { Low for pressurized } \\
\mathrm{H}_{2} \mathrm{O} \text { systems. }\end{array}$ & $\begin{array}{l}\mathrm{H}_{2} \mathrm{O} \text { corrosion of pure } \\
\text { vanadium is high, but } \\
\text { alloying could reduce } \\
\text { corrosion levels. }\end{array}$ \\
\hline Fabrication & $\begin{array}{l}\text { Established technology. } \\
\text { Easily fabricated. }\end{array}$ & $\begin{array}{l}\text { Somewhat difficult. } \\
\text { Welding requires inert } \\
\text { cover gas. }\end{array}$ \\
\hline Activation & Long-term activation. & Low long-term activation. \\
\hline
\end{tabular}


effort is required to quantify the effect of alloying on the water corrosion of vanadium alloys. Austenitic stainless steels, like PCA, are generally considered to be easily fabricated, whereas additional care must be taken in the fabrication of vanadium alloys, particularly for welding, in order to prevent the impurity buildup of oxygen, nitrogen, or carbon. (26)

In order to determine if PCA is capable of an acceptable lifetime for the operating conditions of a D-D reactor, a lifetime analysis has been performed. The analysis, based upon a model developed for the STARFIRE study, coneiders a tubular first wall that receives a uniform neutron flux and a heat flux from one side. The interactions of swelling, creep, and crack growth are followed in two dimensions for a chosen set of operating conditions. The conditions used for the lifetime analysis of the $D-D$ reactor are given in Table 3-10. Crack growth to failure is of particular concern in a D-D reactor because of the relatively high heat flux and the cyclic burn cycle. In the present case, however, little or no crack growth for times to $60,000 \mathrm{~h}$ is predicted for an initial flaw size of $100 \mu \mathrm{m}$. It should be noted that fatigue and crack growth could still be a problem for PCA if the reactor were

Table 3-10. Design and Operating Parameters for Lifetime Analysis

\begin{tabular}{|c|c|}
\hline Tube Diameter (mn) & 20 \\
\hline Wa11 Thickness (mm) & 1.5 \\
\hline Coolant Pressure (psig) & 2000 \\
\hline Coolant Temperature $\left({ }^{\circ} \mathrm{C}\right)$ & 320 \\
\hline Neutron Ha11 Load $\left(\mathrm{MW} / \mathrm{m}^{2}\right)$ & 0.9 \\
\hline Surface Heat Flux $\left(\mathrm{MW} / \mathrm{m}^{2}\right)$ & 0.5 \\
\hline dpa Rate (dpa/MW-yr/m ${ }^{2}$ ) & \\
\hline $\begin{array}{l}\text { Helium Generation Rate } \\
\left.\text { (appm/Mw-yr } / \mathrm{m}^{2}\right)\end{array}$ & $125^{(4)}$ \\
\hline Inltial Crack Length ( $\mu \mathrm{m}$ ) & 100 \\
\hline Burn Time (h) & 2 \\
\hline Dwell Period (s) & 30 \\
\hline Startup/Shutdown Time (s) & 30 \\
\hline
\end{tabular}


operated with a burn cycle considerably shorter than 2 h or if the surface heat load were higher. Swelling and creep are predicted to have a smaller effect in this D-D reactor than in STARFIRE due to the significantly lower neutron flux. This effect is illustrated in Fig. 3-4, which shows that the stress relaxation. is much slower in the D-D reactor than in STARFIRE. Swelling also occurs at a lower rate, and therefore the total dimensional changes in the first wall of a $D-D$ reactor are lower.

Based upon this analysis, PCA should have an adequate lifetime and has been chosen as the primary candidate for the structural material. If the operating parameters of heat load or operating cycle were changed, the structural material choice would have to be re-evaluated, and the selection of a refractory metal, such as V-20Ti, might be necessary.

\subsection{Moderator Materials}

Three moderator materials, $\mathrm{CrN}, \mathrm{Si}_{3} \mathrm{~N}_{4}$, and $\mathrm{SiC}$, have been considered in the blanket, and representative values of their physical properties are given in Table 3-11. (27-29) The desirable properties of moderator materials that would provide the greatest flexibility in the blanket design

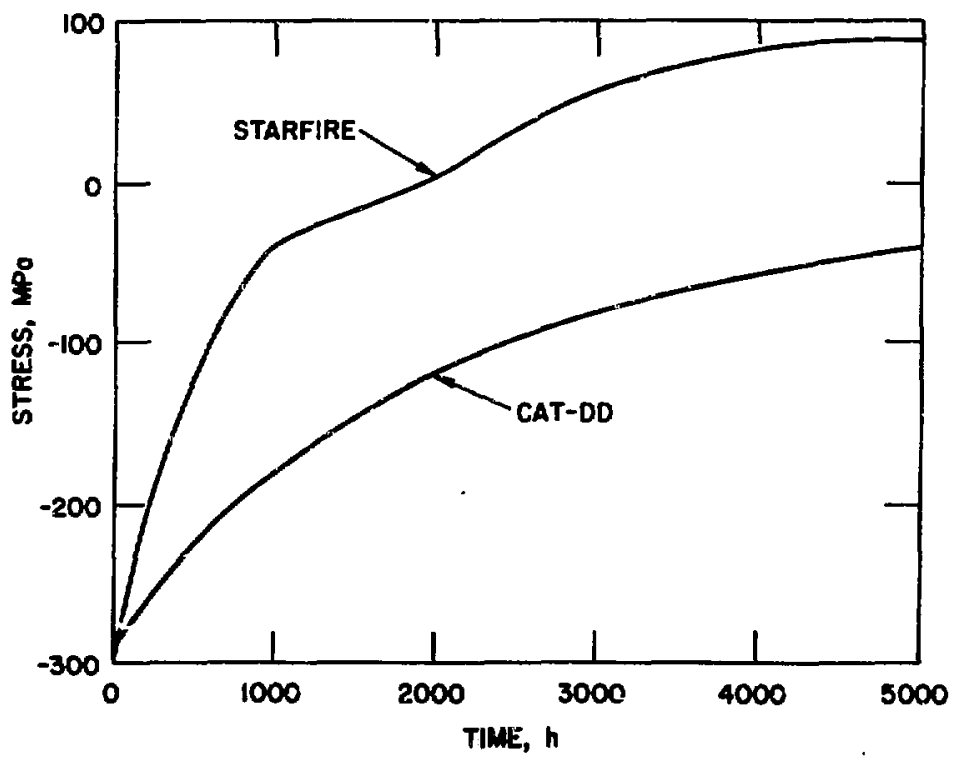

Figure 3-4. Stress relaxation in first wall tube section directly facing plasma in STARFIRE and D-D reactors. 
Table 3-11. Physical Properties of Moderator Materials

\begin{tabular}{|cccccc|}
\hline Material & $\begin{array}{c}\text { M.P. } \\
{ }^{\circ} \mathrm{C}\end{array}$ & $\begin{array}{c}\text { Density } \\
8 / \mathrm{m}^{3}\end{array}$ & $\begin{array}{c}\text { Thermal Cond. } \\
\text { W/m K }\end{array}$ & $\begin{array}{c}\text { Specific Heat } \\
\text { J/kg K }\end{array}$ & $\begin{array}{c}\text { Thermal Exp. (a) } \\
\times 10^{6} / \mathrm{K}\end{array}$ \\
\hline $\mathrm{CrN}$ & $1500^{(\mathrm{b})}$ & 6.1 & 3.5 & 795 & 3.1 \\
$\mathrm{Si}_{3} \mathrm{~N}_{4}$ & $1871^{(\mathrm{b})}$ & 3.2 & 22 & 1100 & 3.6 \\
$\mathrm{SiC}$ & 2827 & 3.2 & 31 & 1150 & 5.7 \\
\hline
\end{tabular}
(a) $500^{\circ} \mathrm{C}$
(b) Decomposes
(c) do room temperature

are higl values for the melting point, thermal conductivity, and specific heat along with a low density that would minimize the weight of the blanket. Based upon these criteria, CrN exhibits the least desirable properties, whereas SiC exhibits the most desirable properties. Since SiC also provides the greatest energy mujtiplication of the three materials, it is the only material considered further.

The crystal structure of SiC is cubic ( $\beta$ ) at low temperatures, but the structure slowly changes to hexagonal $(\alpha)$ when it is heated above $1650^{\circ} \mathrm{C}$ (27) SiC has been cabricated by several processes including reaction sintering, hot pressing, and chemical vapor deposition. Reaction sintered SiC usually contains both $\alpha$ and $\beta$ phases with from 0 to $10 \%$ free carbon and/or silicon. The amount of porosity can vary from 0.1 to $\approx 20 \%$. Commercial hot-pressed SiC may contain up to $5 \mathrm{wt} \%$ of sintering aids, usually $\mathrm{Al}_{2} \mathrm{O}_{3}$. The grain sizes can vary from $0.5 \mu \mathrm{m}$ to $20 \mu \mathrm{m}$ depending on the amount of $\mathrm{Al}_{2} \mathrm{O}_{3}$ and the hot pressing temperature. Like other refractory materials, the mechanical and thermophysical properties can be strongly influenced by the manufacturing method.

The effects of neutron irradiation have only been investigated up to a neutron fluence of $\approx 2 \times 10^{22} \mathrm{n} / \mathrm{cm}^{2}(E>0.1 \mathrm{MeV})$. The limited amount of data indicate that the effects of radiation on several properties examined at temperatures $<1040^{\circ} \mathrm{C}$ appear to saturate. The saturation level of radiation Induced expansion $13 \approx 1 \%$ at room temperature. The saturation level decreases linearly with temperature and reaches $\approx 0.05 \%$ at $1000^{\circ} \mathrm{C}^{(30)}$ At 
temperatures $>1200^{\circ} \mathrm{C}$, void swelling similar to swelling in metals, is observed. At temperatures $<650^{\circ} \mathrm{C}$, effects on mechanical properties also saturate with fluence. (31) Both the fracture strength and Young's Modulus for reaction bonded SiC decrease rapidly up to a dose of $1-3 \times 1.0^{20} \mathrm{n} / \mathrm{cm}^{2}$ and then begin to increase. Saturation is reached at $7-10 \times 10^{20} \mathrm{n} / \mathrm{cm}^{2}$, but the property values are still less than the unirradiated values. The degradation of the mechanical properties has been attributed to internal cracking generated by radiation induced misfit strains between the $\alpha$ and $\beta$ phases as well as the impurities in the material. Further experimentation is required to determine if the saturation of property values extends to the fluence and temperature conditions of a $\mathrm{D}-\mathrm{D}$ reactor.

\subsection{First-Wall Surface Effects}

Selection of the material that serves as the first physical barrier to the plasma is a critical consideration in the design of the first-wall. Low-Z materials appear essential since high-Z impurities eroded from the first wall and plasma chamber components, e.g., the limiter, can severely impact the plasma performance. Also, impurities eroded from the first wall can become energetic ions that subsequently strike the limiter. Since higher $-\mathrm{Z}$ ions produce sputtering yields greater than unity at modest energies (of the order of $100 \mathrm{eV}$ ), excessive erosion of the 1 imiter is predicted if the first wall is constructed of other than low-Z materials.

A significant fraction of the energy emitted from the plasma is in the form of cyclotron radiation. In order to attain an acceptable plasma energy balance it is essential that a large fraction, e.g., possibly $90 \%$ or greater, of this cyclotron radiation be reflected by the wall back into the plasma where it can be absorbed. The surface morphology and structure of the wall are important considerations in designing for high reflectivity.

It is also concluded that portions of the first wall must survive a modest number of large transient surface heat fluxes that result from plasma disruptions. Significant amounts of wall material ablated or vaporized during a disruption will most likely deposit at other regions of the plasma chamber. Becauge of the extensive material redistribution in the plasma chamber that arises both from sputtering during normal operation and ablation during a disruption, a single matertal for all plasma chamber components provides 
Important advantages that may be essential. Deposition of a material, such as graphite, on a metal first wall could substantially affect erosion rates or the integrity of the metal wall. Likewise, deposition of elements from a compound, e.g., $\mathrm{T} \pm \mathrm{C}$ or $\mathrm{T} \pm \mathrm{B}_{2}$, could result in a nonstoichiometric surface layer with properties much different than the ideal compound. It is concluded in the present design study that all first wall components, including the limiter, should be constructed of the same material and that the surface material should be a single element with a low-Z (probably $<10$ ).

The recommended approach for Incorporating low-Z materials into the first wall is the low $Z$ coating (cladding) concept originally advocated in the ANL Experimental Power Reactor Study. (32) A major advantage of this concept relates to the greater flexibility of materials choices in that the surface material or coating can be selected primarily on the basis of its surface properties while the substrate can be selected primarily on the basis of its structural and compatibility characterisics. This concept permits use of $10 w-Z$ materials that would not otherwise be viable candidates.

Table 3-12 summarizes the important considerations in the selection of the primary candidate coating/cladding materials.

Table 3-12. Considerations for Selection of Coating/Cladding Material for the First-Wall

Atomic number (Z)

Physical sputtering yields

Chemical reactivity with hydrogen

Blistering erosion

Compatibility with candidate substrate materials

Melting temperature

Vapor pressure

Elemental cquposition

Thermal conductivity

Radiation damage resistance

Thermal expansion coefficient

Electronic conductivity

Fabricability 


\subsubsection{Phystcal Sputtering}

The major mechanism of wall eroston during operation is predicted to be physical sputtering caused by charge-exchange neutrals. A significant data base for physical sputtering of candidate wall materials has been developed in recent years. It is generally concluded that physical sputtering yields of monoenergetic ions normally incident on candidate wall materials are known or can be predicted within a factor of 2 (a factor of 1.5 in many cases). This accuracy is considered to be within the range of other uncertainties in plasma-wall interaction analyses and adequate for the present study. Physical sputtexing yields used in the present study are based on a model developed by Smith, $(33,34)$ which gives the energy-dependent physical sputtering yields for various plasma particles incident on candidate first-wall materials. The sputtering yield in atoms per ion is given by:

$$
S(E)=\frac{20}{U_{0}} z_{1}^{2} z_{2}^{2} \frac{M_{1}}{M_{2}} \frac{\left(E-E_{t h}\right)}{\left[\left(E-E_{t h}\right)+50 z_{1} Z_{2}\right]^{2}},
$$

where

$$
\begin{array}{ll}
E_{t \dot{n}}=\frac{\left(M_{1}+M_{2}\right)^{2}}{4 M_{1} M_{2}} U_{0}, & \text { for } M_{1}<M_{2}, \\
E_{t h}=\frac{M_{2}}{M_{1}} U_{0}, & \text { for } M_{1}>M_{2},
\end{array}
$$

where $Z_{1}, Z_{2}$ and $M_{1}, M_{2}$ are the atomic numbers and mass numbers of the incident particles and target atoms, respectively; $U_{0}$ is the binding energy in $\mathrm{eV}$; and $E$ is the incident particle energy in eV. Parameters required for the calculation of the physical sputtering yields for several candidate wall materials are given in Table 3-13. The calculated values are in fairly good agreement with reported experimental data including the recent compilation of Roth, et al. (35) Although several models have been proposed, the present model gives an adequate representation over the energy range of interest and it can be easily combined with the Maxwellian distribution function to give the Maxwellian-averaged sputtering yields.

Beryllium has many properties that not only make it suitable for the coating/cladding, but make it superior to other candidates. Boron is also a prime candidate coating material. Primary advantages compared to beryllium 
Table 3-13. Parameters for Calculation of Physical-Sputter Yields for Candidate Wall Materials

\begin{tabular}{lrrr}
$\begin{array}{c}\text { Wal1 } \\
\text { Material }\end{array}$ & Z & M & $\begin{array}{c}\mathrm{U}_{0}, \\
\mathrm{eV}\end{array}$ \\
\hline Be & 4 & 9.0 & 3.4 \\
B & 5 & 10.8 & 5.7 \\
C & 6 & 12.0 & 7.4 \\
A1 & 13 & 27.0 & 3.4 \\
V & 23 & 50.9 & 5.3 \\
Fe & 26 & 55.9 & 4.3 \\
Nb & 41 & 92.9 & 7.6 \\
Mo & 42 & 95.9 & 6.8 \\
W & 74 & 183.9 & 11.1 \\
\hline
\end{tabular}

Include slightly lower physical sputtering yields and a higher melting temperature. The major disadvantages relative to beryllium are a much lower thermal conductivity and a higher hydrogen solubility and permeability.

\subsubsection{Electron Cyclotron Radiation}

Electron cyclotron radiation poses a serious power loss problem for reactors employing the $D-D$ reaction. In order to maintain an energy balance In the plasma, most of this radiation must be reflected from the first wall. The reflectivity of the first wall will depend on the frequency of the radiation, as well as the electromagnetic properties of the first wall. The primary frequency, $v$, of the radiation is given by

$$
v=\frac{B e}{2 \pi m e} \text {, }
$$

where $B$ is the magnetic field strength, $e$ is the electron chare, and $m_{e}$ is the electron rest mass. For the reference design the maximum magnetic field in the plasma is $11.6 \mathrm{Tes} l a$, and therefore, the primary frequency of the cyclotron radiation $1 \mathrm{~s} 3.25 \times 10^{11} \mathrm{~Hz}$. HIgher frequency radiation 18 also expected to be present to a lesser degree. A value of 
$\approx 20$ times the primary frequency, or $6.5 \times 10^{12} \mathrm{~Hz}$, is estimated to be the cutoff frequency of the radiation. (36)

The reflectivity of metals to the cyclotron radiation can be estimated from standard electromagnetic theory. (37) For an incident polarized wave in a vacuum, with its $E$ vector normal to the plane of incidence, the ratio of the incident electric field intensity, $E_{i}$, to the reflected electric field intensity, $E_{r}$, is given by

$$
\frac{E_{i}}{E_{r}}=\frac{K_{m} \cos \theta_{i}-\frac{\lambda}{\delta}(1-j)}{K_{m} \cos \theta_{i}+\frac{\lambda}{\delta}(1-j)},
$$

where $K_{m}$ is the relative magnetic permeability of the metal, $\theta_{i}$ is the angle of incidence, $\lambda$ is the wavelength of the incident wave, $\delta$ is the skin depth of the metal, and $j=\sqrt{-1}$. The skin depth, $\delta$, is given by

$$
\delta=\left(\frac{1}{\pi \nu \sigma \mu}\right)^{1 / 2},
$$

where $\sigma$ is the electrical resistivity and $\mu$ is the magnetic permeability. Using property values of autenitic stainless steel in $\mathrm{Eq} .(3)\left(K_{m} \approx 1.0\right.$, $\lambda=4.6 \times 10^{-5} \mathrm{~m}, \sigma=10^{6}(0 \mathrm{hm}-\mathrm{m})^{-1}, \mu=1.26 \times 10^{-6}$ Henry $/ \mathrm{m}, v=6.5 \times 10^{12}$ $\mathrm{Hz}$, and $\delta \approx 2 \times 10^{-7} \mathrm{~m}$ ) yields $\mathrm{E}_{i} / \mathrm{E}_{\mathrm{r}} \approx-1$. Since the reflectivity, $\mathrm{R}$, is the square of this number, almost total reflection is expected. The result is tho same for an incident wave polarized with its $E$ vector parallel to the plane of incidence.

During normal operation, the first wall is likely to have a thin oxide layer on the surface. The impact of the oxide on the reflectivity of the matertal is, however, expected to be small. A normally incident wave will be transmitted through a non-conductive oxide and then be reflected at the oxide-metal interface. The reflected wave will be re-transmitted through the oxide and emerge back into the vacuum. The only change expected is a phase change in the wave vector of the reflected wave. This phase change will depend upon the oxide thickness and its eleccromagnetic properties. 


\subsubsection{Plasma Disruptions}

One of the serious problems that may be encountered during operation of fusion reactors is the problem of plasma disruption which gives rise to energy fluxes of several hundred times the steady state value. Energy fluxes of the order of 200 to $400 \mathrm{MW} / \mathrm{m}^{2}$ over a short period (e.g., 25 to $250 \mathrm{~ms}$ ) of time will lead to melting and evaporation of the first wall. A number of studies (Refs. 38-31) of D-T fueled fusion reactors have recently been conducted to assess the seriousness of unstable plasma behavior leading to an energy dump over a small portion of the first wall surface. Since the energy dump leads to complex physical and thermodynamic processes, and since the nature of energy dump is not well defined, all of these studies of necessity have been limited in scope. However, the results of these studies indicate that an understanding of a plasma dump is an important aspect of the first wall design. In contrast to D-T burning fusion reactors, the problems assoclated with a plasma dump appear to be even more serious for the $D-D$ fueled fusion reactor. For example, the plasma energy deposited per unit area on the first wall of the reference D-D reactor will be more than four times the plasma energy deposited in a typical D-T fueled fusion reactor such as STARFIRE.

Because of the limited scope of the present study, a detailed plasma dump analysis has not been conducted. However, preliminary results summarized in the following section show the serlousness of the problem. The major parameters to be considered include the following:

$\begin{array}{ll}\text { Total Plasma Energy: } & 8 \times 1.0^{8} \mathrm{~J} \\ \text { Total Surface Area of the } & 1250 \mathrm{~m}^{2} \\ \text { First Wall: } & 1 \mathrm{~mm} \\ \text { Thickness of Be Cooling: } & \end{array}$

It is assumed that the plasma energy is dumped over $30 \%$ of the surface area, and that the Be coating is thermally insulated from the substrate (first wa11). The above assumption leads to complete melting of the coating and to vaporization of $\approx 31 \%$ of the coating. This is an over-simplified analysis and represents an upper limit on the amount of Be coating evaporated

As mentioned earlier, the nature of the plasma dump has not been well understood, and hence no consensus exists on the duration of a plasma dump. 
Some of the previous analyses have shown plasma dump duration to be of the order of 5 to $100 \mathrm{~ms}$. A conservative approach was taken during this analysis to see what happens to the temperature response of the Be coating based on $a$ 100 ms plasma dump. The first wall was assumed to be cooled by sodium entering at $275^{\circ} \mathrm{C}$. The 1-m thick Be coating was divided into five $0.2 \mathrm{~mm}$ thick layers (Nodes 59-63) to calculate the temperature response. A time/temperature history of the Be coating is shown in Fig. 3-5. As the melting point of Be is $\approx 1285^{\circ} \mathrm{C}$ and the first wall is exposed to high vacuum environment, ablation of the first wall will occur before these calculated temperatures are approached. An analysis was conducted to determine whether the plasma dump becomes a less serious problem if the plasma dump time is increased by $100 \%$, i.e., plasma dump time is increased to $200 \mathrm{~ms}$ from $100 \mathrm{~ms}$. The temperature response of the Be coating is shown in Fig. 3-6. From Fig. 3-6 it is apparent that even if the plasma dump times can be as long as $200 \mathrm{~ms}$, a plasma dump is a serious problem, and it needs further careful analysis. Figure 3-7 shows the temperature response of the stainless steel substrate (Node 56, 57, and 58) and the coolant (Node 55).

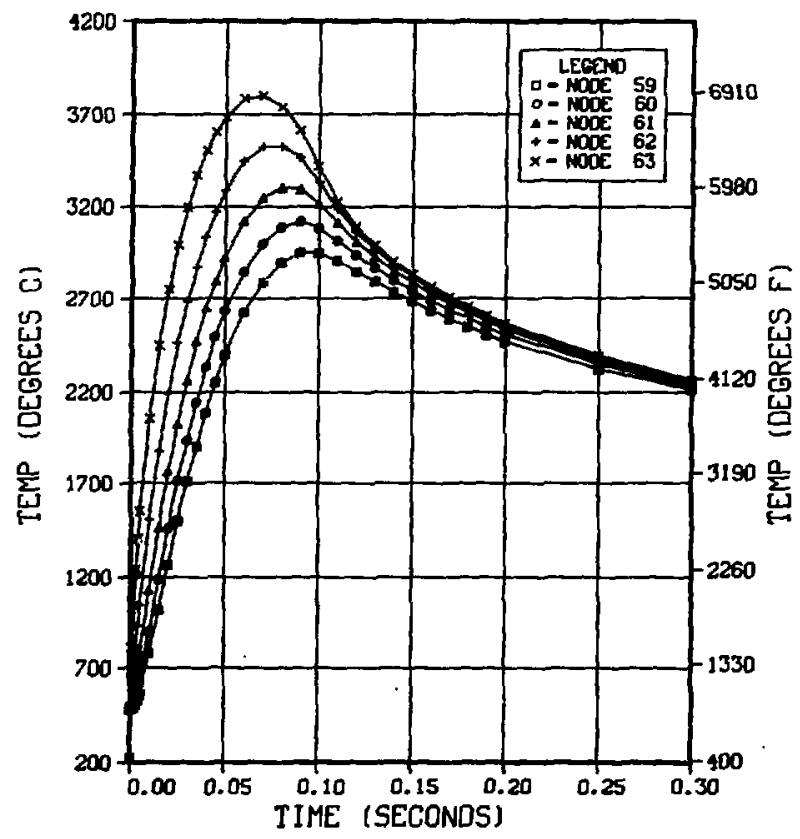

Figure 3-5. Temperature response of Be-Coating for plasma disruption time = 100 ms. 


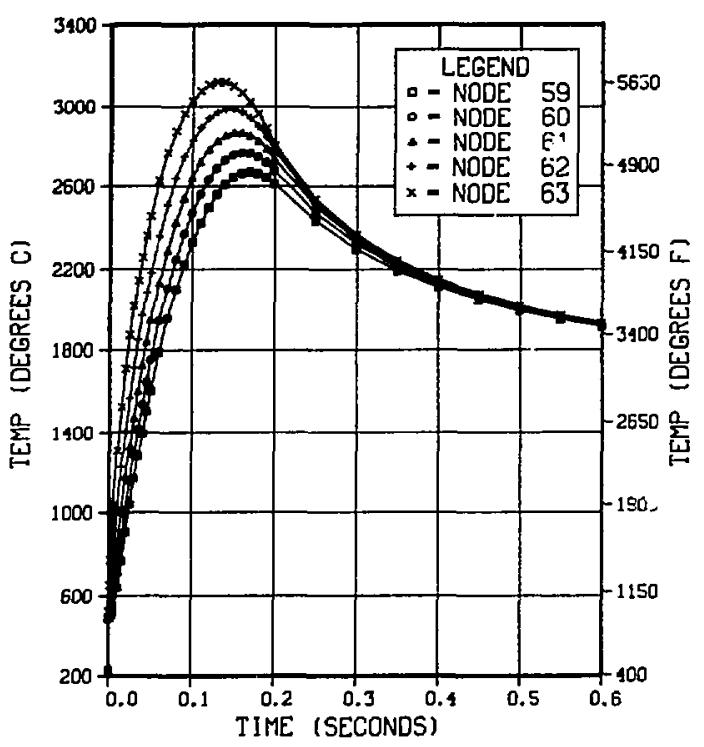

Figure 3-6. Temperature response of Be-coating for plasma disruption time = $200 \mathrm{~ms}$.

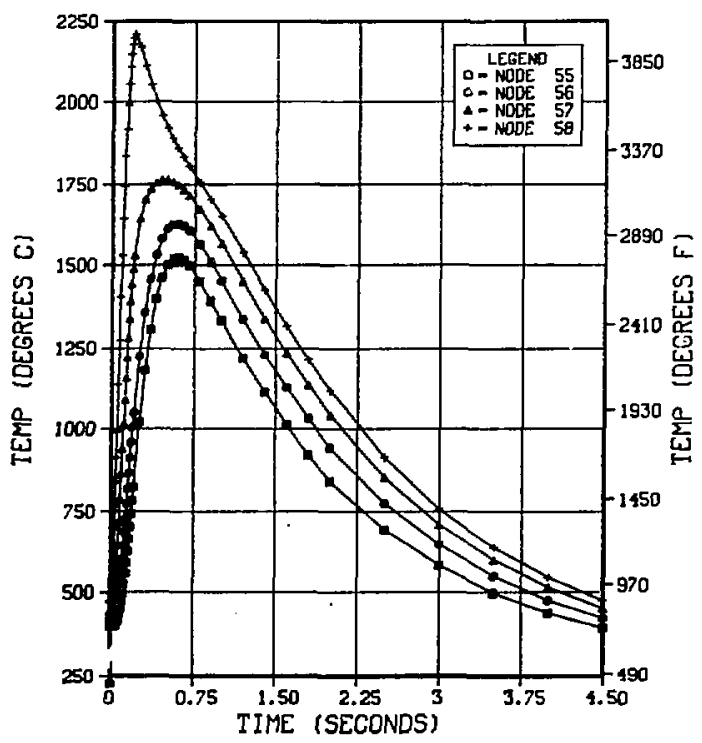

Figure 3-7. Temperature response of structural material for plasma disruption tIme $=200 \mathrm{~ms}$. 
From the results presented in this section and although the analysis presented above is an oversimplification of the physical phenomena, it may be concluded that a plasma dump for $D-D$ reactors appears to be more serious than the plasma dump in $\mathrm{D}-\mathrm{T}$ reactors. A detailed analysis is necessary to more accurately assess the seriousness of the problem.

\section{References}

1. S. Glasstone and A. Sesonske, Nuclear Reactor Engineering, D. Van Nostrand Company, Ltd., p. 79 (1963).

2. R. Bett, Cryogenios 14, 361 (1974).

3. J. R. Horak and T. H. Blewitt, "Isocronal Recovery of Fast Neutron Irradiated Metals," J. Nucl. Mater., 49, 161 (1973/74).

4. E. Seibt, "Irradiation and Annealing Effects of Deuteron Irradiation NbTi and $V_{3} G a$ Multifilamentary Composite Wires at Low Temperature," IEEE Transactions on Magnetics, Vol. MAG-11, No. 2, p. 174 (1974).

5. R. P. Smith, personal communication, Argonne National Laboratory (1979).

6. R. R. Coltman, Jr., et al., "Effects of Radiation at $5 \mathrm{k}$ on Organic Insulators for Superconducting Magnets," Proc. 8th Symp. on Engineering Problems of Fusion Research, Vol. III, p. 1694 (1979).

7. "ANISN-ORNL: Multigroup One-Dimensional Discrete Ordinates Transport Code with Anisotropic Scattering," Oak Ridge National Laboratory, RSIC/CCC-254 (1973).

8. R. W. Roussin, et al., "VITAMIN-C: The CTR Processed Multigroup Cross Section Library for Neutronics Studies," Oak Ridge National Laboratory ORNL/RSIC-37 (ENDF-296) (1980).

9. Y. Gohar and M. Abdou, "MACKLIB-IV: A Library of Nuclear Response Functions Generated with the MACK-IV Computer Program from ENDF/B IV," Argonne National Laboratory, ANL/FPP/TM-106 (1978).

10. D. Garken (compiler), "ENDF/B Summary Documentation," Brookhaven National Laboratory, BNL-17541 (1975).

11. C. C. Baker, "The Impact of Alternate Fusion Fuels on Fusion Reactor Technology - An Initial Assessment Study," Argonne National Laboratory, ANL/FPP/TM-128 (1979).

12. J. Jung and M. Abdou, "Importance of Shield Design in Minimizing Radioactive Materlal Inventory in Tokamaks, " to be published in the Proc. of the 4th ANS Topical Meeting on the Technology of Controlled Nuclear Fusion (October, 1980). 
13. c. C. Baker, et al., "STARFIRE - A Commercial Tokamak Fusion Power Plant Study," Argonne National Laboratory, ANL/FPP-80-1 (1980).

14. "Kobe Steel's Non-magnetic Steel Plate NONMAGNE-30," No. A-78B20, Kobe Steel, Ltd., Kakogawa Works, Japan (1979).

15. C. M. Lederer and V. S. Shirley, eds., Table of Isotopes, 7th ed., John Wiley and Sons, Inc., New York (1978).

16. F. S. L. Hsu and J. E. Kunzler, "Magnetoresistance Probe for Measuring Magnetic Field Intensity in a Small Space," Rev. Sci. Instr. 34, 297 (1963).

17. E. S. Fisher, et al., "Effects of Cyclic Strains on Transport Properties of a Superconducting Composite: Phase 1, Degradation of Electrical Conductivity in Copper at $4.2^{\circ} \mathrm{C}$," Argonne National Laboratory, ANL-77-50 (1977).

18. B. S. Brown, et a1., "Low-Temperature Fast-Neutron Radiation Damage

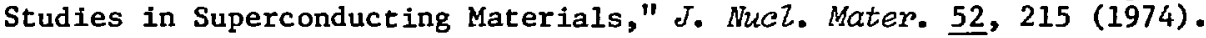

19. M. A. Abdou, "Radiation Considerations for Superconducting Fusion Magnets," Argonne National Laboratory, ANL/FPP/TM-92 (1977).

20. D. M. Parkin and A. R. Sweedler, "Neutron Irradiation of $\mathrm{Nb}_{3} \mathrm{Sn}$ and NbTi Multifilamentary Composites," IEEE Transactions or Magnetics, MAG-11, No. 2, p. 166 (1974).

21. M. Soell, "The Influence of Low Temperature Neutron Irradiation on the Properties of Hard Superconductors," Proc. of the 8th Symposium on Fusion Technology, The Netherlands, p. 965 (1974).

22. H. Ullmair, "Radiation Damage in CTR Magnet Component," Proc. of the International Conf. on Radiation Effects and Tritium Technology for Fusion Reactors, CoNF-750989, Vol.-II, Tennessee, p. II-403 (1975).

23. J. L. Morning, et al., "Chromium: Mineral Commodity Profiles MCP-10," the Bureau of Mines, U.S. Department of the Interior (1978).

24. B. Petkof, "Beryllium: Mineral Commodity Profiles," the Bureau of Mines, U.S. Department of the Interior (1978).

25. D. L. Smith, et al., "Fusion Reactor Blanket/Shield Design Study," Argonne National Laboratory, ANL/FPP-79-1 (1979).

26. R. E. Gold, et al., "Technical Assessment of Vanadium-Base Alloys for Fusion Reactor Applications," Vol. 2, C00-4540-1 (1978).

27. L. H. Rovner, "Fusion Reactor Studies: Potential for Low-Z Materials on the First Wall," Electric Power Research Institute, EPRI 115-2 (1975).

28. Y. S. Touloukian, ed., Thermophysical Properties of High Temperature Solid Materials, MacMillian Company, New York (1976). 
29. Engineering Properties of Selected Ceramics, Vol. 1, Nitrides, Battelle Columbus Laboratories, MCIL-HB-07 (1976).

30. R. J. Price, J. Nuct. Mater. 33, 17 (1969).

31. R. B. Mathews, J. Nucl. Mater. 51, 203 (1974).

32. W. M. Stacey, Jr., et al., "Tokamak Experimenta1 Power Reactor Conceptua1 Design," Argonne National Laboratory, ANL/CTR-76-3 (1976).

33. D. L. Smith, J. Nucl. Mater. 75, 20 (1978).

34. D. L. Smith, Proc. Workshop on Sputtering Caused by Plasma Surface Interactions, CONF-79-07-75 (1979).

35. J. Roth, et al., "Data on Low Energy Light Ion Sputtering," Max-Planck Institut fur Plasmaphysik, IPP 9/26 (1979).

36. C. Boley, private communication.

37. D. Corson and P. Lovain, Introduction to Electromagnetic Fields and Waves, W. H. Freeman and Co., San Francisco (1962).

38. D. L. Smith and I. Charak, "Thermal Responses of Tokamak First-Wall During Cyclic 'lasma Burns," Proc. 7th Symposoium on Engineering Problems of Fusion Research, Knoxville, IEE Publication No. 77CH1267-4-NPS p. 1465 (1977).

39. J. A. Fillo, "First Wall Thermal Hydraulic Models for Fusion Blankets," ASME Paper No. 80-HT-51 (1980).

40. R. J. Onega, W. R. Becraft and E. A. Kukełlka, "The Thermal Consequences to the First Wall of a Deuterium-Tritium-Fueled Tokamak due to a Major Plasma Disruption," Nucl. Eng. Design, 75, 243-257 (1980).

41. L. L. Leobel and W. G. Wolfer, "Evaporation Under Intense Energy Deposition," University of Wisconsin, UWFDM-370, (1980). 
Blank

$3 \cdot 38$ 


\subsection{Magnet Design Studies}

The magnets for a D-D tokamak reactor will likely be larger in size and of a higher magnetic field than those of a D-T reactor. Thus their design is, in general, an extrapolation beyond the magnets of D-T reactor design studies. It should be noted that the magnets of a $\mathrm{D}-\mathrm{C}$ design are themselves an extrapolation from existing superconducting magnets. However, with the successful completion of the Large Coil Project and the 12 Tesla Coil Development Program and with the testing of the magnets for the Fusion Engineering Device or a similar facility, the extrapolation of toroidal field coils to a D-T reactor or beyond to a D-D reactor will be put on a firm footing. on the other hand, as pointed out by the INTOR study, (1) the status of the world program for the development of fast-pulsed superconducting coils, suck as the ohmic heating (OH) coils and equilibrium field (EF) coils, is less adequate.

\subsection{Ohnic Heating Coil System}

The $\mathrm{OH}$ coil system, perhaps more properly called the current induction coil system, induces and maintains the plasma current. If noninductive plasma current drive concepts are developed, then the requirements on the $\mathrm{OH}$ system can be significantly reduced. During the first phase of this D-D reactor study, both pulsed operation and steady-state current drive operation have beein considered. The rest of this section describes the requirements for an OH coil system for pulsed operation without noninductive current drive.

The $\mathrm{OH}$ coil system consists of a central solenoid and several other circular coils, all located outside the toroidal field (TF) coils. The total flux swing required of the $\mathrm{OH}$ coil system is determined from the required inductive volt seconds, the required resistive volt seconds, and the contribution of the EF coil system. The flux swing is given by the product of the effective area within the solenoid and the average field swing, $\Delta \mathrm{B}_{\mathrm{OH}}$, in the solenoid. The area within the solenoid, $33 \mathrm{~m}^{2}$, permits a flux swing of $500 \mathrm{~V}-\mathrm{s}$ for the reference design with a field swing, $\Delta \mathrm{B}_{\mathrm{OH}}=15.2 \mathrm{~T}$, which is achievable with a field reversal from -7.6 to $+7.6 \mathrm{~T}$. Such fields probably are achievable with cabled conductors made of NbTi and copper.

The $\mathrm{OH}$ coils are located outside the TF coil system so that the winding can be arranged to minimize the ac superconducting field on the TF coll. Since the $\mathrm{OH}$ coil is at full negative value before the onset of plasma startup, the 
OH coll windings must also be distributed so that the field produced by the $\mathrm{OH}$ coils in the plasma is less than $10 \mathrm{G}$ or so. This requirement must be fulfilled in order to guarantee a stable startup. Considerations for coil locations are similar to those of the ANL experimental power reactor (EPR) designs. (2,3) The system consists of a central solenoid (\#1), three coils outward and upward from the top of the solenoid ( $\$ 2, \# 3, \# 4)$, a coil above the top

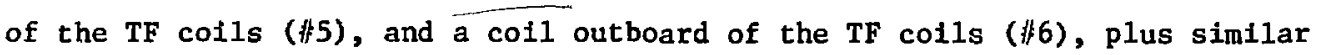
coils below the midplane of the reactor. The solenoid supplies the required flux change linked by the plasma, and the other coils cancel any field in the plasma region due to the solenoid. In particular, coils $\$ 2$, 非, and $\$ 4$ reduce the large field gradient at the inner side of the plasma from the solenoid alone; coil \#5 cancels the linear field gradient. from the solenoid across the plasma; and coil $\$ 6$ cancels the nearly uniform field across the plasma due to the other coils. An approximate method of determining the $\mathrm{OH}$ coil locations and currents is described in Appendix $\mathrm{H}$ of Ref. 4. The coil locations and currents found from the approximate method have been found to provide zero field throughout the plasma within an RMS error of $2 \times 10^{-4}$ relative to the EF field.

The locations of the coil centerlines and the individual coil currents are listed in Table 4-1. The coils are also shown in the cross-sectional view in F'ig. 2-5. The stored energy in the $\mathrm{OH}$ system is a maximum of $20 \mathrm{GJ}$.

Table 4-1. OH Coil Locations and Currents

\begin{tabular}{cccc}
\hline Coil \# & Radial Position & $\begin{array}{c}\text { Axial Position } \\
(\mathrm{m})\end{array}$ & $\begin{array}{c}\text { Current }^{*} \\
\text { (MAT) }\end{array}$ \\
\hline 1 & 3.23 & \pm 4.25 & -58.48 \\
2 & 3.73 & \pm 8.65 & -3.44 \\
3 & 4.23 & \pm 8.95 & -3.44 \\
4 & 4.73 & \pm 9.25 & -3.44 \\
5 & 8.05 & \pm 10.08 & -4.27 \\
6 & 16.23 & \pm 5.33 & -1.54 \\
\hline
\end{tabular}

* The sign is relative to the plasma current. 
Coil \#1, the central solenoid, has a thickness of $0.5 \mathrm{~m}$ (extending from $2.98 \mathrm{~m}$ to $3.48 \mathrm{~m}$ ) and $a$ half-height of $8.5 \mathrm{~m}$. The other colls are sized to have a current density of $18 \mathrm{MA} / \mathrm{m}^{2}$.

\subsection{Equilibrium Field Coil System}

The EF coils provide the bulk of the equilibrium field necessary to keep the plasma positioned in the vacuum chamber with the desired cross-sectional shape and pressure and current distributions. These coils are outside of the TF coils in order to ease the assembly, maintenance, and reliability of the coils, even though this means larger coil currents and stored r nergy.

The required equilibrium field can be determined from the MHD calculations discussed in Secs. 2.1 and 2.2.1. (This required field is the total field of the equilibrium minus the field of the plasma current alone.) The EF coils must produce this required field to a reasonable level of accuracy. In order to do this a tentative set of $\mathrm{EF}$ coil locations is chosen and the currents in the coils are calculated so as to make a least squares fit to the external field calculated from the MHD equilibrium. The energy of the $\mathrm{EF}$ system is simultaneously minimized to the extent that the error of the least squares fit does not exceed an RMS value of $3 \times 10^{-4}$. (This value has been found from experience to adequately reproduce the equilibrium and the plasma boundary shape.) The method is described in detail in Ref. 5. The coil locations can then be chosen to be those which have the lowest stored energy for the given accuracy of $f i t$, subject to any engineering restrictions on the coil placement. The method can be further constrained to determine currents such that the EF and the OH systems are decoupled; that is, the mutual inductance, $\mathrm{M}_{\mathrm{EF}-\mathrm{OH}}$, is negligibly small. The EF and $\mathrm{OH}$ coils are approximately $1 \mathrm{~m}$ from the $\mathrm{TF}$ coils in order to reduce eddy current losses and stray fields which would effectively lower the usable peak field in the TF coils and to reduce out-of-plane forces.

The OH system provides $500 \mathrm{~V}-\mathrm{s}$ to the plasma, and the EF system provides an additional $195 \mathrm{~V}-\mathrm{s}$. The inductive flux necessary to induce the plasma current for the reference design is $500 \mathrm{~V}-\mathrm{s}$, leaving $195 \mathrm{~V}-\mathrm{s}$ to maintain the plasma current against resistive losses. The EF system has a maximum stored energy of 22 GJ with 67 MAT total current. The EF coil locations and currents are shown in Table 4-2. 
Table 4-2. EF Coil Locations and Currents

\begin{tabular}{cccc}
\hline Coil \# & $\begin{array}{c}\text { Radial Position } \\
(\mathrm{m})\end{array}$ & $\begin{array}{c}\text { Vertical Position } \\
(\mathrm{m})\end{array}$ & $\begin{array}{c}\text { Current }^{*} \\
\text { (MAT) }\end{array}$ \\
\hline 1 & 4.20 & \pm 8.00 & 10.85 \\
2 & 4.80 & \pm 8.60 & 6.42 \\
3 & 15.09 & \pm 5.79 & -7.47 \\
4 & 16.66 & \pm 2.04 & -8.67 \\
\hline
\end{tabular}

* The sign is relative to the plasma current.

\subsection{Toroidal Field Coil System}

The primary differences between the TF coils for a D-D tokamak reactor and those for a D-T tokamak reactor are the larger size and higher field typically required for the $D-D$ reactor. These in turn make conductor design and support more difficult than for a D-T reactor. Parameters for the TF coils for the reference design appear in Table 4-3.

\section{Table 4-3. Parameters for TF Magnets}

\begin{tabular}{|c|c|}
\hline Number of coils & 12 \\
\hline Total ampere turns & 360 MA-turns \\
\hline Total stored energy & $250 \mathrm{GJ}$ \\
\hline Total inductance & $490 \mathrm{H}$ \\
\hline \multicolumn{2}{|l|}{ Peak field: } \\
\hline $\begin{array}{l}\text { design } \\
\text { operational }\end{array}$ & $\begin{array}{l}15 \mathrm{~T} \\
14 \mathrm{~T}\end{array}$ \\
\hline Current & $32 \mathrm{kA}$ \\
\hline $\begin{array}{l}\text { Average conductor current } \\
\text { density }\end{array}$ & $3000 \mathrm{~A} / \mathrm{cm}^{2}$ \\
\hline $\begin{array}{l}\text { Ay ige overall current } \\
\text { density }\end{array}$ & $850 \mathrm{~A} / \mathrm{cm}^{2}$ \\
\hline Coil cooling & Liquid He Bath, $4.2 \mathrm{~K}$ \\
\hline \multicolumn{2}{|l|}{ Conductor: } \\
\hline $\begin{array}{l}\text { superconductor } \\
\text { stabilizer } \\
\text { configuration }\end{array}$ & $\begin{array}{l}\mathrm{Nb}_{3} \mathrm{Sn}, \mathrm{NbTi} \\
\text { Copper } \\
\text { Cable }\end{array}$ \\
\hline Structural material & Austenitic SS \\
\hline
\end{tabular}


The cross section of an inner leg of a TF coil is shown in Fig. 4-1. Each coil contains 940 pancake wound turns.

\subsubsection{Choice of Peak Toroidal Field}

Since the reactor thermal power is proportional to the fourth power of the toroidal field, a high field is desirable. However, increasing the field causes an increase in the cost and size of the TF coils, and especially an increase in the amount of support material required. In particular, the coil thickness increases rapidly with field, leading either to an unacceptable shrinking of the area within the $\mathrm{OH}$ solenoid or to an increase in the plasma major radius with a consequent increase in the overall size of the reactor.

A study of the effect of varying the toroidal field was caried ouc using the ANL TF coil model. $(6,7)$ The values of several TF coil system parameters for fields of $14 \mathrm{~T}, 15 \mathrm{~T}$, and $16 \mathrm{~T}$ are shown in Table 4-4. In each case, a major radius of $9.0 \mathrm{~m}$ and aspect ratio of 3.0 were assumed. The values predicted for the STARFIRE D-T reactor study ${ }^{(4)}$ (which are in good agreement with those actually adopted for the STARFIRE TF coils system ${ }^{(8)}$ ) also appear in Table 4-4 for comparison.

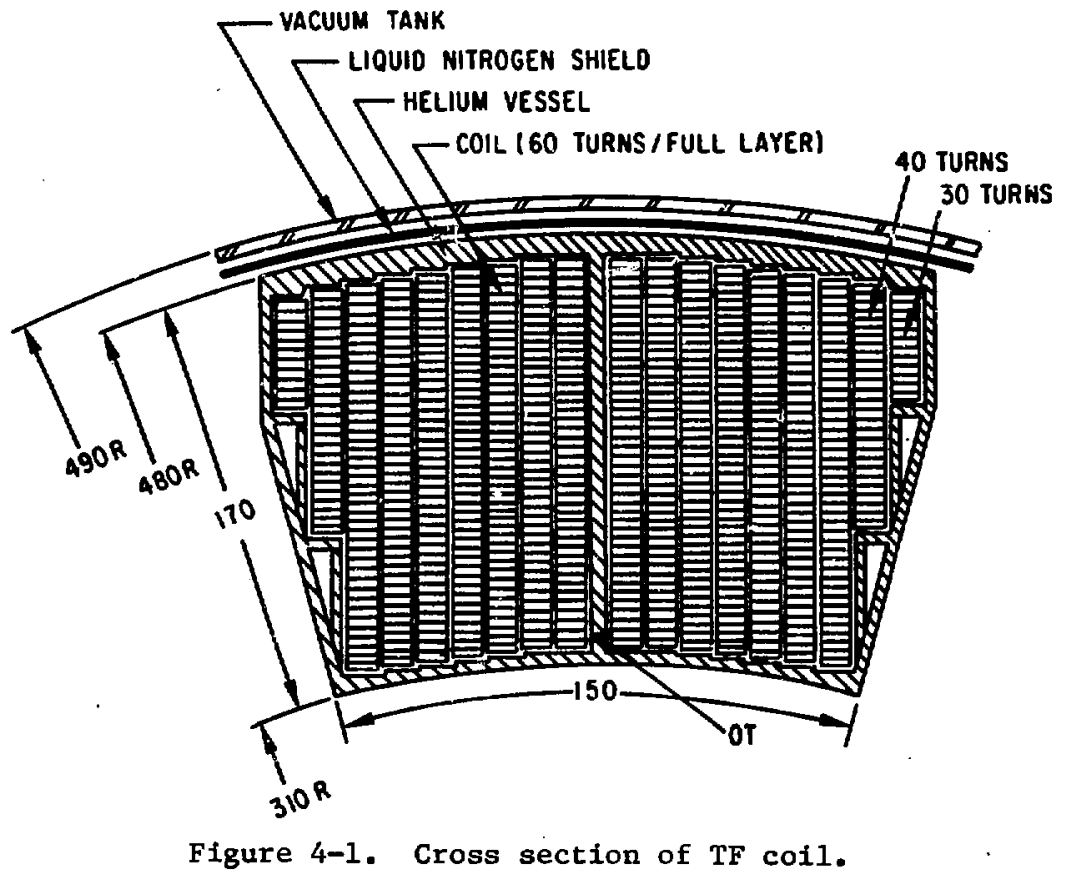


Table 4-4. Comparison of TF Coil Parameters for Different Peak Field Values, as Predicted by the TF Coil Model

\begin{tabular}{lcccc}
\hline Parameter & STARFIRE & $14 \mathrm{~T}$ & $15 \mathrm{~T}$ & $16 \mathrm{~T}$ \\
\hline $\begin{array}{l}\text { Design Peak Field (T) } \\
\text { Coil Thickness (m) }\end{array}$ & 11 & 14 & 15 & 16 \\
Stored Energy (GJ) & 6.91 & 1.48 & 1.70 & 1.94 \\
$\begin{array}{l}\text { Copper Stabilizer } \\
\quad\left(10^{3} \text { metric ton) }\right.\end{array}$ & 2.05 & 4.57 & 5.15 & 5.79 \\
$\begin{array}{l}\text { Stainless Steel Support } \\
\text { Material (10 } \\
\text { ton) }\end{array}$ & 1.59 & 5.06 & 5.94 & 6.92 \\
$\begin{array}{l}\text { OH Flux Swing with } \\
\Delta \mathrm{B} \text { OH = 16 T (V) }\end{array}$ & 266 & 267 & 177 & 91 \\
\end{tabular}

The choice of operational peak was made based on considerations of the advantages of high field vs. the accompanying disadvantage of large size and cost. The toroidal coils have been designed for a maximum field of $15 \mathrm{~T}$ with operation expected to be at $14 \mathrm{~T}$.

\subsubsection{Conductor}

A three leve1, unsoldered, uninsulated "Rutherford" cable has been chosen as the conductor. Four grades of conductor, two employing $\mathrm{Nb}_{3} \mathrm{Sn}$ (11-15 $\mathrm{T}$ and 8-11 $\mathrm{T}$ ) and two employing NbTi (5-8 $\mathrm{T}$ and 0-5 $\mathrm{T}$ ) are envisioned. However, no attempt has been made to optimize the grading; a different grading scheme, perhaps employing six grades, might result in considerable savings of space and material.

From dimensional considerations, the $\mathrm{Nb}_{3} \mathrm{Sn}$ cable was chosen to consist of sixteen 2000 A cables, and the NbTi cable was chosen to consist of twenty 1600 A cables. Each cable consists of six subcables surrounding a central copper subcable. 
In the highest field grade (11-15 T) cable, each subcable consists of six $\mathrm{Nb}_{3} \mathrm{Sn}-\mathrm{Cu}$ composite strands about a $\mathrm{Cu}$ strand (see $\mathrm{Fig}$. 4-2). In the other $\mathrm{Nb}_{3} \mathrm{Sn}$ cable, only three of the substrands are composite. The 5-8 T grade cable also has three composite substrands, in this case NbTi-Cu composite. The low-field grade $(0-5 \mathrm{~T})$ cable has six $\mathrm{Cu}$ strands about a NbTi-Cu composite strand (see Fig. 4-3).

A cabled design was chosen to simplify conductor fabrication, to minimize ac losses from the poloidal fieid system and/or plasma disruptions, to maximize wetted perimeter for cryostability, and to minimize longitudinal strain in the $\mathrm{Nb}_{3} \mathrm{Sn}$ composite. The $\mathrm{Nb}_{3} \mathrm{Sn}$ is reacted after conductor cabling but before coil fabrication.

This design is extrapolated from the conductor design for the STARFIRE reactor study, ${ }^{(8)}$ which in turn is related to the GA/MCA design for the ETF (Engineering Test Facility) $12 \mathrm{~T}$ coil development program. (9) The GE/IGC conductor design, (10) which also consists of $\mathrm{Nb}_{3} \mathrm{Sn}-\mathrm{Cu}$ cables individually housed in a stainless steel support structure with graded radial support, might also be extrapolated to $14 \mathrm{~T}$ operation.

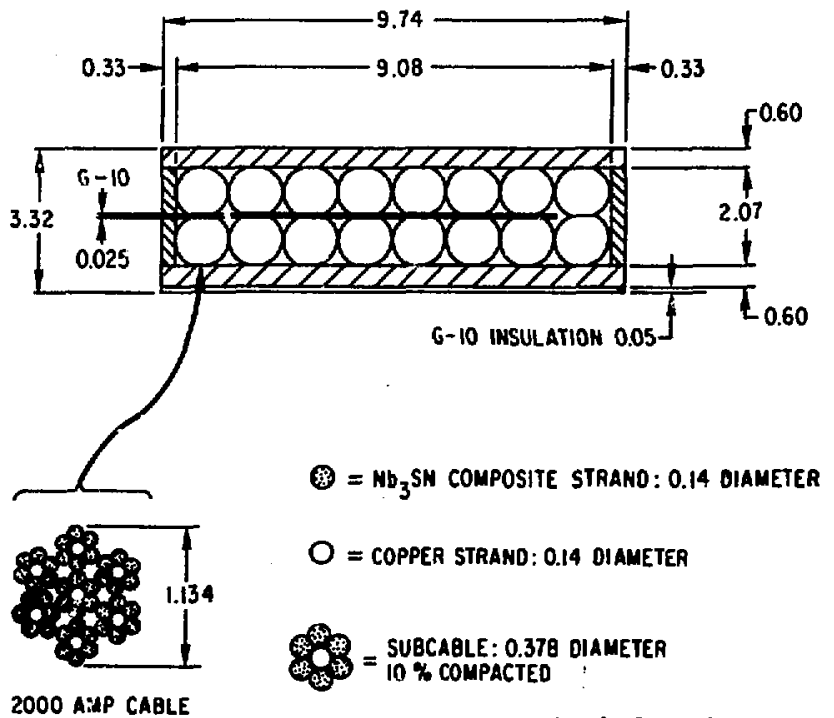

ALL OIMENSIONS IN cm

FIgure 4-2. High field grade (11-15 T) conductor and support. 


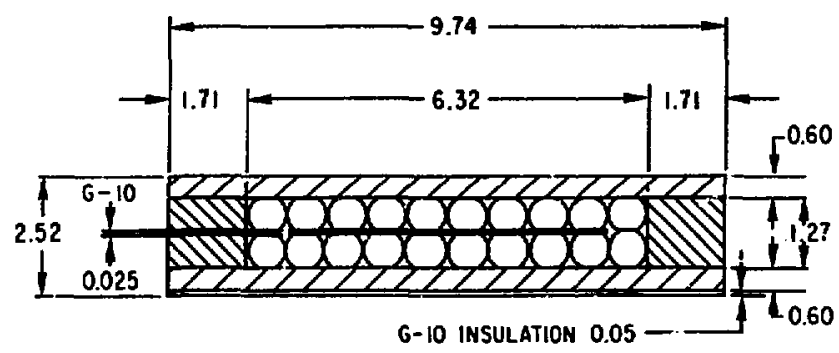

ALL DIMENSIONS IN cm

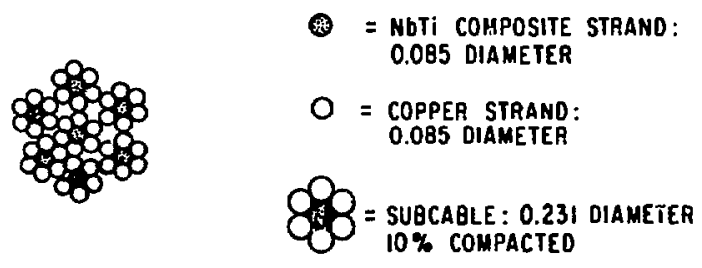

Figure 4-3. Low field grade $(0-5 \mathrm{~T})$ conductor and support.

\subsubsection{Conductor Support}

In a cable conductor design, the copper stabilizer contributes very little to supporting the hoop stress arising from the magnetic forces the TF coill system exerts upon itself. Moreover, in the region of the inner leg, the cable should not have to support the radial forces, lest the cable be compressed and the surface contact with helfum coolant be reduced. Consequently, the conductor is surrounded by a support frame made of stainless steel strips, which carry almost all the hoop and radfal forces generated in the coil. This support frame appears in Figs. 4-2 and 4-3. It is designed for a combined stress of $550 \mathrm{MN} / \mathrm{m}^{2}(80,000 \mathrm{psi})$.

In the curved portion of the coil each support frame generally carries the tension of its conductor, and radial loads are low. In the straight inner leg porition the radial force accumulates radially inward, away from the plasma region. Thus, the radial load is largest and the most stainless steel support material is needed in the turns where the toroidal field is lowest and where the least copper stabilizer and superconductor are needed. 
As can be seen from Figs. 4-2 and 4-3, this permits the overall width of the conductor and support package to be uniform across the coil, as it must be for a pancake-wound coil.

The High-Field Compact Tokamak Reactor (HFCTR) ${ }^{(11)}$ design features an external reinforcing structure to support the TF coils from outside. Such a structure could be desirable for the $D-D$ reactor for two reasons:

(1) There would be no supporting structure at the straight inner leg of the TF coils. Thus, the overall coil thickness in that region would be reduced, and more area would be available for the ohmic heating $(\mathrm{OH})$ flux.

(2) If the conductor were concentrated on the inner side (nearer the plasma) and the support material sere concentrated over the outer, curved portion of the TF coils, then the external equilibrium field coils could be brought closer to the TF coils without exerting large superimposing magnetic fields and ac losses on the TF coil conductor.

Unfortunately, more careful consideration of the forces for the D-D reactor reference design showed that the radial support strips needed to carry the radial loads in the inner leg region and the transverse strips, needed to keep each cab?e from distorting under those radial loads comprised almost all of the support needed against coil tension. Thus very little of the support material could be transferred from the conductor region to an external reinforcing structure, and such a structure would not be useful for this design. The amount of superconductor, copper stabilizer and conductor support material is shown in Table 4-5.

Table 4-5. Material in TF Coils (metric tons)

$\mathrm{Nb}_{3} \mathrm{Sn}$

NbTi 74

Copper 5100

Stainless Steel (conductor Bupport) 5900 


\subsubsection{Cooling}

The TF coils are bath cooled by liquid helium at $4.2 \mathrm{~K}$. Passages through the insulation between the cable and the support frame, through the support frame itself, and through the insulation between the support frames of neighboring turns and neighboring pancakes, permit the free passage of liquid helium and helium vapor.

\section{References}

1. INTOR Group, "Internationa1 Tokamak Reactor," Nucl. Fusion 20, 349-388 (1980).

2. L. R. Turner, S. T. Wang, J. R. Purce11, "Superconducting Ohmic-Heating Coils for the Argonne TEPR Design Study," Proc. 6th Symposium on Engineering Problems of Fusion Research, San Diego, pp. 1089-1092, (1975).

3. L. R. Turner, S. T. Wang, S. H. Kim, Y. C. Huang, and R. P. Smith, "Superconducting Magnet Systems for the ANL EPR Design," Proc. 7th Symposium on Engineering Problems of Fusion Research, Knoxville, Pp. 746-750 (1977).

4. C. C. Baker, et al., "STARFIRE - Commercial Tokamak Fusion Power Plant Study," Argonne National Laboratory, ANL/FPP-80-1 (1980).

5. K. Evans, Jr., D. A. Ehst, and P. Messerschnidt, "Equilibrium Field Coil Considerations for Tokamak Reactors," Proc. 3rd Topical Meeting on the Technology of Controlled Nuclear Fusion, ANS Pub. No. CONF-780508, Vol. 2, p. 1084 (1978).

6. L. R. Turner and M. A. Abdou, "Computational Model for Superconducting Toroidal-Field Magnets for a Tokamak Reactor," Proc. 7th Symposium on Engineering Problems of Fusion Research, Knoxville, pp. 762-766 (1977).

7. L. R. Turner and M. A. Abdou, "Computational Model for Superconducting Toroidal-Field Magnets for a Tokamak Reactor," Argonne National Laboratory, ANL/FPP/TM-88 (1977).

8. J. S. Alcorn, L. R. Turner, and S. T. Wang, "Superconducting Toroidal Field Coil System for STARFIRE," Fourth ANS Topical Meeting on the Technology of Controlled Nuclear Fusion, King of Prussia, Pennsylvania (1980).

9. J. S. Alcorn, J. R. Purce11, W. Y. Chen, Y-H. Hsu, "Status of the GA/MCA 12 Tesla Coil Development Program," 1980 Applied Superconductivity. Conference, Santa Fe, New Mexico (1980).

10. J. P. Helnrich, et al., "Scoping Study of a 12 T Toroidal Field Coil for the Fusion Engineering Test Factlity," ibid. 
11. D. R. Cohn, et al., "High Field Compact Tokamak Reactcr (HFCTR) Conceptual Design," MIT Plasma Fusion Center, RR-78-2 (1978). 
Blank

$4-12$ 


\subsection{Tritium/Fuel/Vacuum Considerations for the D-D Design}

A catalyzed D-D reactor burns large quantities of tritium and ${ }^{3}$ he, both of which are produced in the plasma by $D-D$ fusion reactions. The tritium exhaust handled by the impurity controi system is reduced from that in a D-T reactor, but tritium reprocessing systems are still necessary to purify and recycle the tritiun exhaust. Tritiuin breeding and associated processing systems are not used in the $D-D$ reactor. The general tritium handing philosophy presented in the STARFIRE D-T design (1) is applicable for the D-D design and is necessary in order to ensure both worker and public safety.

The impurity control system for the D-D design handles a somewhat larger gas load than does a typical D-T reactor; therefore; the vacuum system has to be appropriately larger. In addition, reprocessing systems have to be provided-which purify and isotopically enrich the deuterium and the reinjected ${ }^{3} \mathrm{He}$ and remove the protium and ${ }^{4} \mathrm{He}$.

The fuel handling and reprocessing systems for the D-D design are presented and compared to those in the STARFIRE D-T design. Both designs use a limiter/vacuum system for impurity control, utilizing a high recycling of the deuterium and tritium with a consequently high fractional burnup.

\subsection{Fuel Cycle}

A schematic of the fuel reprocessing cycle for the $D-D$ reactor is shown in Fig. 5-1. The exhaust from the plasma is removed with compound cryopumps which are part of the 1 imiter/vacuun system. Ufon regeneration of the vacuum pumps, the fuel is processed for chemical purification, isotopic enrichment, storage, and refueling. The chemical purification subsystem is designed to remove all condensible impurities $\left(C D_{x}, D_{2} O, N_{2}\right.$, etc.). The helium is separated from the $D_{2}$ fuel by a falling film condenser, after which the helium is isotopically enriched by means of cryogenic distillation. (1-3) Separation. factors for helium are reportedly higher than those for the cryogenic distillation of hydrogen isotopes. (4) The hydrogen isotopes are separated by means of cryogenic distillation at $\approx 20 \mathrm{~K}$. The protium waste stream is primarily $\mathrm{HD}$; the fuel stream can consist of $\mathrm{D}_{2} / \mathrm{D}-\mathrm{T}$ or separate $\mathrm{D}_{2}, \mathrm{~T}_{2}$ streams depending on fueling requirements. The components of the fuel ceprocessing cycle are quite similar to those in a D-T fuel processing cycle (Fig. 5-2) with the additional feature of isotopic enrichment of helium. 


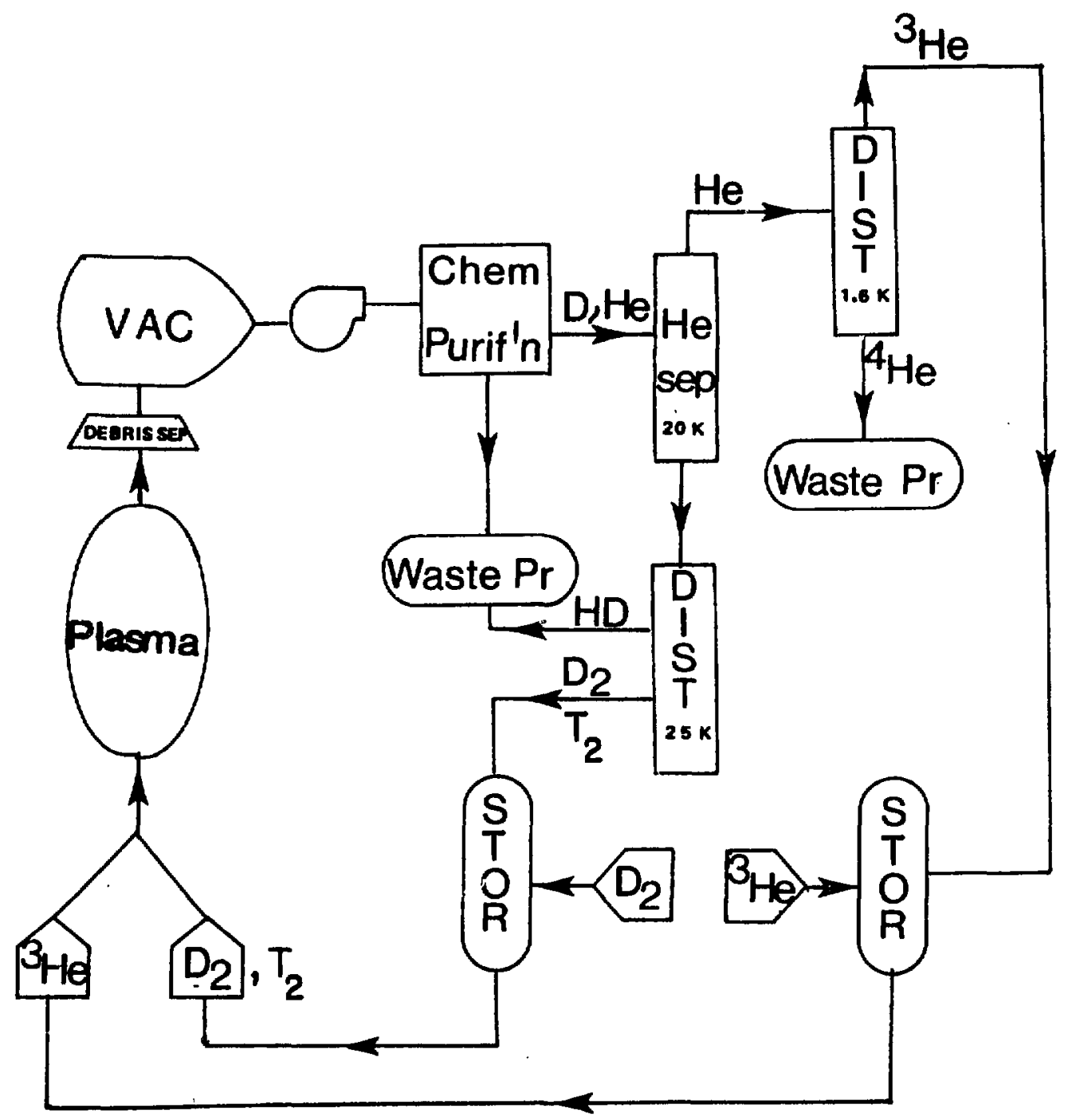

Figure 5-1. Fuel processing cycle for catalyzed D-D. 


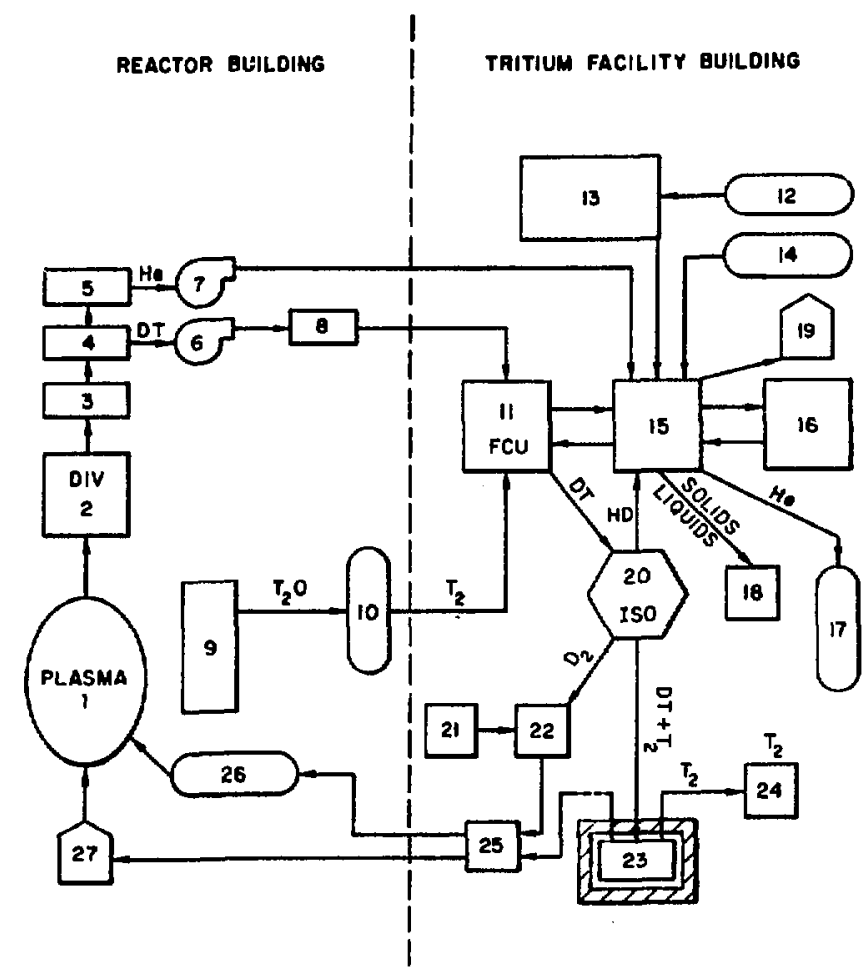

1. Plasma Chamber

15. Tritiated Waste Treatment

2. Limiter Plates

16. Tritiated Water Recovery Unit

3. Debris Separator

4. D-T Cryocondensation Pump

5. Helium Pump

6,7. Regeneration Pumps

8. Metal Bellows Pumps

9. Breeder Blanket

10. Electrolysis Unit

17. Helium (tritium-free)

18. Tritiated Waste -- Liquids and Solids

19. Detritiated Gases: $\mathrm{N}_{2}, \mathrm{O}_{2}$, $\mathrm{CO}_{2}$, Ar

20. Isotopic Separation Unit

11. Fuel cleanup Uit

12. Tertlary Enclosures

21. $\mathrm{D}_{2}$ Supply

22. $\mathrm{D}_{2}$ Storage

23. $\mathrm{DT}$ and $\mathrm{T}_{2}$ Storage

13. Atmospheric Tritium Recovery System

24. $T_{2}$ Shipment/Receiving

25. Fuel Blender

14. Secondary Enclosures, Purge

26. Gas Fueling Streams

27. Pellet Fueler

Figure 5-2. Tritium facility scenario for D-T reactor. 
Mass flow rates in the fuel reprocessing cycle have been determined for both the reference $D-D$ and the STARFIRE $D-T$ design. They are presented in Table 5-1. For the D-D system the fractional burnup for deuterium is 0.17; for tritium it is 0.87 . Each day $2.4 \mathrm{~kg}$ of deuterium, $1.0 \mathrm{~kg}$ of ${ }^{3} \mathrm{He}, 0.3 \mathrm{~kg}$ of

${ }^{4} \mathrm{He}, 80 \mathrm{~g}$ of protium, and $17 \mathrm{~g}$ of tritium are exhausted. In addition, $2.9 \mathrm{~kg}$ of deuterium, $1.0 \mathrm{~kg}$ of ${ }^{3} \mathrm{He}$, and $17 \mathrm{~g}$ of tritium are injected into the plasma by the fueling system.

\subsection{Fuel Reprocessing, Fuel Supply, and Tritium Safety}

Tritium inventories, shown in Table 5-2, are determined on the basis of the mass flow rates shown in Table 5-1. The "vulnerable" inventory is that portion of the tritium which is located in the reactor building. Tritium physically located in the separate fuel reprocessing building or in the

Table 5-1. Fue1 Systern Parameters for the Cat-D-D Reactor and the STARFIRE D-T Reactor

\begin{tabular}{|c|c|c|}
\hline & $\mathrm{D}-\mathrm{D}$ & $\mathrm{D}-\mathrm{T}$ \\
\hline \multicolumn{3}{|l|}{ Plant and Plasma Parameters } \\
\hline $\begin{array}{l}\text { Power (MW) } \\
\text { Plant Availability } \\
\text { Ion Density }\left(10^{20} \text { ions/m }{ }^{3}\right) \\
\text { Plasma Volume }\left(\mathrm{m}^{3}\right) \\
\text { Evacuation Volume }\left(\mathrm{m}^{3}\right) \\
\text { Surface Area }\left(\mathrm{m}^{2}\right) \\
\text { Particle Confinement Time (s) } \\
\text { Reflection Coefficient } \\
\text { Fractiona1 Burnup (Deuterium) } \\
\text { Fractional Burnup ('ritium) }\end{array}$ & $\begin{array}{l}2700 \\
0.75 \\
1.66 \\
1850 \\
3990 \\
1250 \\
3.7 \\
0.9 \\
0.17 \\
0.87\end{array}$ & $\begin{array}{l}4000 \\
0.75 \\
0.8 \\
783 \\
950 \\
755 \\
1.8 \\
0.9 \\
0.42 \\
0.42\end{array}$ \\
\hline \multicolumn{3}{|l|}{ Mass Flow Parameters (g) } \\
\hline $\begin{array}{l}\text { Deuterium Burned Per Day } \\
\text { Deuterium Exhausted Per Day } \\
\text { Deuterium Fueled Per Day }\end{array}$ & $\begin{array}{r}482 \\
2390 \\
2872\end{array}$ & $\begin{array}{l}360 \\
506 \\
866\end{array}$ \\
\hline Protium Exhausted Per Day & 79 & 10 \\
\hline He-4 Exhausted Per Day & 319 & 712 \\
\hline $\begin{array}{ll}\text { He-3 } & \text { Burned Per Day } \\
\text { He-3 } & \text { Exhausted Per Day } \\
\text { He-3 } & \text { Fueled Per Day }\end{array}$ & $\begin{array}{l}125 \\
994 \\
994\end{array}$ & $-\infty$ \\
\hline $\begin{array}{l}\text { Tritium Burned Per Day } \\
\text { Tritium Exhausted Per Day } \\
\text { Tritium Fueled Per Day } \\
\text { Tritium Bred Per Day }\end{array}$ & $\begin{array}{r}101 \\
17 \\
17 \\
-\end{array}$ & $\begin{array}{r}536 \\
760 \\
1296 \\
562\end{array}$ \\
\hline
\end{tabular}


Table 5-2. Tritium Inventory (g) for the D-D Reactor and the STARFIRE D-T Reactor

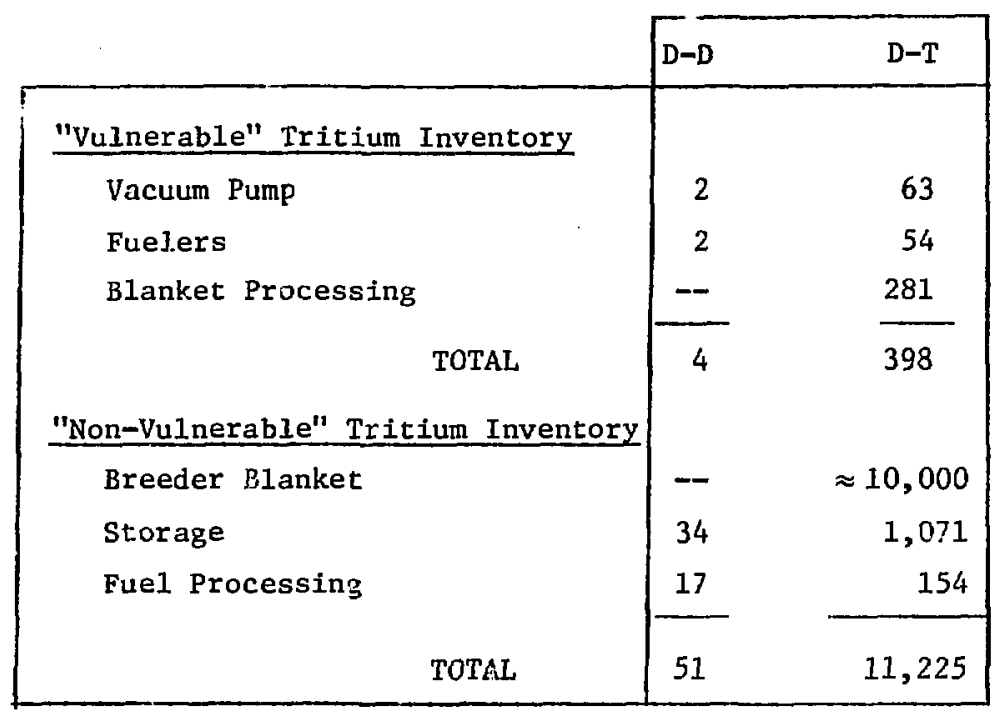

storage area has a much lower potential for release to the environment. For the D-D system, two days of tritium fueling $(34 \mathrm{~g}$ ) is assuned to be in storage: for the STARFIRE D-T system, two days of tritium burnup $(1.1 \mathrm{~kg})$ is in storage. The "non-vulnerable" inventory for the D-D system is approximately two orders of magnitude smaller than that for the $D-T$ reactor. The tritium inventory classiffed as "vulnerable" is also two orders of magnitude smaller than that for the D-T reactor, but since one gram of tritium is equivalent to 9600 Curies, it still represents an important safety concern.

In the D-D design, as in the STARFIRE design, the goal is to contain all tritium releases whether due to normal leakage or to accidental releases within the confines of the plant. To accomplish this, the following safeguards, similar to those used in STARFIRE, are utilized. The outer walls of all potential tritium containing areas are lined with a tritium barrier (stainless steel or aluminum). The materials and equipment used in a tritium area are selected to minimize surface adsorption. Tritium areas are operated at reduced atmospheric pressure to minimize tritium out-leakage. The atmospheric tritiated water (HTO) level in all areas is maintained at $<5 \mu \mathrm{Cl} / \mathrm{m}^{3}$. 
Tritium systems utilize triple containment where reasonable and practical; double containment is used throughout. The number and length of lines used to transport tritium between different buildings are mininized. Multiple, discrete flow paths between units are used to partition the tritium inventory and thus reduce the magnitude of a tritium release. The tritium waste generated is minimized by (1) processing tritiated water, (2) minimizing use of organics, (3) minimizing the contamination of organics where they are functionally necessary, (4) using all metal seals in valves, pumps, etc., and (5) reprocessing tritiated waste. Any waste generated within the plant is packaged in as small a volume as possible. The impact of a tritium release from the coolant system is minimized by: (1) maintaining the tritium inventory in the coolant at levels below $1 \mathrm{Ci} / \rho_{\text {; }}$ (2) minimizing leaks in the primary coolant system; and (3) recovering all tritiated water. Timely decontamination of potential tritium spills within the containment is provided by: (1) dedicating an appropriately sized atmospheric tritium recovery unit (ATR) to each tritium containing area; and (2) interfacing the heating, ventilating, and air conditioning systems with the ATR systems to prevent a tritium release to the outside environment.

Fuel reprocessing and storage are handled in a separate building from the reactor building. This building, designed for contact maintenance, has an air environment and is free of gamma and neutron radiation. All units are under remote, independent computer control; the computer is equipped with an uninterruptible power supply to ensure that all systems can be shut-down in the event of a power failure. All processing units are of modular design to facilitate replacement. Multiple units are provided and full redundancy is built into the fuel reprocessing facility to ensure maximum reliability and availability. The tritium storage area is sited in the fuel reprocessing building. It consists of a shielded area in which an inert cover gas is used for fire protection. Because of the small amount of stored tritium ( $34 \mathrm{~g}$ ), low-pressure gaseous storage in tanks is provided.

The deuterium required for two days fueling $(6 \mathrm{~kg})$ is stored in the fuel reprocessing building. No resource problems are foreseen. 
A kilogram of ${ }^{3} \mathrm{He}$ is required for. initial startup. In addition, a two day fuel supply $(2 \mathrm{~kg})$ is stored in the fuel reprocessing bullding to insure plant operation in the event of a fallure in the fuel reprocessing systems. The cost of producing ${ }^{3} \mathrm{He}$ and its availability are the main reasons for recovering it in the fuel reprocessing system. Potential available U.S. resources of ${ }^{3} \mathrm{He}$ are estimated at $200-500 \mathrm{~kg}$. (4) If the ${ }^{3} \mathrm{He}$ were not recycled, the $D-D$ reference design would consume the U.S. resources in one year. The amount of ${ }^{3} \mathrm{He}$ consumed could be lowered by re-design (see Sec. 2.2.7) but would still amount to a large fraction of the available resources.

\subsection{Vacuum System Analysis}

The total gas load for the $D-D$ system is $44.4 \mathrm{~Pa} \mathrm{~m} / \mathrm{s}$ which is 2.4 times that of the STARFIRE (1) design. As a first approximation, the sizes of the limiter duct, and the plenum region of the D-D design (see Fig. 2-5), are assumed to be approximately the same as in the STARFIRE design. As shown for the STARFIRE limiter/vacuum system, the major impedance in the vacuum design is in the 24 vacuum ducts. Their impedance is twice that of the rest of the vacuum system (limiter duct, plenum, vacuum pumps). The vacuum system for the D-D reactor is designed so that the steady-state pressure in the limiter slot is the same as that in the D-T design. To accomplish this, the vacuum ducts are both decreased in length and increased in diameter to increase the pumping speed at the limiter. The cryopanel surface area in each cryopump has to be increased by a factor of 2.4 to handle the increased helium gas load. The vacuum system parameters for the D-D system are presented in Table 5-3 as are those for the STARFIRE D-T design.

\subsection{Conclusions}

The tritium handing, fuel reprocessing, and vacuum pumping requirements for the Cat-D-D reactor fuel system can be compared to the STARFIRE $\mathrm{D}-\mathrm{T}$ reactor systems. The significant conclusions are:

1. Fuel reprocessing for both are generally similar and present no major technological difficulties. 
Table 5-3. Vacuum System Parameters for the D-D Reactor and the STARFIRE D-T Reactor

\begin{tabular}{|c|c|c|}
\hline & $D-D$ & $D-T$ \\
\hline 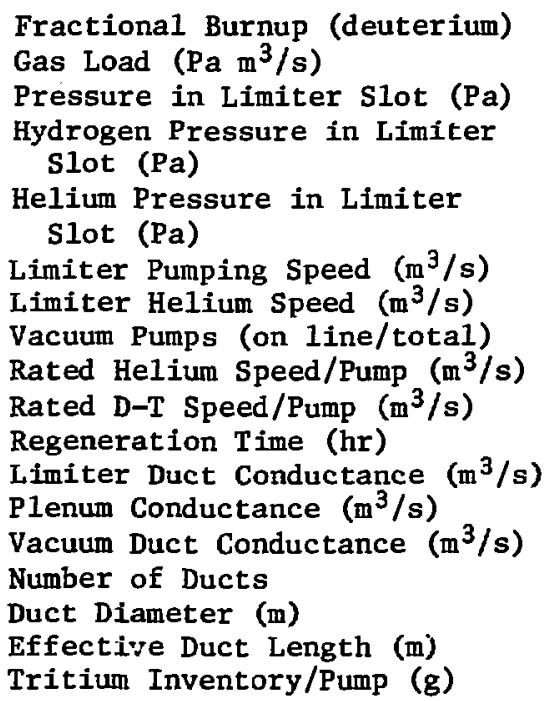 & $\begin{array}{c}0.17 \\
44.4 \\
0.04 \\
0.024 \\
0.016 \\
1110 \\
1110 \\
24 / 48 \\
120 \\
200 \\
2 * \\
4090 * \\
13700 \\
3830 \\
24 \\
1.2 \\
2 \\
0.08\end{array}$ & $\begin{array}{c}480 \\
490 \\
24 / 48 \\
120 \\
200 \\
2 \\
4090 \\
13700 \\
730 \\
24 \\
1 \\
10 \\
2.6\end{array}$ \\
\hline
\end{tabular}

* The assumption is made that the conductances of the components of the D-D 1imiter/vacuum system are equivalent to those of the STARFIRE D-T design.

2. The "vulnerable" tritium inventory is reduced by two orders of magnitud 'a the D D system as compared to the STARFIRE D-T design. This reduces the risk associated with a tritium release.

3. Although the risk is reduced, all of the tritium safety systems required in the $D-T$ design are also required in the $D-D$ design to ensure worker and public safety. 
4. Total tritium and fuel reprocessing costs for a $D-D$ fusion reactor are approximately the same as for a D-T reactor. Vacuum pumping requirements are somewhat higher.

5. Since ${ }^{3} \mathrm{He}$ availability is 1 imited, fuel reprocessing of this fuel is required.

6. The exhaust from the plasma can be adequateig handled by a limiter/ vacuum design using compound cryopumps.

\section{References}

1. C. C. Baker, et al., "STARFIRE - Commercial Tokamak Fusion Power Plant Study," Argonne National Laboratory, ANL/FPP-80-1 (1980).

2. W. R. Wilkes, "Distillation of He Isotopes," Proc, of ICEC-4, Eindhoven, 1972, IPC Science and Technology Press, p. 119-121 (1972).

3. W. R. Wilkes, "3 $\mathrm{He}-{ }^{4} \mathrm{He}$ Distillation Apparatus," Mound Laboratory, MLM-2005, p. 15 (March, 1973).

4. T. Ben Rhinehammer and Layton J. Wittenberg, "An Evaluation of the Fuel Resources and Requirements for the Magnet1c Fusion Energy Program," Mound Laboratory, MLM-2419, p. 102 (Detober, 1978).

5. W. R. Wilkes, Mound Laboratory, private communication. 
Blark

$5-10$ 


\subsection{Summary and Conclusions}

This report has presented the results of studies leading up to an initial design of a tokamak fusion reactor operating on a D-D fuel cycle. The approach has been to make as much use as possible of the beneficial features of a D-D fuel cycle, but not to extrapolate unnecessarily from extensively studied, D-T reactor designs, in particular the STARFIRE commercial reactor design. In this way a fair comparison of the advantages and penalties of a $D-D$ reactor relative to a $D-T$ reactor can be made.

The present report only deals with the studies that have led to a choice of a $D-D$ reactor configuration and some of the initial studies of this reference design. A complete analysis of the reference design and a complete comparison with a D-T reactor will be presented in a future report. For this reason some of the conclusions that are presented here are tentative, but sufficient study has been made to put most of them on a relatively firm basis.

\subsection{General Features}

The choice of the tokamak configuration has been made for essentially the same reasons as it usually is made for a D-T device; that is, the tokamak is closer to reactor viability than any other concept, and it has been studied more than any other concept. The D-D device is very similar to a D-T device: Approximately half of the neutrons produced are $14 \mathrm{MeV}$ neutrons from the D-T reaction, and most of the energy comes from these D-T neutrons. It is in fact largely a D-T reactor operated without tritium fueling. The principal advantages of the D-D reactor arise from the lack of necessity to breed tritium. This feature makes the use of lithium and lithium compounds unnecessary. In addition the blanket/shield can be optimized for reactor power performance rather than for tritium breeding. In particular the inboard section can be made thinner, leading to better utilization of the toroidal magnetic field, and increased neutron energy multiplication can be achleved, leading to a greater power output. The tritium levels in a D-D reactor appear to be as much as two orders of magnitude less than in a comparable D-T reactor. However, there is still sufficient tritium that it is not possible to eliminate any major components of a D-T reactor if worker and public safety is to be assured.

The principal disadvantage of a D-D reactor is that the power production is less. than $5 \%$ of that of a tritiun-fueled reactor for the same 
beta, toroidal field, and physical slze. As a consequence, a D-D reactor must necessarily be substantially larger and/or operate at substantially higher fields or higher plasma betas than a D-T reactor of comparable thermal power. The design of larger devices and higher-field magnets is of course more difficult. Moreover, since the auxilliary systems, such as plasma heating, chrrent drive, magnet power supplies, and vacuum pumping are then typically larger, the parasitic power losses represent a larger fraction of the thermal power resulting in lower efficiency and even further reduced net electric power. It is also possible that the larger energy stored in the plasma may be a more serious problem in the event of a plasma disruption.

A second disadvantage is that a D-D reactor must likely operate at higher temperatures (25 - $30 \mathrm{keV}$ compared to 8 - $10 \mathrm{keV}$ for a typical D-T system). Cyclotron and bremsstrahlung radiation losses both increase with temperature. It is not known if diffusion losses increase or decrease with temperature in these temperature ranges, but there are models such as ripple diffusion and trapped particle modes which show losses increasing strongly with temperature. These factors affect the achievement of ignition. Using the assumptions made in the present study, ignition in a D-D reactor appears to require an order of magnitude larger confinement parameter, $\mathrm{nt}$, and an order of magnitude fewer impurities compared to a D-T reactor.

A third feature of a $D-D$ reactor is that a larger fraction of the power coming out of the plasma is in the form of heat (charged particles or radiation) rather than neutrons. If neutron damage of the first-wall/blanket/ shield system were the limiting factor, this would be an advantage. For the type of design considered in this report (and for STARFIRE), howe ser, the heat load is the limiting factor, and this becomes a disadvantage for a D-D reactor. STARFIRE, for example, supports a total wall load of $3.6 \mathrm{MW} / \mathrm{m}^{2}$ with a heat load of $0.9 \mathrm{MW} / \mathrm{m}^{2}$, while the pulsed version of the reference $D-D$ design is limited to $1.5 \mathrm{MW} / \mathrm{m}^{2}$ with a heat 1 oad of $0.8 \mathrm{MW} / \mathrm{m}^{2}$.

It is especially difflcult to overcome the disadvantage of lower power production, and it would seem that $D-D$ reactors would not be built for power production if it were possible to utilize D-T reactors. If, however, D-T reactors (because of problems associated with tritium fueling and/or breeding or Iifetime limitations due to neutron damage effects) were not feasible, then D-D reactors could likely be bullt in their place with reasonable extrapolations of parameters considered adequate for D-T reactors. 
It can be seen that the D-T reactor with full tritiun fueling and the D-D reactor with no tritium fueling (beyond that produced in the plasma) are at opposite ends of a possible contiuum. It is concelvable that an optimum design might have some fraction of full tritium fueling and hence be somewhere between $D-D$ and $D-T$ reactors as defined in this report.

\subsection{Plasma Engineering Considerations}

A steady-state power and particle balance model has been developed to do parametric, design optimization, and sensitivity studies for reactors with deuterium-based fuels. This model uses profile-averaged equations with specified profiles and utilizes a coordinate system based on numerically calculated magnetohydrodynamic (MHD) equilibrla. The model takes account of superthermal fusions. It has not been considered reasonable to make use of 1-D calculations, since the diffusion coefficients cannot be considered to be accurately known. A feature of this model in the range of interest of $D-D$ reactors is the appearance of more than one solution for a given set of parameters.

Conventional MHD equilibria with relatively broad pressure profiles, moderate elongation and D-shapedness, and safety factor values of 1.0 at the axis and 3.0 at the limiter have been consldered. The maximum credible beta has been assumed to scale as $A^{-1}$. The scaling, $B_{T}=.36 / A$, has been the standard choice.

It has been found that the maximum impurity concentration allowable for ignition decreases approximately exponentially with the nuclear charge of the impurity and that the allowable concentration is an order of magnitude less than that for a $\mathrm{D}-\mathrm{T}$ reactor.

The reactor performance improves with decreasing temperature until just above the lowest temperature, typlcally 25-30 keV, that allows Ignition. Bremsstrahlung is the largest power 1088 , followed by cyclotron radiation.

The pressure must be constant on flux lives, and the stability of the MHD equilibrium improves with broader presoure profiles. The density and temperature have been assumed to be constant on flux 1ines, also. Performance favors sharp density and broad temperature profiles, but there are indications broad density and sharp temperature profiles are more likely. A compromise of equally strarp density and temperature profiles has been used as a standard case. 
Cyclotron radiation has been calculated from the Trubnikov model with a standard reflection coefficient, $r_{c}=0.9$. The major effect of lower reflection coefficients on the performance is to raise the $n \tau$ required for ignition. Below $\Gamma_{c} \approx 0.4$, ignition becomes very difficult.

As a standard case the particle confinement time has been taken to be one-fourth the electron energy confinement time, and the ion energy confinement time has been taken to be four times the electron energy confinement time. In conjunction with the low particle confinement, high recycling at the wall has been assumed. The major effect of changing the ratios of the confinement times is to change the required confinement parameters, although ignition is not obtained if the particles are too well confined or if the Ion energy is not confined well enough with respect to the electron energy.

The reference case has been taken to be a fully catalyzed D-D reactor; that 1s, all of the tritium and ${ }^{3} \mathrm{He}$ that diffuse out of the plasma is reinjected. Although the performance degrades, operation is possible if none of the tritium is reinjected. For the reference configuration, however, at least $95 \%$ of the ${ }^{3} \mathrm{He}$ must be reinjected. This fraction could be lower with relaxed assumptions on impurity content and on the cyclotron reflection coefficient, but it does not appear likely that significant ${ }^{3} \mathrm{He}$ could be diverted to run a $\mathrm{D}-{ }^{3} \mathrm{He}$ reactor, for example.

The bulk of the design studies have kept the first-wall loading (in particular the heat load) and the ohmic heating magnetic field swing fixed at values that are considered to be their 1 imits $\left(\approx 0.8 \mathrm{MW} / \mathrm{m}^{2}\right.$ for the heat load for the first-wall concepts considered in this report and $\approx 15-16$ for the field swing). (There is no field swing limitation for a steady-state, current-driven reactor. However, the parasitic power loss for current drive be impractically large for a D-D reactor, and the conventional, pulsed case has been treated more extensively for this report.) If these quantities are kept constant, a sequence of reactors with different sizes, toroidal fields, and aspect ratios is found. The small aspect ratios have larger sizes, lower peak toroidal fields, larger plasma currents, and greater power outputs.

A reference design has been chosen from such a series with the objective of not extending any of the major parameters (size, peak toroidal field, plasma beta, or thermal power) any more than necessary from the values used for STARFIRE. The reaulting device has an $8.6 \mathrm{~m}$ major radius, $14 \mathrm{~T}$ peak 
toroidal field, $11 \%$ beta, and $2.5 \mathrm{GW}$ thermal power. (Additional paraneters are given in Table 2-10 on page 2-19.) The remainder of the studies have been made primarily for this reference device.

The burn cycle of the reference design has been studied using a timedependent model with features similar to the power and particle baiance model. Extra tritium and ${ }^{3} \mathrm{He}$ are injected during the startup to minimize the amount of auxilliary heating needed, and a long startup is used to minimize the power supply requirements.

The burn cycle consists of (1) the "ohmic heating" period (18 s) during which the ohmic heating colls are ramped up and a small amount of auxilliary heating is applied, (2) the "main heating period" (27 s) during which there are $5 \mathrm{~s}$ of $100 \mathrm{MW}$ of auxilliary heating followed by a ramp of the deuterium density accompanied by higher-than-steady-state values of the tritium and 3he densities, (3) a "steady-state" period $(2.5 \mathrm{hr})$ during which a small iodine density is maintained to insure thermal stability and enhance plasma radiation, (4) a "shut-down" period (30 s), and (5) a "dwell" period (30 s). The latter two periods have not yet been treated in detail.

A limiter/vacuum system similiar to that for STARFIRE has been chosen for impurity control. The requirements for this system are fairly similiar to those for STARFIRE except that transport power to the limiter is about twice as much, and the total gas load is about 2.4 times as much.

Several options (lower hybrid waves, compressional Alfven waves, and magnetosonic waves) have been investigated for steady-state current drive. Alfven and magnetosonic waves appear to be wore efficient for driving current, but there are engineering problems such as antenna design that need to be resolved. Further study is needed to define a system with sufficiently low parasitic power to be viable for a $D-D$ reactor.

\subsection{First Wall/Blanket/Shield Considerations}

Since there is no tritium breeding in a D-D reactor, the blanket/shield can be optimized to (1) maximize the neutron energy multiplication and (2) minimize the inboard blanket/shield thickness subject to the constraint that adequate shielding of the toroldal field coils 18 provided. The neutronic model used has been an infinite cylinder with particle transport calculated using ANISN with a 46-neutron/21-gan group structure using the VITAMIN-C and MACKIB-IV libraries. The focus has been on materials with a high $(n, \gamma)$ 
reaction potential and a high energy release for this reaction.

It is important to make the inboard blanket/shield as thin as possible to increase the magnetic field in the plasma and hence increase the power output. A neutronic analysis of the inboard blanket/shield has been conducted for two candidate coolants (pressurized light water and helium gas) and four candidate shielding materials (PCA, tungsten, $\mathrm{TiH}_{2}$, and water). The primary structural material in all cases has been an advanced austentic stainless steel (PCA). The minimum blanket/shield thickness is obtained for tungsten with a water coolant. Tungsten produces no long-term activation products; however, resources are limited, and its cost is relatively high. A blanket/shield constructed of tungsten would be $82 \mathrm{~cm}$ thick or about $40 \mathrm{~cm}$ thinner than the STARFIRE blanket/shield, which contains low-density $\mathrm{LiAlO}_{2}$ for tritium breeding.

Since the thickness of the outboard blanket/shield is less critical, the outboard blanket can be designed to increase neutron energy multiplication. Four candidate materials for the blanket have been considered. PCA has been taken as the reference case, but PCA could pose a chromium resource problem owing to high-level, long-term activation, precluding recycling. Three refractory materials ( $\mathrm{CrN}, \mathrm{Si}_{3} \mathrm{~N}_{4}$, and $\mathrm{SiC}$ ) have been considered for their relatively low activation and/or iatural abundance. The total neutron energy multiplciation varies from 1.94 for PCA to 1.34 for $\mathrm{Si}_{3} \mathrm{~N}_{4}$. If helium is used instead of water for the coolant, the energy multiplication for PCA drops to 1.4. Water coolant appears to be essential for energy multiplication. Use of a 10-cm thick beryllium muitiplier could increase the multiplication by an additional $0.2-0.8$, depending on the blanket material.

A series of thermal hydraulic analyses has been carried out for two first wall/blanket concepts: (1) a coolant panel-type first wall attached to monolithic blanket blocks and (2) cylindrical modules with hemispherical front ends. Water, helium, and sodium have been considered as heat transport fluids, and silicon nitride, silicon carbide, and chronium nitride have been considered as blanket materials. For the coolant panels fairly narrow coolant channels with stainless steel as the structural material and water as the coolant provide an acceptable design. Helium cooling would require shorter and larger channels and refractory metals to withstand the higher operating temperature. The pumping power losses for the cylindrical module design are quite small. Because of the small module size, however, blanket 
design and manifoiding a large number of such units may be difficult. Chromium nitride does not appear to be viable for this design because of the high operating temperature. Hot spots in the filler elements between modules do not seem to be a problem.

Preliminary results indicate pumping losses are $2.5 \%$ for a sodium coolant compared to less than $1 \%$ for water coolant.

The structural material evaluations have focussed on two candidates, PCA and V-20Ti. The concerns are the poor thermophysical properties if PCA and the potentially high corrosion rate of V-20Ti in a water coolant. PCA appears to have an adequate fatigue lifetime for the reference first-wall heat fluxes provided the burn cycle is greater than $5000 \mathrm{~s}$.

The physical properties of the moderator materials, $\mathrm{CrN}, \mathrm{Si}_{3} \mathrm{~N}_{4}$, and $\mathrm{SiC}$, have been surveyed. For the oferating conditions of a D-D reactor, SiC has the most desirable properties, whereas $\operatorname{CrN}$ has the least desirable. The available data indicate that bulk radiation effects should saturate at low levels for the present operating temperatures. High fluence data is needed to confirm this prediction.

A consideration of first wall surface effects indicates that for the reference design all first wall components and the limiter should be constructed of the same material and that the surface material should be a single element with $\mathrm{Z} \leqslant 10$. The low- $\mathrm{Z}$ coating (cladding) concept is recommended. On an overall basis beryllium appears to be a superior candidate for the first-wall coating. Boron is also a prime candidate.

Calculations indicate almost total reflection of cyclotron radiation from a stainless steel first wall. Presence of a thin oxide layer should not affect this conclusion.

Preliminary studies have been made of the effect of a plasma disruption on the first wall. Because of the higher amount of stored energy in the plasma, a plasma disruption in a D-D reactor could melt and vaporize the first-wall coating even for disruption times as long as $200 \mathrm{~ms}$. Further analyses are required to devleop a first wall concept that would withstand projected plasma disruptions.

\subsection{Magnet Design Conslderations}

Although a steady-state version of the reference design has been studied in a preliminary fashion, most of the effort for this report has been directed toward the conventional, ohmically-driven version. The ohmic heating (OB) 
system, which is primarily responsible for inducing the plasma current, consists of a central solenoid and five pairs of circular coils all outside the toroidal field (TF) coils. The OH system provides $500 \mathrm{~V}-\mathrm{s}$ with a field swing from $-7.6 \mathrm{~T}$ to $+7.6 \mathrm{~T}$. It is held at full negative field just before startup and ramped to full positive value during the $18 \mathrm{sec}$ "ohmic heating" period. At full field the fleld produced in the plasma by the oH system is zero within an RMS error of $2 \times 10^{-4}$ relative to the full equilibrium field (EF). The maximum stored energy in the $\mathrm{OH}$ system is $20 \mathrm{GJ}$.

The EF system, which provides the bulk of the equilibrium field necessar to keep the plasma positioned in the chamber with the desired cross-sectional shape and pressure and current distributions, consists of four pairs of circular coils, also all outside of the TF coils. In addition to maintaining the plasma equilibrium, the EF system provides $195 \mathrm{~V}-\mathrm{s}$ to help induce the plasma current. Of the total $695 \mathrm{~V}-\mathrm{s}$ supplied to the plasma, $500 \mathrm{~V}-\mathrm{s}$ are needed to inductively initiate the current, and $195 \mathrm{~V}-\mathrm{s}$ are available to maintain the plasma against resistive losses. The EF system has a maximum stored energy of 22 GJ with 67 MAT of current. The EF' and the OH systems are completely decoupled, so that changes in one system do not induce voltages in the other.

The TF system consists of twelve constant tension coils designed for a peak field of $15 \mathrm{~T}$ with operation expected to be at $14 \mathrm{~T}$. Designs of 14, 15, and $16 \mathrm{~T}$ were considered. The conductor is a three level, unsoldered, uninsulated, "Rutherford" cable with four grades of conductor. The two highfleld grades employ $\mathrm{Nb}_{3} \mathrm{Sn}$, and the two low-field grades employ $\mathrm{NbT}$ as superconductor. The conductor is copper stabilized with the loop stresses supported by a support frame made of stainless steel strips. The design is similiar to that used in the STARFIRE studies but extrapolated to higher field.

\subsection{Tritium/Fue1/Vacuum Considerations}

No major technological difficulties are expected in the design of the fuel reprocessing systems for the $D-D$ reference design. Fueling requirements per day are $2.9 \mathrm{~kg}$ of deuterium, $1 \mathrm{~kg}$ of ${ }^{3} \mathrm{He}$, and $17 \mathrm{~g}$ of tritium. The exhaust consists of $2.4 \mathrm{~kg}$ of deuterium, $1 \mathrm{~kg}$ of ${ }^{3} \mathrm{He}, 17 \mathrm{~g}$ of tritium, $0.3 \mathrm{~kg}$ of ${ }^{4} \mathrm{He}$, and $80 \mathrm{~g}$ of protium.

The $D-D$ design both produces and burns tritium in the plasma. No 
outside tritium breeding capability is required, and the tritium exhaust is reduced from a comparable D-T design. As a consequence, the tritium inventories, both "vulnerable" and "non-vulnerable", are two orders of magnitude smaller than in a similar D-T reactor. The tritium still represents a significant safety concern; therefore, the tritium safeguards proposed in the STARFIRE design are necessary in the D-D design.

Reprocessing of the ${ }^{3}$ He is easily accomodated within the fuel reprocessing system. Reprocessing is required from U.S. resource considerations if additional sources are not available.

The limiter/vacuum system is designed to maintain the pressure in the limiter at $\approx 0.04 \mathrm{~Pa}$, the same as in the STARFIRE design. Because the D-D design has a gas load 2.4 times that in STARFIRE, the vacuum ducts are decreased in length and increased in diameter to provide the additional conductance required. In addition, the cryopanel surface area is increased to handle the additional load. 